\section{small methods}

Postfach 101161 69451 Weinheim

Germany

Courier services:

Boschstraße 12

69469 Weinheim

Germany

Tel.: (+49) 6201606531

Fax: (+49) 6201606500

E-mail: small-methods@wiley.com
Dear Author,

Please correct your galley proofs carefully and return them no more than four days after the page proofs have been received.

Please limit corrections to errors already in the text; cost incurred for any further changes or additions will be charged to the author, unless such changes have been agreed upon by the editor.

The editors reserve the right to publish your article without your corrections if the proofs do not arrive in time.

Note that the author is liable for damages arising from incorrect statements, including misprints.

Please note any queries that require your attention. These are indicated with a $Q$ in the PDF and a question at the end of the document.

Reprints may be ordered by filling out the accompanying form.

Return the reprint order form by fax or by e-mail with the corrected proofs, to WileyVCH : small-methods@wiley.com

\section{WILEY-VCH}

To avoid commonly occurring errors, please ensure that the following important items are correct in your proofs (please note that once your article is published online, no further corrections can be made):

- Names of all authors present and spelled correctly

- Titles of authors correct (Prof. or Dr. only: please note, Prof. Dr. is not used in the journals)

- Addresses and postcodes correct

- E-mail address of corresponding author correct (current email address)

- Funding bodies included and grant numbers accurate

- Title of article OK

- All figures included

- Equations correct (symbols and sub/superscripts)

Corrections should be made directly in the PDF file using the PDF annotation tools. If you have questions about this, please contact the editorial office. The corrected PDF and any accompanying files should be uploaded to the journal's Editorial Manager site. 


\section{Author Query Form}

Journal

SMTD

Article

smtd201900853

Dear Author,

During the copyediting of your manuscript the following queries arose.

Please refer to the query reference callout numbers in the page proofs and respond to each by marking the necessary comments using the PDF annotation tools.

Please remember illegible or unclear comments and corrections may delay publication.

Many thanks for your assistance.

\begin{tabular}{|c|c|c|}
\hline Query No. & Description & Remarks \\
\hline Q-OO & $\begin{array}{l}\text { Open access publication of this work is possible via Wiley OnlineOpen. Information about this } \\
\text { is available at: https://authorservices.wiley.com/author-resources/Journal-Authors/licensing-open- } \\
\text { access/open-access/onlineopen.html. } \\
\text { The cost of publishing your manuscript OnlineOpen may be covered by one of Wiley's national } \\
\text { agreements. To find out more, visit https://authorservices.wiley.com/author-resources/Journal- } \\
\text { Authors/open-access/affiliation-policies-payments/index.html. } \\
\text { Note that eligibility for fee coverage is determined by the affiliation of the primary corresponding } \\
\text { author designated at submission. Please log in to your Wiley Author Services account at https:// } \\
\text { authorservices.wiley.com/ and confirm your affiliation to see if you are eligible. } \\
\text { Instructions for placing an OnlineOpen order can be found at: https://authorservices.wiley.com/ } \\
\text { author-resources/Journal-Authors/open-access/how-to-order-onlineopen.html. } \\
\text { To publish your article open access, please complete the order process before completing your proof } \\
\text { corrections. }\end{array}$ & $\begin{array}{l}\text { please publish } \\
\text { this paper in } \\
\text { subscription way }\end{array}$ \\
\hline Q1 & $\begin{array}{l}\text { Please confirm that forenames/given names (blue) and surnames/family names (vermilion) have } \\
\text { been identified correctly. }\end{array}$ & They are right \\
\hline Q2 & $\begin{array}{l}\text { Please note that it is not as per journal style to feature or to provide information regarding numbers } \\
\text { of articles published, awards, or patents, as well as information on external editorial work, in author } \\
\text { biographies. This text has therefore been deleted. }\end{array}$ & Ok \\
\hline Q3 & Please check that all author names and affiliations are presented correctly. & they are right \\
\hline Q4 & $\begin{array}{l}\text { Please confirm that all elements of the TOC image are original. If they are not, a new TOC image is } \\
\text { required, even if you have permission to use it, it nevertheless has to be } 100 \% \text { original. }\end{array}$ & it is original \\
\hline Q5 & Please check all equations have been correctly typeset. & Some equations have been $\mathrm{c}$ \\
\hline Q6 & Please confirm that figure 1 is original, i.e., has not been published before. & it is original \\
\hline Q7 & $\begin{array}{l}\text { Please obtain permission for figure reproduction for all figure elements that are not original and cite } \\
\text { them in the following way: Reproduced with permission. [Ref.] Copyright Year, Publisher. }\end{array}$ & we have requested all the copyrig \\
\hline
\end{tabular}

Please confirm that Funding Information has been identified correctly.

Please confirm that the funding sponsor list below was correctly extracted from your article: that it includes all funders and that the text has been matched to the correct FundRef Registry organization names. If a name was not found in the FundRef registry, it may not be the canonical name form, it may be a program name rather than an organization name, or it may be an organization not yet included in FundRef Registry. If you know of another name form or a parent organization name for a "not found" item on this list below, please share that information.

\begin{tabular}{|l|l|}
\hline FundRef Name & FundRef Organization Name \\
\hline King Abdullah University of Science and Technology & King Abdullah University of Science and Technology \\
\hline
\end{tabular}




\section{REVIEWS}

J. Yin, W. Zhang, N. A. Alhebshi,

N. Salah, H. N. Alshareef*...... 1900853

Synthesis Strategies of Porous Carbon for Supercapacitor Applications

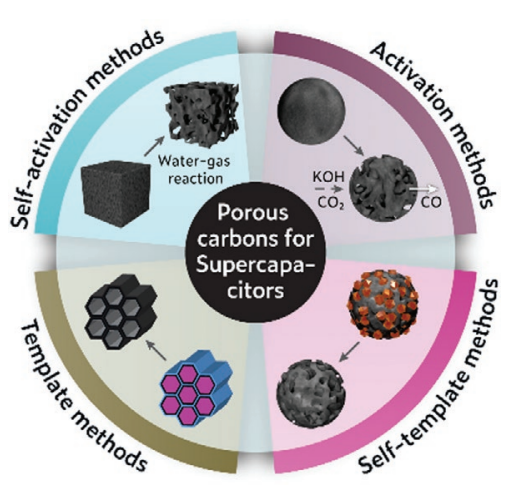

The synthesis strategies of porous carbon for supercapacitor (SC) applications, including traditional methods and novel emerging methods developed in recent years, are reviewed in this article. This review proposes promising future directions and synthesis strategies for porous carbons used in SC applications. 


\section{Synthesis Strategies of Porous Carbon for Supercapacitor Applications}

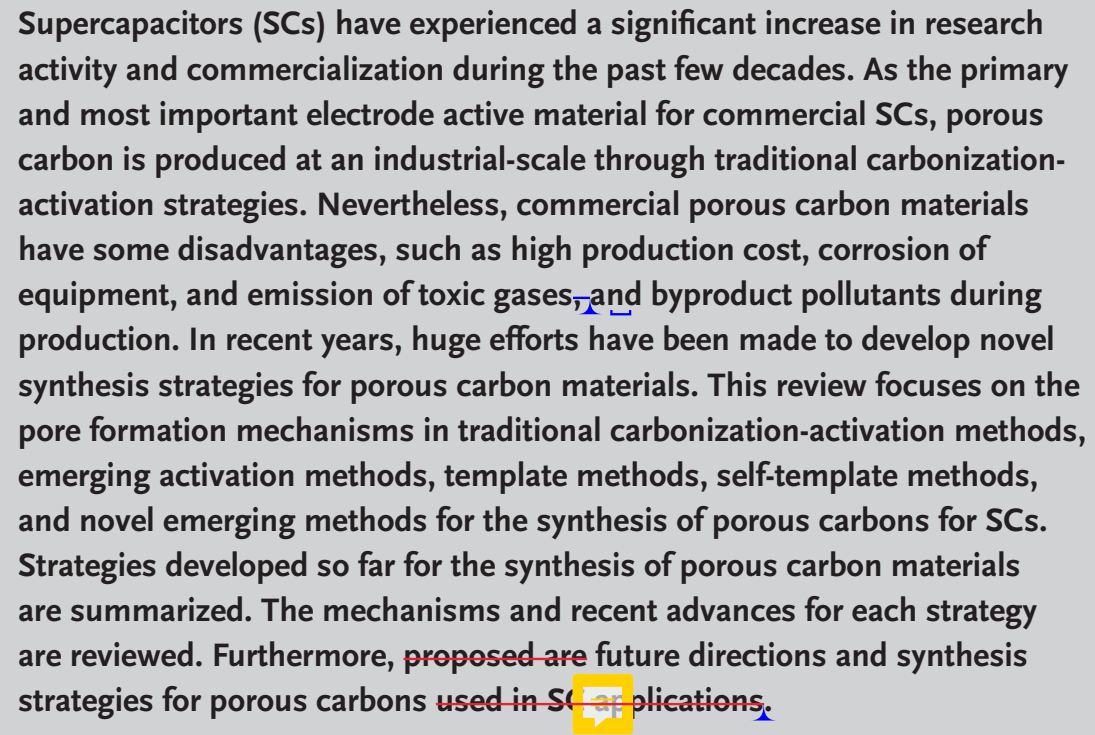

Supercapacitors (SCs) have experienced a significant increase in research activity and commercialization during the past few decades. As the primary and most important electrode active material for commercial SCs, porous carbon is produced at an industrial-scale through traditional carbonizationactivation strategies. Nevertheless, commercial porous carbon materials have some disadvantages, such as high production cost, corrosion of equipment, and emission of toxic gases,and byproduct pollutants during production. In recent years, huge efforts have been made to develop novel synthesis strategies for porous carbon materials. This review focuses on the pore formation mechanisms in traditional carbonization-activation methods, emerging activation methods, template methods, self-template methods, and novel emerging methods for the synthesis of porous carbons for SCs. Strategies developed so far for the synthesis of porous carbon materials are summarized. The mechanisms and recent advances for each strategy are reviewed. Furthermore, proposed are future directions and synthesis strategies for porous carbons used in Sf af plications.

\section{Introduction}

Supercapacitors (SCs) are high-power energy storage devices based on the fast accumulation/release of charges at the electrode/electrolyte interface through electrostatic or electrochemical ion adsorptions. SCs have two subcategories, including electric double-layer capacitors (EDLCs) and pseudocapacitors. ${ }^{[1]}$ The application of pseudocapacitors in commercial devices has been hampered by the intrinsic high cost of $\mathrm{RuO}_{2}$ and the electrochemical instabilities

Dr. J. Yin, Dr. W. Zhang, Prof. H. N. Alshareef

Materials Science and Engineering

Physical Science and Engineering Division

King Abdullah University of Science and Technology (KAUST)

Thuwal 23955-6900, Saudi Arabia

E-mail: husam.alshareef@kaust.edu.sa

Prof. N. A. Alhebshi

Physics Department

Faculty of Science

King Abdulaziz University

Jeddah 21589, Saudi Arabia

Prof. N. Salah

Center of Nanotechnology

King Abdulaziz University

Jeddah 21589, Saudi Arabia

The ORCID identification number(s) for the author(s) of this article can be found under https://doi.org/10.1002/smtd.201900853.

DOI: 10.1002/smtd.201900853 of most transition-metal compounds 10 (represented by manganese oxide) in 11 aqueous electrolytes. ${ }^{[1]}$ As a result, most 12 commercially available SCs are EDLCs 13 assembled using porous carbon elec- 14 trodes and organic electrolytes composed 15 of tetraethylammonium tetrafluorobo- 16 rate solute and acetonitrile or propylene 17 carbonate solvents. ${ }^{[2]}$ Nowadays, com- 18 mercial SCs are starting to supplement 19 lithium-ion batteries (LIBs) in some 20 pivotal but small number of applications. 21 These applications include regenerative 22 braking systems in hybrid electric vehi- 23 cles, frequency regulation in smart grid, 24 energy storage modules in electronics, 25 and uninterruptable power supply. ${ }^{[3]} \quad 26$

There are two reasons for the limited 27 commercial deployment of SCs. On the 28 one hand, the energy densities of SCs 29 are limited to as low as $5-8 \mathrm{Wh} \mathrm{kg}^{-1} 30$ $\left(\approx 250 \mathrm{Wh} \mathrm{kg}^{-1}\right.$ for LIB, and $\approx 40 \mathrm{Wh} \mathrm{kg}^{-1} \quad 31$ for lead-acid battery). ${ }^{[4]}$ On the other hand, the capital cost per 32 watt-hour of SC is much higher than LIB and lead-acid battery. ${ }^{[5]} 33$ The energy storage cost of SCs is $\approx 20000 \$ \mathrm{kWh}^{-1}$ which is 34 20 times that of LIB $\left(1000 \$ \mathrm{kWh}^{-1}\right)$ and more than 100 times 35 that of lead-acid battery $\left(150 \$ \mathrm{kWh}^{-1}\right) \cdot{ }^{[6]}$ The high capital cost 36 of SC is mainly ascribed to the high cost of porous carbon elec- 37 trode active materials. Porous carbons used for SC applications 38 have high prices ranging from 30 to $50 \$ \mathrm{~kg}^{-1}$ depending on 39 their specific surface areas (SSAs) and pore volumes which 40 are determining factors for the capacitances of SCs. ${ }^{[7]}$ As an 41 example, the YP-80F (SSA $2100 \mathrm{~m}^{2} \mathrm{~g}^{-1}$ ) from Kuraray chemical 42 costs more than YP-50F (SSA $1660 \mathrm{~m}^{2} \mathrm{~g}^{-1}$ ). The high cost of 43 porous carbon increases the cost of SC devices and the levelized 44 cost of energy storage devices (LCES). LCES, to some extent, 45 limits the widespread of SCs. LCES determines how much we 46 spend on energy storage devices per watt-hour energy output 47 during its entire lifetime (Equation (1))

$\mathrm{LCES}=\frac{C_{\mathrm{c}}+C_{\mathrm{m}}}{n \times E \times \mathrm{EE}}$

here $C_{\mathrm{c}}$ is the capital cost, $C_{\mathrm{m}}$ is the maintenance cost, $n$ is the 52 lifetime cycling number, $E$ is the energy stored in the round- 53 trip energy storage process (depending on voltage, capacity, and 54 its depth of discharge), EE is the energy efficiency. To lower 55 LCES, we can either decrease the numerator or increase the 56 denominator. Given the advantages of ultralong cycling life, low 57 maintenance, and high EE for SCs, if we can lower the $C_{\mathrm{c}}$ of 58 SCs to the level of LIB, we can significantly expand their market 59 
penetration. Hence, the development of low-cost porous carbon using simple and scalable preparation methods has significant practical implications.

The capacitance and energy of an EDLC-type SC greatly depend on the porous architecture of porous carbon electrodes which store energy through the electrostatic charge accumulation at the electrode/electrolyte interface. The capacitance of a porous carbon electrode can be calculated based on the model proposed by Helmholtz, as indicated by Equation (2)

$C=\frac{\varepsilon_{\mathrm{r}} \varepsilon_{\mathrm{o}} A}{d}$

where $\varepsilon_{\mathrm{r}}$ is the electrolyte dielectric constant, $A$ is the active surface area of the porous carbon electrode, $\varepsilon_{\mathrm{o}}$ is the permittivity of vacuum, and $d$ is the distance of the electric double layer. The capacitance of EDLC is proportional to the active surface area of porous carbon. Although the pore size and surface chemistry of porous carbons influence the construction of the electric double layer, the development of high surface area porous carbon is the main strategy to enhance the capacitance of EDLC-type SC. According to the classification of the International Union of Pure and Applied Chemistry (IUPAC), the pores in porous materials are classified into macropore $(>50 \mathrm{~nm})$, mesopore $(2-50 \mathrm{~nm})$, and micropore $(<2 \mathrm{~nm}) \cdot{ }^{[8]}$ In the case of electrode materials used for SC, macropores of porous carbons serve as reservoirs of electrolyte ions. Mesopores serve as the diffusion channels for electrolyte ions. Micropores of porous carbon materials play the dominant roles for ion storage since micropores contribute more to high SSA and capacitance compared with mesopores and macropores. From the synthetic perspective, any carbon sources can be transformed into porous carbonaceous materials. Besides, structural parameters, such as SSA, pore-size distribution, surface functionalities, and tap density can be engineered by controlling the synthetic parameters. Nevertheless, the preparation of porous carbon relies on empirical protocols using different carbon sources, such as resins, petrochemicals, coal, transition-metal carbide, lignin, cellulose, and polymers. So, it is imperative to summarize the synthesis methodologies of porous carbons into different groups based on their pore formation mechanisms (as shown in Figure 1).

Traditionally, porous carbons are prepared by a combined carbonization-activation strategy. Generally, carbonization is realized by carbonizing organic precursors at temperatures ranging from 400 to $1000^{\circ} \mathrm{C}$ in an inert atmosphere. Through carbonization, we can get nonporous solid carbons known as coal char or biochar. Pore-forming agents (porogens) are used to create pores in the activation process. The obtained coal char or biochar then undergo oxidation reactions with activation agents $\left(\mathrm{CO}_{2}, \mathrm{O}_{2}\right.$, air, or $\mathrm{H}_{2} \mathrm{O}$ in physical activation; $\mathrm{KOH}, \mathrm{Na}_{2} \mathrm{CO}_{3}$, $\mathrm{ZnCl}_{2}$, or $\mathrm{H}_{3} \mathrm{PO}_{4}$ in chemical activation). ${ }^{[9,10]}$ Most commercially available porous carbons are produced from coconut shells by physical activation using steam as an activation agent, which yields porous carbons with high purity and SSA of $\approx 1500 \mathrm{~m}^{2} \mathrm{~g}^{-1}$. Chemical activation strategy is usually applied to produce porous carbons with high SSAs ranging from 1000 to $3000 \mathrm{~m}^{2} \mathrm{~g}^{-1}$ using $\mathrm{KOH}$ or $\mathrm{NaOH}$ as the activation agents. ${ }^{[11-13]}$ The production of chemically activated porous carbons is limited to lab-scale due to their high production cost owing to

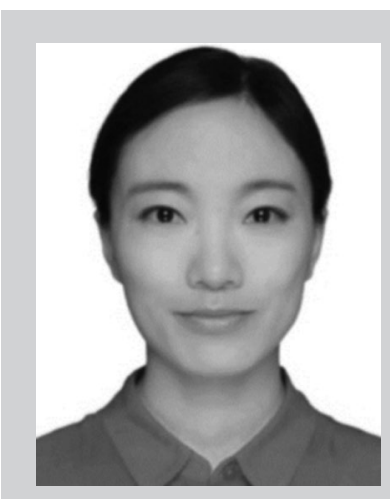

Jian Yin is a postdoctoral researcher in Professor, Husam Alshareef's group at King Abdullah University of Science and Technology (KAUST), Saudi Arabia. She received her Ph.D. degree in inorganic chemistry from the College of Chemistry, Jilin University in 2019 under the supervision of Professor Haibo Lin. Her research activity mainly focuses on carbon materials for supercapacitors, lithium-ion batteries, and lead-acid batteries.

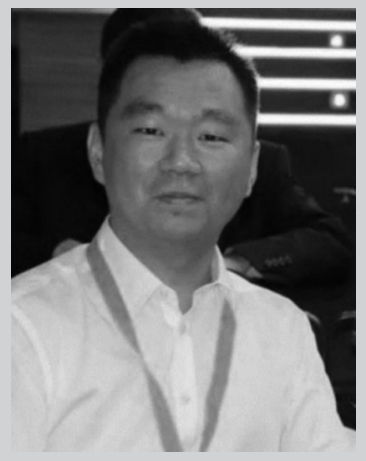

Wenli Zhang is now a postdoctoral fellow in Professor Husam Alshareef's group at King Abdullah University of Science and Technology (KAUST), Saudi Arabia. Under the supervision of Professor Haibo Lin, he obtained his B.Eng. degree from Jilin University, China, in 2011, and Ph.D. in physical chemistry from Jilin University, China, in 2017. Currently, his research interests focus on carbonaceous materials for rechargeable batteries and supercapacitors.

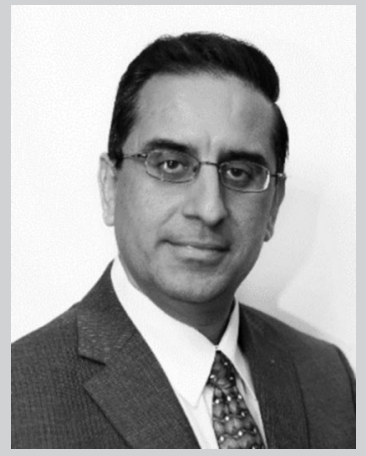

Husam N. Alshareef is a professor of materials science and engineering at King Abdullah University of Science and Technology (KAUST). He obtained his Ph.D. at North Carolina State University, Raleigh, USA. He then did his post-doctoral work at Sandia National Laboratory, USA. Following 10 years in the semiconductor industry, he joined KAUST in 2009, where he has been running a research group focused on developing inorganic nanomaterials for energy and electronics. He is a Fellow of the Royal Society of Chemistry, Fellow of the American Physical Society, IEEE Distinguished Speaker in Nanotechnology, and Senior Member of IEEE. He was chair of the 2014 Materials Research Society (MRS) Fall Meeting in Boston, USA, and has served on various MRS committees.

the high activation agent/char ratios (normally ranging from 1 to 5 , sometimes up to 10$),{ }^{[14,15]}$ and the high cost of activation agent (especially $\mathrm{KOH}$ ). The SSAs and pore-size distributions 


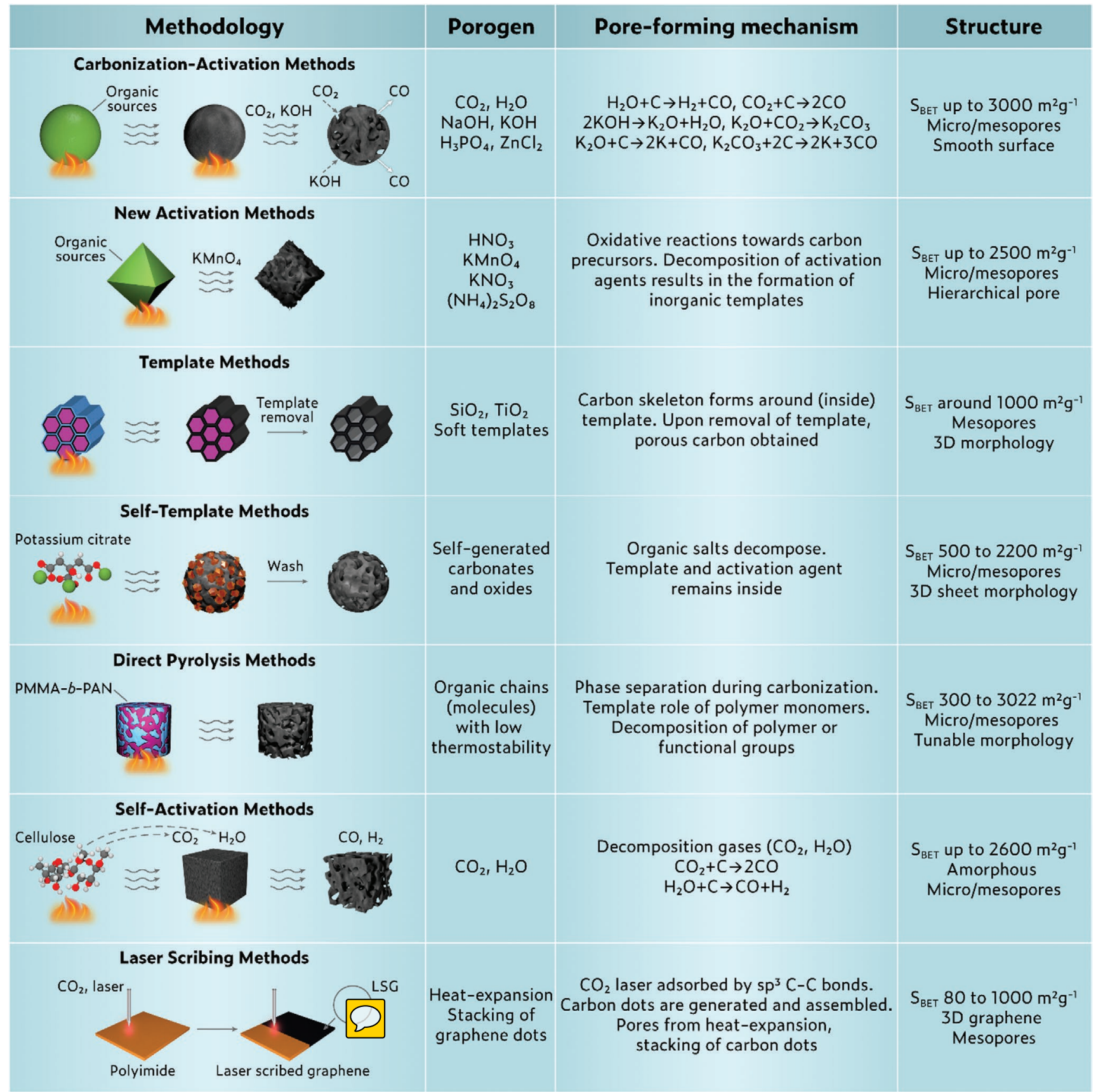

Figure 1. Synthesis methodologies used to produce porous carbons for SC applications. The porogens, pore-forming mechanisms, and structural characteristics of the resultant porous carbons are summarized.

of porous carbons obtained by carbonization-activation strategy vary with preparation parameters and activation agents, as will be discussed later.

Recently, there has been a fast development using novel emerging activation agents such as copper chloride $\left(\mathrm{CuCl}_{2}\right)$ and potassium permanganate $\left(\mathrm{KMnO}_{4}\right)$ for the preparation of porous carbons. ${ }^{[16,17]}$ These novel activation agents produce porous carbons with high SSA and unique morphologies but may generate toxic gases that need further decontamination. As the synthesis of chemically activated porous carbons using these novel activation agents is not environmentally friendly, 50 the search for environmentally benign chemical activation 51 agents and green chemical activation processes is critical for 52 the sustainable development of porous carbons. 53

Various template methods have been applied as versatile 54 strategies for the preparation and assembly of mesoporous 55 carbons. ${ }^{[18]}$ The advantage of template methods is that they 56 can finely tune the pore-size distribution by tuning the 57 template size, enabling extremely narrow pore-size distribu- 58 tion. However, the synthesis and removal of templates are 59 
tedious procedures that increase production complexity and cost. Besides, the pore sizes of porous carbons prepared from template methods are usually dominated by mesopores, which are largely restricted by the template sizes.

Carbide-derived carbons (CDCs) are microporous carbon materials produced from a high-temperature etching of metal carbides (TiC, $\mathrm{SiC}, \mathrm{VC}_{2}$ ) under chlorine gas atmosphere. CDC is the earliest example that uses the self-generated template as a porogen. ${ }^{[19]}$ Recently, researchers have become more inclined to use abundant alkaline metal-organic salts as the carbon precursors by applying self-template strategies. In these strategies, the pyrolysis-generated metal oxides or metal carbonates act as templates and activation agents. To obtain porous carbons, these templates are further removed by water or acid washing. ${ }^{[20,21]}$ Metal-organic framework (MOF)-derived porous carbons can also be grouped into the self-templated carbons, as the porogens of these obtained carbons are also generated during carbonization. ${ }^{[22]}$ With the fast development of MOFs for energy storage applications, more and more elaborately designed MOF-derived porous carbons are being produced based on the self-template role of MOFs.

Direct pyrolysis of various organic precursors, such as co-polymers, chemically treated biomasses, and polyionic liquids, has been developed fast since this strategy does not need specially added porogens and post-treatments. ${ }^{[23]}$ Direct pyrolysis method holds great promise to be exploited as the second-generation preparation technology for porous carbon electrodes in SCs. In recent years, there has been a fast development in using $\mathrm{CO}_{2}$ laser scribing technique to prepare porous laser-scribed graphene (LSG) electrodes for SC applications. ${ }^{[24]}$ Laser scribing is usually carried out in an ambient environment without the protection of inert gases. The vast biomass precursors that can be used in laser scribing make this technique attractive to realize renewable graphitic porous carbons with different pore architectures. Besides the laser scribing technique, there are several emerging carbonization methods such as microwave carbonization, ${ }^{[25,26]}$ dehydrogenation/deoxygenation, ${ }^{[27,28]}$ and dehalogenation. ${ }^{[29]}$ Some of these methods produce porous carbons with high SSAs, which makes these techniques promising for the fabrication of SC electrodes. Nevertheless, some of these techniques need to be carefully designed to obtain effective porogens during carbonization.

There exist many reviews discussing porous carbon materials for SCs, such as $2 \mathrm{D}$ porous carbons, ${ }^{[30]}$ porous carbons for flexible and wearable $\mathrm{SCs}^{[31]}$ porous carbons derived from copolymers, ${ }^{[23]}$ porous carbons derived from renewable biomasses, ${ }^{[32]}$ graphene-based materials, ${ }^{[3]}$ and nanoporous carbons from molecular design. ${ }^{[18]}$ These reviews mainly focus on the textural properties, surface chemistries, and capacitive performances of porous carbons. However, it is important to know how these porous carbons are generated through certain porogens, and the different mechanisms that these porogens undergo for the preparation of porous carbons. Although carbon nanotubes and carbon aerogels are commonly used as electrode active materials in $\mathrm{SCs}^{[33]}$ they possess relatively low SSA and specific capacitance compared with commercial porous carbons. Given the above considerations, this review focuses on the fundamental mechanism aspects of both traditional and emerging synthesis strategies of porous carbon for SC applications. Additionally, we discuss the remaining 1 challenges and suggest new synthesis strategies of porous car- 2 bons for commercial SC applications.

\section{Carbonization-Activation Methods}

Porous carbons prepared from combined carbonizationactivation strategies are usually called activated carbons. Activated carbons were initially used to describe the activated coal chars or biochars with high SSAs that could be used as adsorbents for purification or carriers of catalysts. With the invention of SC by General Electric's H.I. Becker in 1957, activated carbon became the primary and most important electrode active material in SC applications. Generally, activated carbons are produced by two separate steps, i.e., carbonization and activation. ${ }^{[9]}$ Carbonization is usually carried out by pyrolysis in an inert atmosphere. Carbonization enables the formation of nonporous solid carbonaceous materials with high carbon content and low oxygen or hydrogen contents. The obtained carbonaceous materials are then activated chemically or physically to obtain activated carbon.

\subsection{Carbonization}

\section{2}

Carbonization is a complex physicochemical process in which many reactions take place concurrently, such as dehydrogenation, deoxygenation, condensation, crosslinking, hydrogen transfer, and isomerization. ${ }^{[34]}$ During the carbonization process, dehydrogenation, deoxygenation, and crosslinking reactions proceed with the release of volatile compounds, finally resulting in carbonaceous residue. ${ }^{[35]}$ Usually, the pyrolysis processes are carried out under an inert atmosphere. As replacements of pyrolysis, some novel techniques like hydrothermal carbonization, ${ }^{[36]}$ microwave-assisted carbonization, ${ }^{[34]}$ dehydrogenation/deoxygenation enabled by high concentrated sulfuric acid, ${ }^{[28]}$ and dehalogenation of halogenated organic polymers ${ }^{[37]}$ have also been applied to perform the carbonization process. These novel carbonization techniques enable the formation of carbonaceous materials with novel structures and different chemical compositions compared with traditional carbonization methods. Chaiwat et al. reported a pressurized hot water treatment of cellulose, which suppresses the tar formation by producing a random and highly cross-linked carbonaceous structure. ${ }^{[36]}$ Furthermore, Zhao et al. investigated the relationship between the torrefaction temperature, residence time, and the char yield of torrefied corncobs (Figure 2a). ${ }^{[38]}$ Results show that by increasing torrefaction temperature and residence time, a higher char yield can be achieved because the crosslinking and charring of cellulose mainly occurred at relatively high temperatures around $300^{\circ} \mathrm{C}$. Microwave radiation can penetrate the organic solutions and solid organics like lignocellulose, thereby achieving rapid and volumetric heating, which enables effective carbonization. ${ }^{39]}$ The advantages of microwave-assisted carbonization include: 1) reducing heating time; 2) providing volumetric heating; 3) instantaneous start and stop of heating; and 4) reducing the reactor size. Chen et al. employed the microwaves to torrefy . . . .

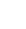
. . . 
1

2

4

5

6

7

8

9

10

11

12

13

14

15

16

17

18

19

20

21

22

23

24

25

26

27

28

29

30

31

32

33

34

35

36

37

38

39

40

41

42

43

44

45

46

47

48

49

50

51

52

53

54

55

56

57

58

59

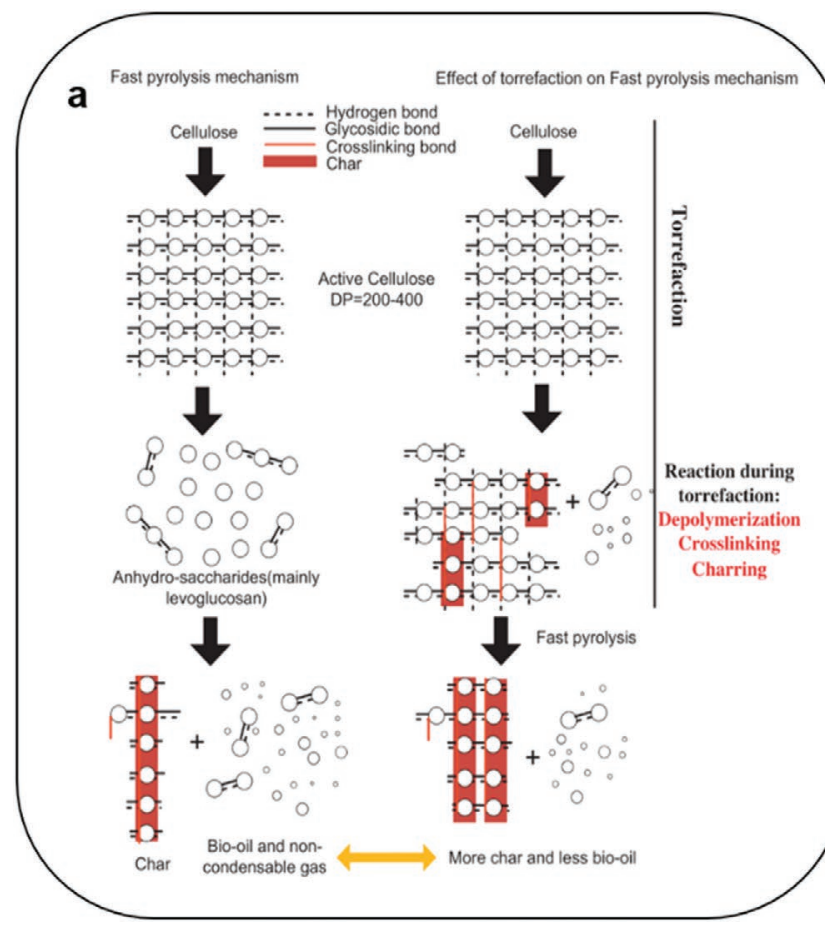

Figure 2. a) Effects of torrefaction on fast pyrolysis of cellulose. Reproduced with permission. ${ }^{[38]}$ Copyright 2012, Elsevier. b) TEM images and schematic illustrations of the physical characterization, Fourier-transform infrared spectroscopy (FT-IR), and Raman spectra obtained for green tea-derived carbon under temperatures of 700, 800, and $900^{\circ} \mathrm{C}$ (GT-700, 800, and 900). Reproduced with permission. ${ }^{[41]}$ Copyright 2014, Elsevier.

the biomass in solutions of water or diluted sulfuric acid at $180{ }^{\circ} \mathrm{C} .{ }^{[40]}$ The calorific value of bagasse increased up to $20.3 \%$ from wet torrefaction, which indicates the partial carbonization achieved by microwave carbonization.

Despite these numerous reports on various novel carbonization methods, pyrolysis is still the most common and most widely used carbonization technique to prepare carbonaceous materials. During pyrolysis, disordered carbons containing a relatively large amount of defects form at low temperature, while high-temperature results in partially ordered carbons were composed of defective graphene layers (Figure 2b). ${ }^{41]}$ The pyrolysis process is so complex that it is hard to be elaborated in detail. Generally, in low-temperature pyrolysis, the organics experience the following reactions: losing adsorbed water (temperature $<150{ }^{\circ} \mathrm{C}$ ), dehydration from the carbohydrate unit, $\left(<250{ }^{\circ} \mathrm{C}\right)$, scission of $\mathrm{C}-\mathrm{O}$ and $\mathrm{C}-\mathrm{C}$ bonds by free radical reactions $\left(<400{ }^{\circ} \mathrm{C}\right)$, and aromatization. ${ }^{[42]}$ Because the deoxygenation reactions begin at temperatures around 400-600 ${ }^{\circ} \mathrm{C}$, the low-temperature carbonized carbon is of high oxygen content, while the high-temperature carbonized carbon is of low oxygen content. During pyrolysis, the $\mathrm{sp}^{2}$ hybridized graphene nanodomains also increase with the decrease of turbostratic $\mathrm{sp}^{3}$ hybridized carbons. Even though the carbonaceous structures highly rely on different carbon precursors, Kercher and Nagle proposed a general quasi-percolation model to describe the structural evolution of carbon during pyrolysis. ${ }^{[43]}$ In the quasi-percolation model, when the carbonization temperature is increased above $600{ }^{\circ} \mathrm{C}$, the large turbostratic crystallites grew very little, but the graphene sheets grew substantially. Meanwhile, volumetric shrinkage occurs due to b
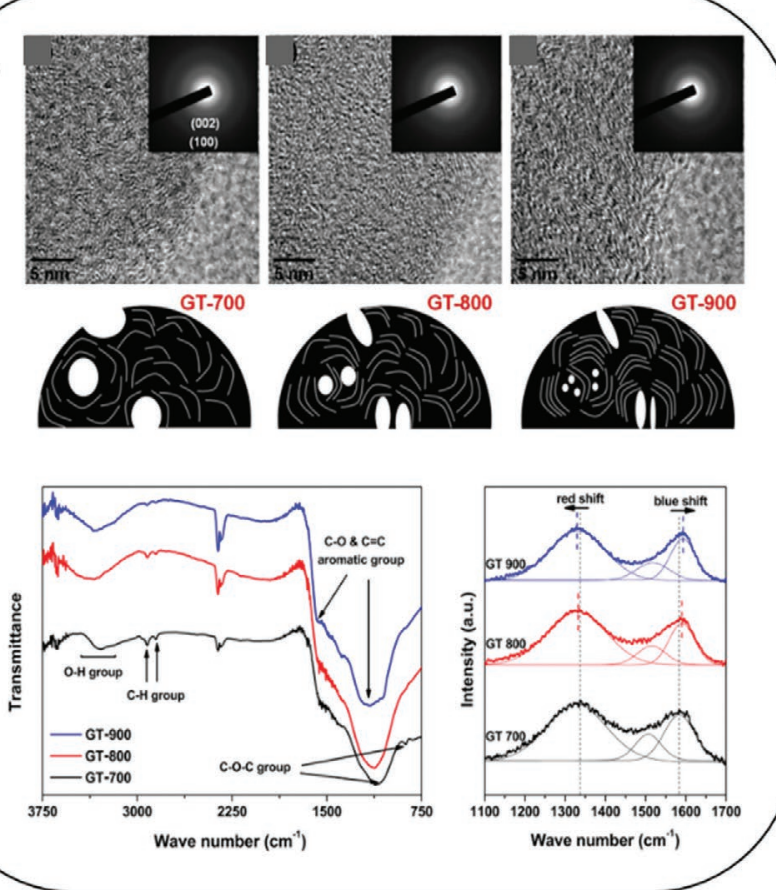

the condensation of turbostratic structures. At $\approx 900{ }^{\circ} \mathrm{C}$, gra- 30 phene layers significantly impinge on each other. This general 31 carbonization scenario of various carbon sources can help us 32 understand the physical or chemical activation processes since 33 oxygen content (depends on the pyrolysis temperature), crystal 34 structure (graphitic degree), and pristine pore (original pores 35 in coal char) may influence the pore-forming process in the 36 activation process.

\subsection{Physical Activation}

1

2

3

5

6

7

8

10

11

12

13

14

15

16

17

18

19

20

21

22

24

25 26 27 28

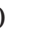
2 (3) .

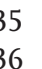
36 38

Physical activation of char usually proceeds with an oxidizing 42 atmosphere in a temperature-controlled tube furnace filled 43 with inert gases operated at high temperatures ranging from 44 600 to $1200{ }^{\circ} \mathrm{C}$. Normally, steam or $\mathrm{CO}_{2}$ is used as activation 45 agents in physical activation..$^{[9]}$ Compared with solid chemical 46 activation agents $(\mathrm{NaOH}, \mathrm{KOH})$, steam and $\mathrm{CO}_{2}$ show low 47 corrosive effects with the production facilities, which is more 48 suitable for practical application. ${ }^{[44]}$ Researches have shown that 49 the physical activation temperatures have nearly linear effects 50 on micropore volumes. ${ }^{[45-47]}$ Few pores are developed by gas 51 generation, and evolution, the pores in porous carbon mainly 52 form through oxidative reactions (Equations (3) and (4)) in 53 oxidizing atmospheres (e.g., $\mathrm{H}_{2} \mathrm{O}$ and $\mathrm{CO}_{2}$ ) during the physical 54 activation process ${ }^{[48]} \quad 55$

$\mathrm{C}+\mathrm{H}_{2} \mathrm{O} \rightarrow \mathrm{CO}+\mathrm{H}_{2}$

(3) 57

$\mathrm{C}+\mathrm{CO}_{2} \rightarrow 2 \mathrm{CO}$

(4) 59 
2

3

6
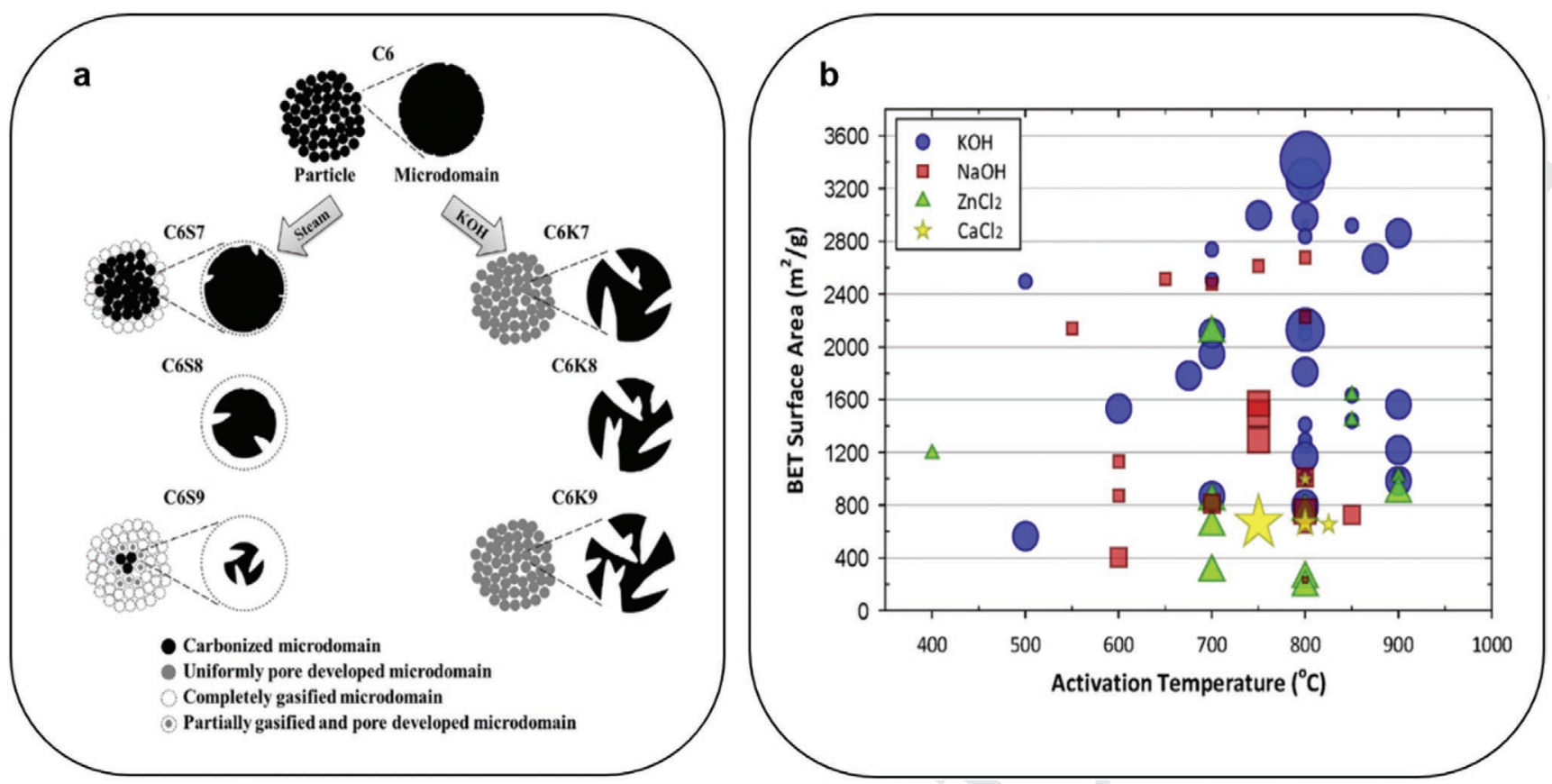

Figure 3. a) Structural mechanism model of pore formation in the carbon material using steam and $\mathrm{KOH}$ as activation agents. Reproduced with permission. ${ }^{[46]}$ Copyright 2016, Elsevier. b) SSAs of porous carbons as a function of the chemical activation agents $(\mathrm{KOH}, \mathrm{NaOH}, \mathrm{ZnCl} 2$, and $\mathrm{CaCl}$ ) and activation temperatures. Reproduced with permission. ${ }^{[59]}$ Copyright 2017, Elsevier.

Physical activation permits tailoring of the pore-size distribution more accurately and narrowly, which results in more micropores than the chemical activation. Besides, physical activation reduces both the particle and microdomain sizes in the resultant activated carbons. ${ }^{[46]}$ Srinivasakannan et al. investigated the effects of physical activation using $\mathrm{CO}_{2}$ and chemical activation using $\mathrm{H}_{3} \mathrm{PO}_{4}$ and $\mathrm{ZnCl}_{2}$ on the porous structures of activated carbon. ${ }^{[49]}$ Their results show that chemical activations using $\mathrm{H}_{3} \mathrm{PO}_{4}$ or $\mathrm{ZnCl}_{2}$ as activation agents result in the formation of porous carbons with relatively higher tap densities, a higher proportion of mesopores, accompanied by lower weight losses during the activation processes. Compared with chemical activation, physical activation usually has the characteristics of high activation temperatures, long activation time, relatively low yields, low tap density, small pore sizes, and low SSA (Figure 3a). ${ }^{[46]}$ However, from a production point of view, physical activation shows low corrosion toward the reactor compared with chemical activation. So physical activation is more feasible and widely used for industrial production. To improve the SSA of porous carbons produced by physical activation, Şahin and Saka produced activated carbons from corn shells by physical activation method using $\mathrm{CO}_{2}$ and $\mathrm{H}_{2} \mathrm{O}$ as activation agents and a two-step pretreatment using the activated agents of $\mathrm{ZnCl}_{2}$ and $\mathrm{HCl}$. With the increase of impregnation concentration of agents, Brunauer-Emmett-Teller (BET) SSA and pore volume of the produced activated carbon reached to $1779 \mathrm{~m}^{2} \mathrm{~g}^{-1}$ and $0.927 \mathrm{~cm}^{3} \mathrm{~g}^{-1}$, respectively. ${ }^{[50]}$

\subsection{Traditional Chemical Activation}

Compared with physical activation, chemical activation offers several advantages: high carbon yields, relatively low-temperature processes, and high mesopore ratios in the resultant porous carbon..$^{[45,47]} \mathrm{A}$ large number of studies have demonstrated the synthesis of porous carbon by chemical activation with the abundant choices of carbon sources and activation agents such as alkaline metal hydroxides, alkaline metal carbonates, and phosphoric acids. Besides, researchers could exert the unique chemical or structural characteristics of carbon sources to synthesize various porous carbons with different pore structures. ${ }^{[43-45]}$ Traditionally, potassium hydroxide $(\mathrm{KOH}),{ }^{[51,52]}$ sodium hydroxide $(\mathrm{NaOH}),{ }^{[53,54]}$ zinc chloride $\left(\mathrm{ZnCl}_{2}\right),{ }^{[55]}$ phosphoric acid $\left(\mathrm{H}_{3} \mathrm{PO}_{4}\right),{ }^{[49,56]}$ sodium carbonate $\left(\mathrm{Na}_{2} \mathrm{CO}_{3}\right),{ }^{[57]}$ and potassium carbonate $\left(\mathrm{K}_{2} \mathrm{CO}_{3}\right)^{[57,58]}$ have been used as activation agents. For a high-level summary of the effect of traditional chemical activation agents on porous carbon, the relationships between the SSA and activation temperature of the activated carbon are shown in Figure $3 \mathrm{~b}$ for a few chemical activation agents. ${ }^{[59]}$ The data indicate that $\mathrm{KOH}$ is the most powerful activation agent, while $\mathrm{NaOH}$ takes the second place. Salt activation agents, such as $\mathrm{ZnCl}_{2}$, produce porous carbons with lower SSAs. Normally, chemical activation can produce porous carbons with high SSAs ranging from 500 to $3600 \mathrm{~m}^{2} \mathrm{~g}^{-1} \cdot{ }^{[60,61]}$ Lin et al. compared the effects of hydroxide activation agents, such as $\mathrm{NaOH}, \mathrm{KOH}$ and a specific mixture of them on the chemical activation of biochar from rice husk. ${ }^{[62]}$ The derived activated carbon using $\mathrm{NaOH}, \mathrm{KOH}$, and the mixture of them were termed as NC, KC, and NKC, respectively. NC, KC, and NKC exhibited SSAs of 2260, 1702, and $2747 \mathrm{~m}^{2} \mathrm{~g}^{-1}$, and pore volumes of $1.31,0.74$, and $1.40 \mathrm{~cm}^{3} \mathrm{~g}^{-1}$, respectively. Interestingly, NKC possessed the most developed pore structure and widest pore-size distribution among three porous carbon materials. Their results indicate that the pore size of all three samples is centered at $1.0 \mathrm{~nm}$ with a
1 
wide range of $0.5-3.0 \mathrm{~nm}$, while $\mathrm{NaOH}$ assists the formation of mesoporous structure compared with $\mathrm{KOH}$. When used as electrodes of SC, NKC displayed a specific capacitance of 194.6 $\mathrm{F} \mathrm{g}^{-1}$ at $0.5 \mathrm{~A} \mathrm{~g}^{-1}$ tested by galvanostatic charge-discharge (GCD) in $\mathrm{H}_{2} \mathrm{SO}_{4}$ electrolyte.

Carbonization and activation can be combined in one step. The combination of activation and carbonization can result in highly macroporous carbons, which is due to the fact that organics can be easily decomposed in alkaline media at high temperatures. In this regard, the ratio of activation agent/ organic precursor should be controlled below one. Zhang et al. synthesized a 3D porous carbon foam (PCF) with one-step carbonization of $\mathrm{K}_{2} \mathrm{CO}_{3}$ containing chitosan. ${ }^{[63]} \mathrm{PCF}$ shows a high SSA about $1030 \mathrm{~m}^{2} \mathrm{~g}^{-1}$ and micropores centered at $0.66 \mathrm{~nm}$. The specific capacitance of PCF was $246.5 \mathrm{~F} \mathrm{~g}^{-1}$ at $0.5 \mathrm{~A} \mathrm{~g}^{-1}$, while $67.5 \%$ of its capacitance was maintained at $100 \mathrm{~A} \mathrm{~g}^{-1}$. Fuertes et al. mixed polypyrrole (PPy) and $\mathrm{KOH}$, and did carbonization and activation in one step. ${ }^{[64]}$ The as-prepared porous carbon showed an ultrahigh SSA of 3000-3500 $\mathrm{m}^{2} \mathrm{~g}^{-1}$ and a pore volume up to $2.6 \mathrm{~cm}^{3} \mathrm{~g}^{-1}$. They further investigated the pore size development along with the activation temperature. ${ }^{[65]}$ In the case of PPy used as carbon precursor, narrow micropores of $1 \mathrm{~nm}$ were formed at $600{ }^{\circ} \mathrm{C}$, and a large fraction of mesopores centering at $2.7 \mathrm{~nm}$ was formed at $800^{\circ} \mathrm{C}$. Similarly, Zhang et al. synthesized a hierarchical porous carbon by carbonizing lignin and $\mathrm{KOH}$ directly. ${ }^{[66]}$ The obtained hierarchical porous carbon exhibited an SSA of $907 \mathrm{~m}^{2} \mathrm{~g}^{-1}$ with a wide pore-size distribution ranging from 0.6 to $40 \mathrm{~nm}$ and a high specific capacitance of $165.0 \mathrm{~F} \mathrm{~g}^{-1}$ at $0.05 \mathrm{~A} \mathrm{~g}^{-1}$ in $\mathrm{H}_{2} \mathrm{SO}_{4}$ electrolyte. Although with the same $\mathrm{KOH}$ activation agent, the obtained porous carbon materials showed different porous architecture, SSA, and specific capacitance, which is resulted from the different activation activities of $\mathrm{KOH}$ toward different organic precursors.

The activation mechanism of the normally used chemical activation agents is still not well understood due to the various variables and different carbon precursors used in the activation process. In the case of $\mathrm{KOH}$, pores formed below $500{ }^{\circ} \mathrm{C}$ are caused by the evaporation of volatiles from dehydrating reactions or radical reactions. ${ }^{[10]}$ In the chemical activation stage, the pores are further developed with the consumption of carbon, as shown in Equation (5). Equation (5) normally occurs at temperatures lower than $570{ }^{\circ} \mathrm{C}$. Although this reaction occurs at low temperature, the produced $\mathrm{K}$ further reacts with $\mathrm{KOH}$ forming $\mathrm{K}_{2} \mathrm{O} . \mathrm{K}_{2} \mathrm{CO}_{3}$ begins to form at around $400{ }^{\circ} \mathrm{C}$ due to the reaction between $\mathrm{K}_{2} \mathrm{O}$ and $\mathrm{CO}_{2}$ pyrolysis gases (Equation (6)). ${ }^{[10]}$ $\mathrm{KOH}$ is completely consumed at $600{ }^{\circ} \mathrm{C}$. So the main etching agents of $\mathrm{KOH}$ activation are $\mathrm{K}_{2} \mathrm{CO}_{3}$ and $\mathrm{K}_{2} \mathrm{O}$ (reactions are shown in Equations (7) and (8)) around $700{ }^{\circ} \mathrm{C}$. Meanwhile, the activation products of $\mathrm{CO}_{2}$ may also take some part in the poreforming process due to their physical activation effects

$\mathrm{KOH}+2 \mathrm{C} \rightarrow 2 \mathrm{~K}+3 \mathrm{H}_{2}+2 \mathrm{~K}_{2} \mathrm{CO}_{3}$

$\mathrm{K}_{2} \mathrm{O}+\mathrm{CO}_{2} \rightarrow \mathrm{K}_{2} \mathrm{CO}_{3}$

$\mathrm{K}_{2} \mathrm{CO}_{3}+2 \mathrm{C} \rightarrow 2 \mathrm{~K}+3 \mathrm{CO}$

$\mathrm{K}_{2} \mathrm{O}+\mathrm{C} \rightarrow 2 \mathrm{~K}+\mathrm{CO}$
From the structural consideration, the influences of car- 1 bonization and activation temperatures on the crystal struc- 2 ture of porous carbon are still needed to be explored, as 3 the graphitic carbon and amorphous carbon show different 4 electrochemical behaviors as electrodes of SC. The oxygen- 5 containing functional groups also need to be investigated, 6 as the defective oxygen-containing sites are highly active 7 toward chemical activation. Although papers are reporting 8 the influence of carbonization temperatures toward chemical 9 activation, ${ }^{[67]}$ the influence of carbonization temperatures 10 on the crystalline structures and surface functional groups 11 of porous carbons need to be studied in detail since the 12 oxygen functional groups sometimes limit the cycling life of 13 an SC. ${ }^{[68]}$

Chemical activation is the most widespread method for the 15 preparation of porous carbons in lab-scale research. Due to the 16 high consumption of the $\mathrm{KOH}$ activation agent and the highly 17 corrosive environment of $\mathrm{KOH}$ at high temperatures toward 18 reactors, $\mathrm{KOH}$ activation is unlikely to be used in industrial 19 production. Besides, chemical activation generates a lot of 20 contaminants that are generally high alkaline and polluting. 21 Toward future industrial productions, green synthesis methods 22 need to be developed, and the quantities of chemical activation 23 agents should be reduced.

\section{New Chemical Activation Methods 27}

Porous carbon materials with high SSA up to thousands of 29 square meters per gram can be easily achieved by chemical 30 activation. However, the traditional chemical-activation syn- 31 thesis strategies suffer from the drawbacks of severe corrosion 32 of reactor, small pore size, and pore structure collapse due to 33 the high temperatures. Another consideration of chemical 34 activation is its environmental impact. Since chemical activation 35 produces highly concentrated alkaline pollutants, which need 36 to be further treated to minimize the emission of pollutants, 37 this inevitably increases the production cost of porous carbon. 38 In recent years, there has been a huge effort to search for 39 efficient chemical activation agents. Even though these chem- 40 ical activation agents may not be considered as green agents, 41 they provide opportunities to develop new activation strategies 42 for the synthesis of porous carbons. These new chemical agents 43 can be classified according to their different activation mecha- 44 nisms into three groups: molten salt, decomposable salt, and 45 oxidative salt.

\subsection{Molten Salt Etching}

Molten salt etching methods are used to describe methodolo- 51 gies which use corrosive molten chemical agents that react with 52 carbon to generate porous structures under high temperatures. 53 In recent years, $\mathrm{CuCl}_{2},{ }^{[17,69]} \mathrm{NiCl}_{2},{ }^{[70,71]} \mathrm{NaCl}^{,[72-74]} \mathrm{KCl},{ }^{[74]} 54$ and $\mathrm{FeCl}_{3}{ }^{[75-77]}$ have been used as molten salts in chemical 55 activation. For example, $\mathrm{CuCl}_{2}$ was proved to show less destruc- 56 tive effect on the natural structure of the biomass precursor, 57 while traditional activation agents like $\mathrm{KOH}$ and $\mathrm{ZnCl}_{2}$ crushed 58 the carbon precursors into carbon fragments in the activation 59 


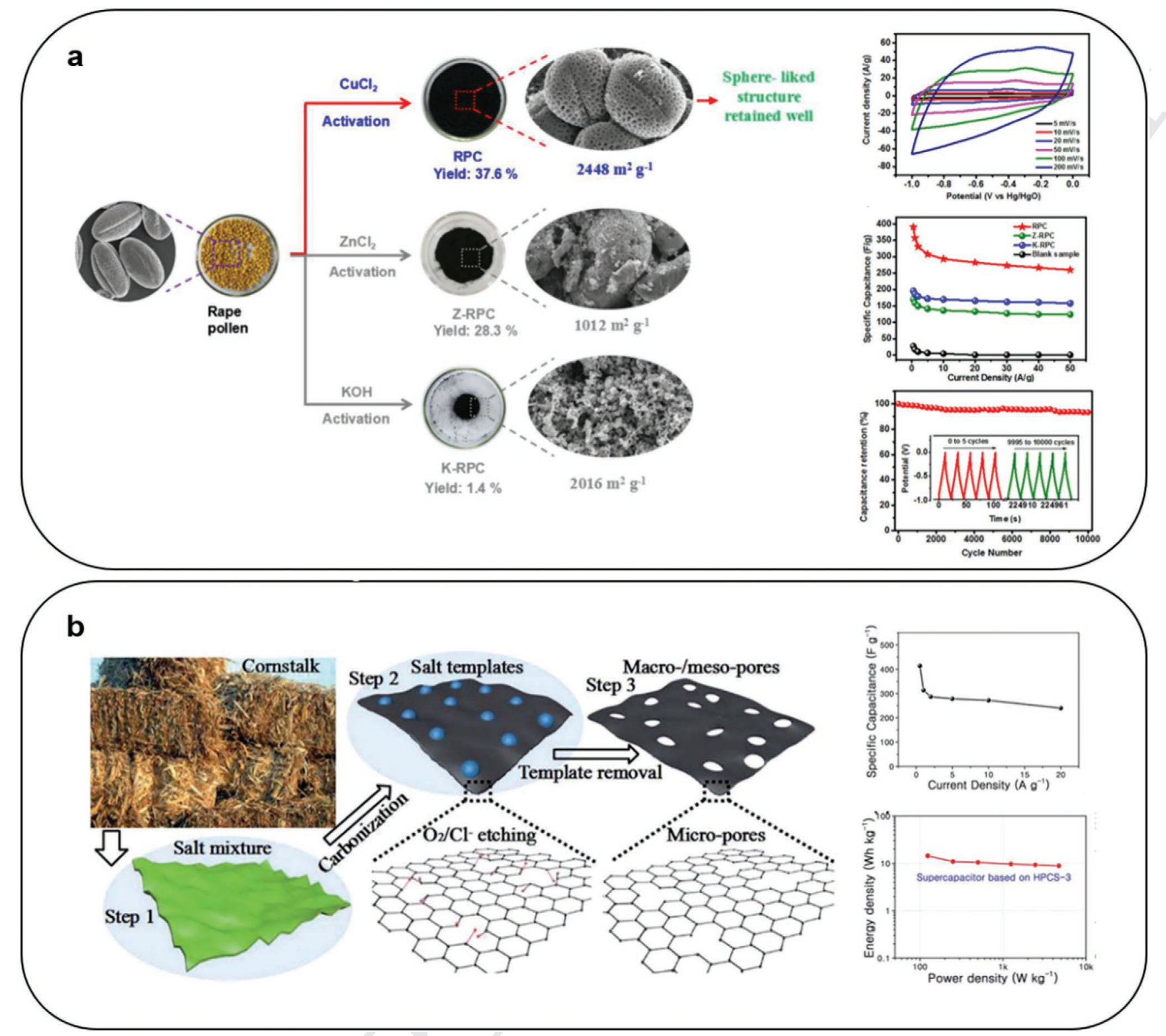

Figure 4. a) The preparation schematic diagram of RPC, Z-RPC, and K-RPC as activation agents (left); CV curves of RPC at different scan rates, specific capacitances of RPC, Z-RPC, K-RPC, and the blank sample at different current densities and the long-term cycling test measured at $20 \mathrm{~A} \mathrm{~g}^{-1}$ (inset graph is the GCD curves of RPC). Reproduced with permission. ${ }^{[17]}$ Copyright 2018, The Royal Society of Chemistry. b) The preparation schematic diagram

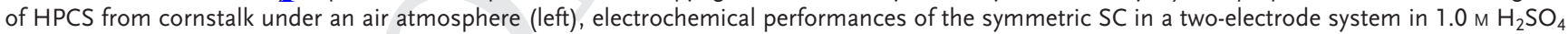
aqueous electrolyte, specific capacitances of HPCS-3//HPCS-3 at different current densities, and Ragone plot (right). Reproduced with permission. ${ }^{\text {[72] }}$ Copyright 2018, The Royal Society of Chemistry.

process (Figure 4a). ${ }^{[17]}$ The mechanisms of $\mathrm{CuCl}_{2}$ porogen are described as follows ${ }^{[69]}$

$3 \mathrm{CuCl}_{2}+\mathrm{C}+2 \mathrm{H}_{2} \mathrm{O} \rightarrow \mathrm{Cu}+2 \mathrm{CuCl}+\mathrm{CO}_{2}+4 \mathrm{HCl}$

$4 \mathrm{CuCl}+\mathrm{C}+2 \mathrm{H}_{2} \mathrm{O} \rightarrow 4 \mathrm{Cu}+\mathrm{CO}_{2}+4 \mathrm{HCl}$

The sphere-like porous carbon prepared from $\mathrm{CuCl}_{2}$ activation (RPC) exhibited a high SSA up to $2488 \mathrm{~m}^{2} \mathrm{~g}^{-1}$, with the pore size distributed below $2 \mathrm{~nm}$ and pore-size distribution centered at $1.2 \mathrm{~nm}$. With the same activation temperature, porous carbon derived from $\mathrm{ZnCl}_{2}$ activation (Z-RPC) shows a wide pore-size distribution ranging from 1 to $60 \mathrm{~nm}$ while the pore size of $\mathrm{KOH}$ activation porous carbon (K-RPC) is distributed below $3 \mathrm{~nm}$. Moreover, RPC exhibits a high yield up to $37.6 \%$ based on the raw materials, which is much higher than that of Z-RPC $(28.3 \%)$ and K-RPC $(1.4 \%)$. When used as electrodes of SC, the porous carbon prepared from $\mathrm{CuCl}_{2}$ activation presents a high gravimetric capacitance of $390 \mathrm{~F} \mathrm{~g}^{-1}$ at $0.5 \mathrm{~A} \mathrm{~g}^{-1}$ in $6.0 \mathrm{~mol} \mathrm{~L}^{-1} \mathrm{KOH}$ aqueous electrolyte. The mechanism of $\mathrm{CuCl}_{2}$ activation is demonstrated by the formation of $\mathrm{Cu}$ and $\mathrm{CuCl}$ intermediate species. Namely, carbon is oxidized by $\mathrm{Cu}^{2+}$
1 
ions. Since there is no mechanism study in this report, the role of $\mathrm{Cl}^{-}$ion needs to be confirmed. From a practical production view, the outlet gases from $\mathrm{CuCl}_{2}$ activation need to be determined and purified for green synthesis. The mixture salt of $\mathrm{KCl}$ and $\mathrm{NaCl}$ has also been developed as the molten salt agent. Wang et al. investigated the pore-forming mechanism of the cornstalk in $\mathrm{KCl} / \mathrm{NaCl}$ mixture molten slat using thermogravimetric techniques. ${ }^{[72]}$ They found that oxygen molecules act as an etching agent at lower temperatures, while at temperatures of above $800{ }^{\circ} \mathrm{C}, \mathrm{Cl}^{-}$ions diffuse into the carbon skeleton and etch it, which assists the formation of micro- and mesopores (Figure 4b). By employing this strategy, the as-prepared hierarchical porous carbon with SSA of $1588 \mathrm{~m}^{2} \mathrm{~g}^{-1}$ exhibited a high specific capacitance of $407 \mathrm{~F} \mathrm{~g}^{-1}$ at $1 \mathrm{~A} \mathrm{~g}^{-1}$. Chen et al. reported that the SSAs of porous carbons prepared with the mixture molten salt of $\mathrm{KCl}$ and $\mathrm{NaCl}$ are higher than porous carbons prepared with mere $\mathrm{KCl}$ or $\mathrm{NaCl}^{\left[{ }^{[74}\right]}$ With the help of $\mathrm{KCl}$ and $\mathrm{NaCl}$ mixture, porous carbons generate micropores and mesopores centered at $\approx 1.4,2.7$, and $3.8 \mathrm{~nm}$, respectively. This research also proved that $\mathrm{KCl}$ agent creates more micropores and $\mathrm{NaCl}$ creates more mesopores from the same carbon precursor, which is similar to the conclusion of Lin et al. ${ }^{[62]}$ So it can be concluded that cations such as $\mathrm{K}^{+}$and $\mathrm{Na}^{+}$take part in the activation process, which affects the micropore or mesopore formation. $\mathrm{FeCl}_{3}$ is another molten salt that can be used as an activation agent. Combined with $\mathrm{ZnCl}_{2}$ and $\mathrm{KCl}$, the molten salt mixture can produce hierarchical porous carbon with SSAs up to $3155 \mathrm{~m}^{2} \mathrm{~g}^{-1}$. ${ }^{[76}$ The role of $\mathrm{FeCl}_{3}$ during activation has been investigated. ${ }^{[75]} \mathrm{FeCl}_{3}$ breaks hydrogen bonds below $100{ }^{\circ} \mathrm{C}$ and depolymerizes organic material at $135{ }^{\circ} \mathrm{C}$. When the temperature increased to $200-330^{\circ} \mathrm{C}$, dehydroxylation reactions take place as shown by Equation (11). At $330-700{ }^{\circ} \mathrm{C}$, the generation of $\mathrm{Fe}_{2} \mathrm{O}_{3}$ and $\mathrm{CO}_{2}$ promotes the development of micropores, as described in Equations (12) and (13). During this process, the microporous structure of porous carbon is further developed by the formation of Lewis acid with the synergistic effect of $\mathrm{Fe}^{3+}$ and $\mathrm{Cl}^{-}$. Moreover, the reaction products of iron oxides also show a positive influence on the formation of micropores. Porous carbon exhibited a relatively stable structure at temperatures ranging from 700 to $800{ }^{\circ} \mathrm{C}$. The reduction reactions of iron oxides further modified the microporous structure of amorphous carbon (Equations (14)-(16))

$\mathrm{FeCl}_{3}+2 \mathrm{H}_{2} \mathrm{O} \rightarrow \mathrm{FeOOH}+3 \mathrm{HCl}$

$\mathrm{FeOOH} \rightarrow \mathrm{Fe}_{2} \mathrm{O}_{3}+\mathrm{H}_{2} \mathrm{O}$

$\mathrm{Fe}_{2} \mathrm{O}_{3}+\mathrm{C} \rightarrow 4 \mathrm{Fe}_{3} \mathrm{O}_{4}+\mathrm{CO}_{2}$

$2 \mathrm{Fe}_{2} \mathrm{O}_{3}+3 \mathrm{C} \rightarrow 4 \mathrm{Fe}+3 \mathrm{CO}_{2}$

$\mathrm{Fe}_{3} \mathrm{O}_{4}+2 \mathrm{C} \rightarrow 3 \mathrm{Fe}+2 \mathrm{CO}_{2}$

$\mathrm{Fe}_{3} \mathrm{O}_{4}+4 \mathrm{C} \rightarrow 3 \mathrm{Fe}+4 \mathrm{CO}$

The role of $\mathrm{Cl}^{-}$ion in chlorides still needs to be confirmed using in situ techniques. Additionally, other porogens, such as $\mathrm{KOH}$ and $\mathrm{NaOH}$, can be added into the molten salts to contribute to the porous structure of carbon products.
Undoubtedly, the molten salt strategy is milder compared with 1 chemical activation methods. However, the high cost of molten 2 salt used for preparation is an obstacle for practical production. 3

\subsection{Decomposable Salts Etching}

Various salts are decomposable and thus, the decomposition 8 gases can etch carbons to form pores. The decomposable salt is 9 a huge family with numerous members such as zinc acetate, ${ }^{[78]} 10$ $\mathrm{Zn}\left(\mathrm{NO}_{3}\right)_{2},{ }^{[79]} \mathrm{NaNO}_{3},{ }^{[80]}$ calcium acetate, ${ }^{[81]}$ sodium acetate, ${ }^{[82]} 11$ $\mathrm{MgCO}_{3},{ }^{[83]}$ sodium chloroacetate, ${ }^{[84]} \mathrm{K}_{3} \mathrm{PO}_{4},{ }^{[85]} \mathrm{NaH}_{2} \mathrm{PO}_{4},{ }^{[86]} 12$ tetraethylorthosilicate, and potassium acid phthalate. Generally, 13 Zn salts are regarded as a dehydration agent. ${ }^{[87]}$ The mechanism 14 of $\mathrm{Zn}$ salts is supposed to promote the formation of double 15 bonds between the carbon atoms by capturing $\mathrm{H}_{2} \mathrm{O}$ molecules 16 from organic carbon sources. ${ }^{[88,89]}$ Moreover, it is well-known 17 that the condensation reactions of aromatic hydrocarbons, 18 such as alkylation and acylation reactions, are more likely to 19 take place in the presence of Zn components. ${ }^{[90,91]}$ Thus, Zn 20 components can be used as a cyclo-addition porogen. As an 21 example, a kind of polyacrylonitrile (PAN)/pitch/lignin-based 22 carbon nanofibers (CNFs) with ZnO (PPL-Zn) was fabricated 23 by one-step electrospinning the mixture of PAN, pitch, lignin, 24 and zinc acetate. The decomposition product, $\mathrm{Zn}$, was removed 25 during the high-temperature annealing process. CNF exhibited 26 an SSA of $1194 \mathrm{~m}^{2} \mathrm{~g}^{-1}$ and a specific capacitance of $165 \mathrm{~F} \mathrm{~g}^{-1} 27$ (Figure 5a). ${ }^{[78]}$ The porous carbon that prepared with decom- 28 posable zinc acetate presented an SSA almost two times that 29 of the CNF fabricated without zinc acetate. Especially as a 30 porogen, zinc acetate shows the ability to increase the SSA and 31 mesopore volume.

Li et al. fabricated a cross-coupled macro- and mesoporous 33 carbon material by using the decomposable and water-remov- 34 able $\mathrm{NaNO}_{3}$ as porogen in the gelatin biopolymer aerogel 35 (Figure 5b). ${ }^{[78]}$ This porous carbon exhibited small-sized 36 mesopores (2-4 nm) and macropores (50-150 nm) which gave a 37 high SSA of $2872.2 \mathrm{~cm}^{2} \mathrm{~g}^{-1}$. $\mathrm{NaNO}_{3}$ begins to decompose above 38 $600{ }^{\circ} \mathrm{C}$, generating pyrolysis gases of $\mathrm{N}_{2}, \mathrm{O}_{2}$, and NO, which 39 assists in creating mesoporous structure in the final porous 40 carbon product. Antonietti et al. studied a series of salts with 41 oxygen-containing anions on their abilities to create pores in 42 the molten $\mathrm{LiCl} / \mathrm{KCl}$ system (melting point of $353{ }^{\circ} \mathrm{C}$ ). ${ }^{[92]}$ In the 43 liquid flux media of $\mathrm{LiCl} / \mathrm{KCl}$, a series of oxysalts were used to 44 prepare porous carbons with the SSA up to $3200 \mathrm{~m}^{2} \mathrm{~g}^{-1} \cdot{ }^{[93,94]} 45$ Meanwhile, the pore-forming mechanisms of oxysalt anions 46 have been described as follows

$\mathbf{O H}^{-}: \mathrm{C}+2 \mathrm{OH}^{-} \rightarrow \mathrm{CO}+\mathrm{H}_{2} \uparrow+\mathrm{O}^{2-}$

$\mathrm{CO}_{3}^{2-}: \mathrm{C}+\mathrm{CO}_{3}^{2-} \rightarrow 2 \mathrm{CO}+\mathrm{O}^{2-}$

$\mathrm{NO}_{3}^{-}: 5 \mathrm{C}+4 \mathrm{NO}_{3}^{-} \rightarrow 5 \mathrm{CO}_{2}+2 \mathrm{~N}_{2} \uparrow+2 \mathrm{O}_{2} \uparrow$

$\mathbf{P O}_{4}^{3-}: \mathrm{a}: 2 \mathrm{C}+\mathrm{PO}_{4}^{3-} \rightarrow 2 \mathrm{CO}+\mathrm{PO}_{2}^{3-}$

$\mathrm{b}: \mathrm{C}+2 \mathrm{PO}_{2}^{3-} \rightarrow \mathrm{CO}+2 \mathrm{P} \uparrow+3 \mathrm{O}^{2-}$

$\mathbf{S O}_{4}^{2-}: \mathrm{a}: \mathrm{C}+\mathrm{SO}_{4}^{2-} \rightarrow \mathrm{CO}+\mathrm{SO}_{3}^{2-}$ 
2

7

8

11

12

13
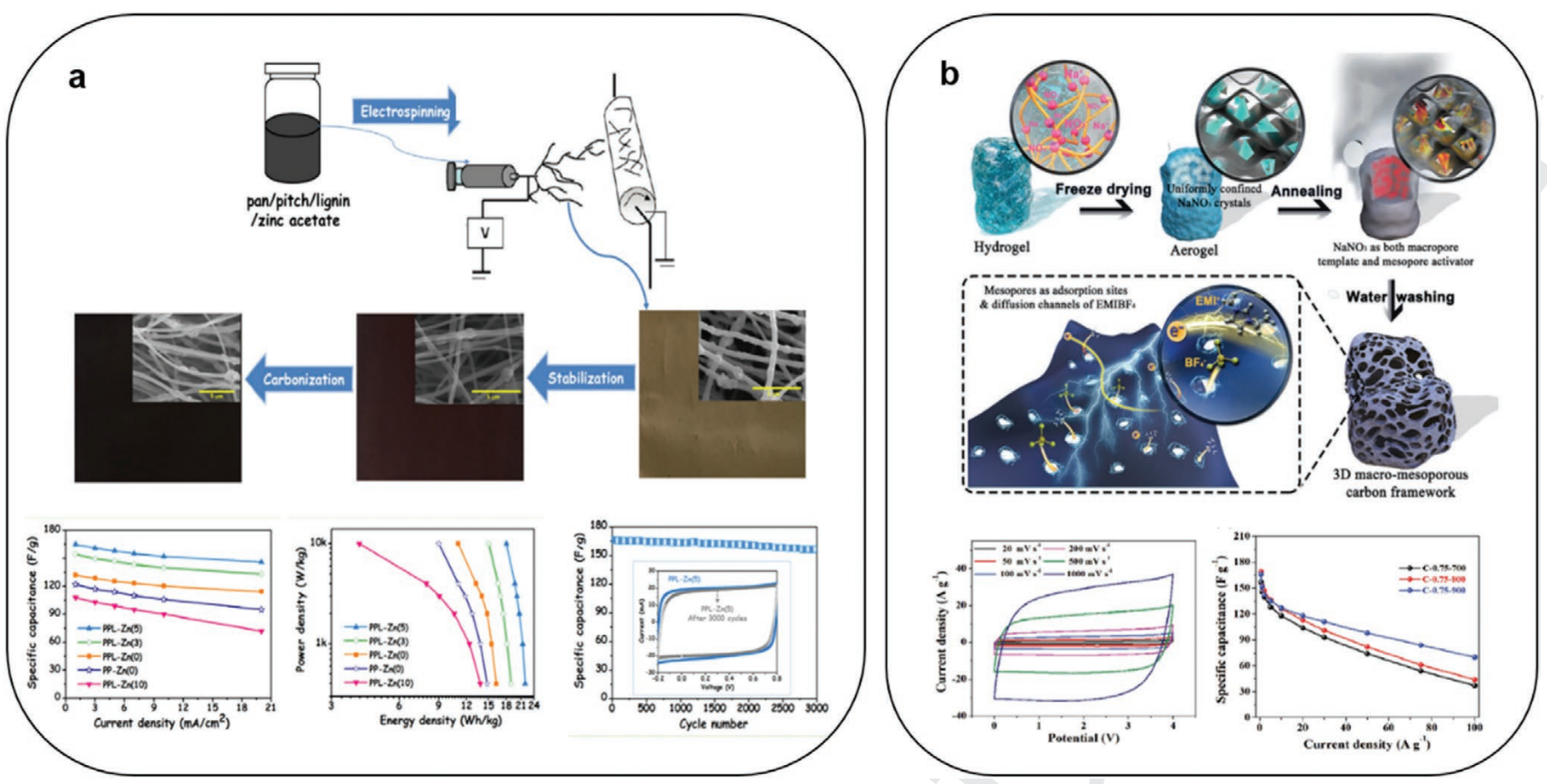

Figure 5. a) The preparation schematic diagram of PPL-Zn composite (above). Electrochemical tests of the two electrodes in $6 \mathrm{~mol} \mathrm{~L}^{-1} \mathrm{KOH}$ aqueous electrolyte: specific capacitances as a function of current densities, Ragone plots, and the cycling performance over $3000 \mathrm{cycles}$ of PPL-Zn at $1 \mathrm{~mA} \mathrm{~cm}{ }^{-2}$ (below). Reproduced with permission. ${ }^{[78]}$ Copyright 2019, Elsevier. b) The synthesis schematic diagram of 3D cross-coupled macro- and mesoporous carbon electrode via $\mathrm{NaNO}_{3}$ as porogen strategy and its application in ion liquid-based capacitor at $4 \mathrm{~V}$ (above), CV plot, and rate capability of porous carbon prepared with $\mathrm{NaNO}_{3}$ porogen (below). Reproduced with permission. ${ }^{[80]}$ Copyright 2018, Wiley-VCH.

$\mathrm{b}: 2 \mathrm{C}+\mathrm{SO}_{3}^{2-} \rightarrow 2 \mathrm{CO}+\mathrm{S} \uparrow+\mathrm{O}^{2-}$

$\mathrm{ClO}_{3}^{-}: 3 \mathrm{C}+2 \mathrm{ClO}_{3}^{-} \rightarrow 3 \mathrm{CO}_{2}+2 \mathrm{Cl}^{-}$

Generally, the cations of these salts, such as $\mathrm{K}^{+}$, are believed to take part in chemical activation, as described in Equations (5)-(8). However, Liu and Antonietti argued that in the case of potassium oxysalts, like $\mathrm{KH}_{2} \mathrm{PO}_{4}$, it is the anion groups of $\mathrm{H}_{2} \mathrm{PO}_{4}^{-}$rather than $\mathrm{K}^{+}$that manage the carbothermal reduction under the temperature below $1000^{\circ} \mathrm{C}$ based on thermodynamic considerations. ${ }^{[95]}$ The precise mechanism still needs to be further analyzed using various physicochemical methods and in situ techniques. Based on the above mechanisms, many oxygen-containing salts based on these anions have the potential to be used as activation agents.

\subsection{Oxidative Salt Etching}

The pore engineering of carbon materials can also be achieved with oxidative activation agents. Oxidative activation agents such as $\mathrm{HNO}_{3},{ }^{\left[{ }^{[9-98]}\right.} \mathrm{KMnO}_{4},{ }^{[25,99,100]} \mathrm{KNO}_{3},{ }^{[101,102]}$ and $\mathrm{Mn}\left(\mathrm{NO}_{3}\right)_{2}{ }^{[103]}$ were used to create porous carbons by oxidizing carbon at room temperature or high annealing temperatures. Wang et al. treated carbon cloth with $\mathrm{KMnO}_{4}, \mathrm{HNO}_{3}$, and $\mathrm{H}_{2} \mathrm{O}_{2}$, respectively, at room temperature. After treatment, the SSA of carbon cloth increased from 5.3 to $61.2 \mathrm{~m}^{2} \mathrm{~g}^{-1}$. ${ }^{[9]}$ Yang et al. fabricated single-wall carbon nanohorns (SWNHs) with high SSA up to $1464 \mathrm{~m}^{2} \mathrm{~g}^{-1}$ and high pore volume about $1.05 \mathrm{~cm}^{3} \mathrm{~g}^{-1}$ by merely soaking SWNHs with $69 \% \mathrm{HNO}_{3} .{ }^{[9]}$ The treatment of
$\mathrm{HNO}_{3}$ can efficiently produce microporosity in the range of 0.4-1.9 $\mathrm{nm}$. On the other hand, $\mathrm{KMnO}_{4}$ turned out to be an effective porogen for hierarchical porous carbon. When $\mathrm{KMnO}_{4}$ was applied as an activation agent, the derived carbon exhibited more macropores and mesopores compared with the carbon materials activated by $\mathrm{KOH} \cdot{ }^{[100]}$ A large number of macropores and mesopores were generated due to the reactions described in Equations (25)-(27). $\mathrm{KMnO}_{4}$ is decomposed into $\mathrm{K}_{2} \mathrm{MnO}_{4}$, $\mathrm{MnO}_{2}$, and $\mathrm{O}_{2}$. These products play crucial roles in etching carbon skeleton and creating mesoporous structure. When the temperature increases to $700{ }^{\circ} \mathrm{C}$, the decomposed $\mathrm{K}_{2} \mathrm{CO}_{3}$ shows apparent influence on the creation of the microporous structure of carbon material, which has been discussed in Section 2.3. The $\mathrm{KMnO}_{4}$-activated carbon exhibited an SSA up to $1199 \mathrm{~m}^{2} \mathrm{~g}^{-1}$ and a pore volume of $11.7 \mathrm{~cm}^{3} \mathrm{~g}^{-1}$. The capacitances of $\mathrm{KMnO}_{4}$-activated carbon are $242 \mathrm{~F} \mathrm{~g}^{-1}$ at $1 \mathrm{~A} \mathrm{~g}^{-1}$ and $145 \mathrm{~F} \mathrm{~g}^{-1}$ at $10 \mathrm{~A} \mathrm{~g}^{-1}$

$2 \mathrm{KMnO}_{4} \rightarrow \mathrm{K}_{2} \mathrm{MnO}_{4}+\mathrm{MnO}_{2}+\mathrm{O}_{2}$

$\mathrm{K}_{2} \mathrm{MnO}_{4}+\mathrm{C} \rightarrow \mathrm{K}_{2} \mathrm{CO}_{3}+\mathrm{MnO}$

$2 \mathrm{MnO}_{2}+\mathrm{C} \rightarrow 2 \mathrm{MnO}+\mathrm{CO}_{2}$

The $\mathrm{KNO}_{3}$ generates huge expansion when carbon is heated under an inert atmosphere due to the strong explosive characteristic of $\mathrm{KNO}_{3}$. Wang et al. used $\mathrm{KNO}_{3}$ to put substantial inner stress to explode the carbon into slices, as shown in Figure 6a. ${ }^{[102]}$ After $\mathrm{KOH}$ activation, the obtained porous carbon nanosheets (PCNSs) exhibited an SSA up to $2788 \mathrm{~m}^{2} \mathrm{~g}^{-1}$, and
1 


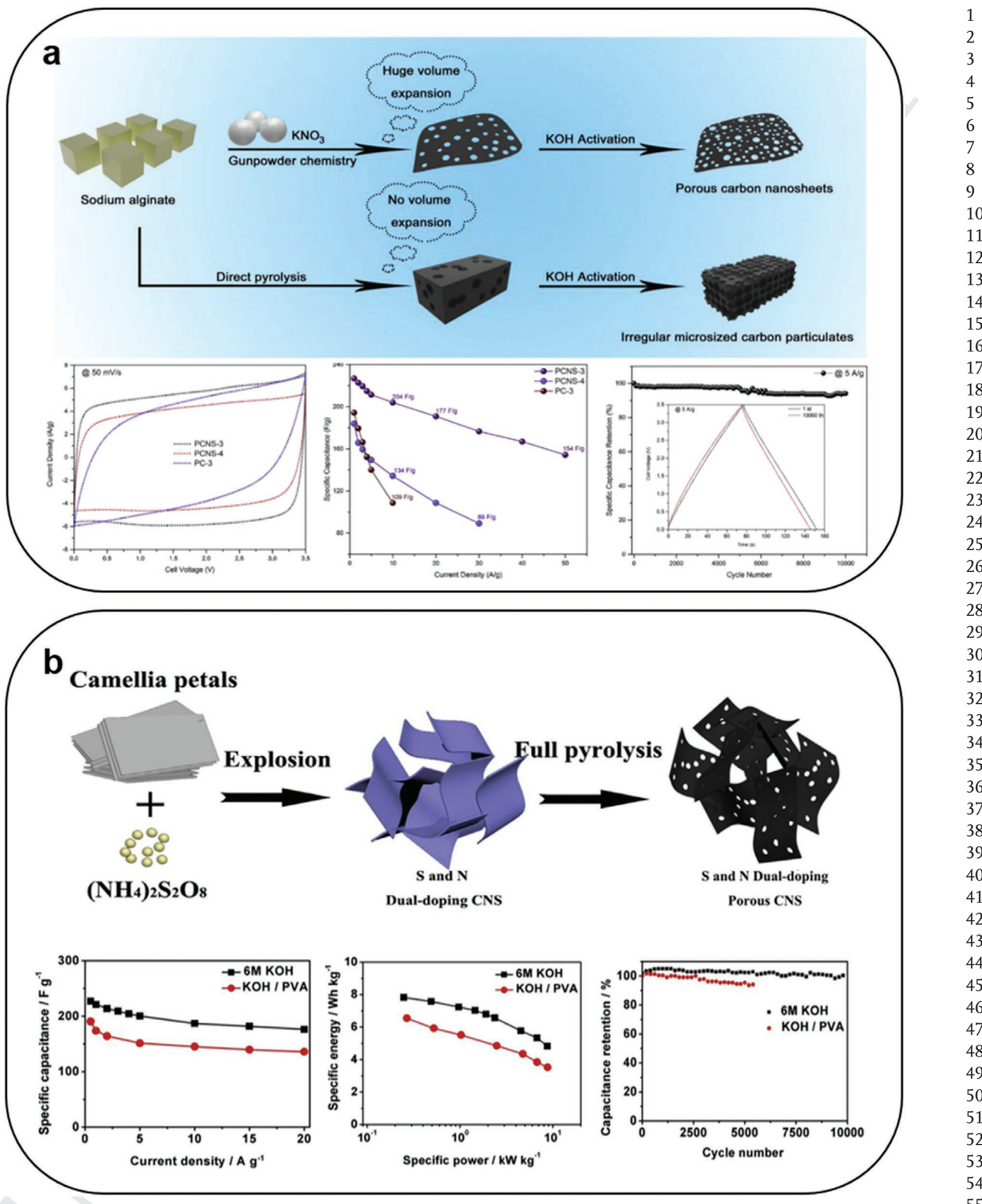

Figure 6. a) The preparation schematic of porous carbons with $\mathrm{KNO}_{3}$ exploding carbon into slices (above). $\mathrm{CV}$ curves at a scan rate of $50 \mathrm{mV} \mathrm{s}{ }^{-1}$, 55 rate capability as a function of current densities, and cycling stability test of the PCNS-based SC at 5 A g $^{-1}$ for 10000 cycles (the inset is the GCD profiles of the initial and 10 000th cycles). Reproduced with permission. ${ }^{[102]}$ Copyright 2019, Elsevier. b) The preparation schematic of CNSs (above), the correlation of specific capacitances with current densities, Ragone plot, and the GCD cycling performance of CNS (below). Reproduced with permission. ${ }^{[104]}$ Copyright 2016, Elsevier.

1 2 ( 西 6 57 58 
1 high mesopore volume. Because of the high mesopore volume 2 of PCNS, PCNS showed a superior rate performance. PCNS 3 exhibited a high specific capacitance of $226.9 \mathrm{~F} \mathrm{~g}^{-1}$ at $1 \mathrm{~A} \mathrm{~g}^{-1}$, 4 while a specific capacitance of $154.3 \mathrm{~F} \mathrm{~g} \mathrm{~g}^{-1}$ still maintained at $550 \mathrm{~A} \mathrm{~g}^{-1}$

6
$2\left(\mathrm{NH}_{4}\right)_{2} \mathrm{~S}_{2} \mathrm{O}_{8} \rightarrow\left(\mathrm{NH}_{4}\right)_{2} \mathrm{~S}_{2} \mathrm{O}_{7}+\mathrm{O}_{2}$

$\left(\mathrm{NH}_{4}\right)_{2} \mathrm{~S}_{2} \mathrm{O}_{7} \rightarrow 2 \mathrm{NH}_{3}+2 \mathrm{SO}_{3}+\mathrm{H}_{2} \mathrm{O}$

Another typical oxidative chemical activation agent is ammonium persulfate $\left(\left(\mathrm{NH}_{4}\right)_{2} \mathrm{~S}_{2} \mathrm{O}_{8}\right) \cdot\left(\mathrm{NH}_{4}\right)_{2} \mathrm{~S}_{2} \mathrm{O}_{8}$ decomposes first at temperatures higher than $180{ }^{\circ} \mathrm{C}$ (Equation (28)), and finally decomposes completely into $\mathrm{NH}_{3}, \mathrm{SO}_{3}$, and $\mathrm{H}_{2} \mathrm{O}$ at temperatures higher than $400{ }^{\circ} \mathrm{C}$ (Equation (29)). $\cdot^{[104,105]}$ In a one-step experiment fabricating PCNSs, camellia petals were mixed with $\left(\mathrm{NH}_{4}\right)_{2} \mathrm{~S}_{2} \mathrm{O}_{8}$ and carbonized at high temperature (Figure 6b). ${ }^{[04]}$ The obtained CNS exhibited a high SSA of $1122 \mathrm{~m}^{2} \mathrm{~g}^{-1}$, specific capacitances of $227.0 \mathrm{~F} \mathrm{~g}^{-1}$ at $0.5 \mathrm{~A} \mathrm{~g}^{-1}$ and $176.2 \mathrm{~F} \mathrm{~g}^{-1}$ at $20 \mathrm{~A} \mathrm{~g}^{-1}$.

\section{Template Methods}

\subsection{Hard Templates}

Template synthesis is one of the most mature methods to fabricated carbon materials with well-defined pore structures and narrow pore-size distributions. Hard templates such as

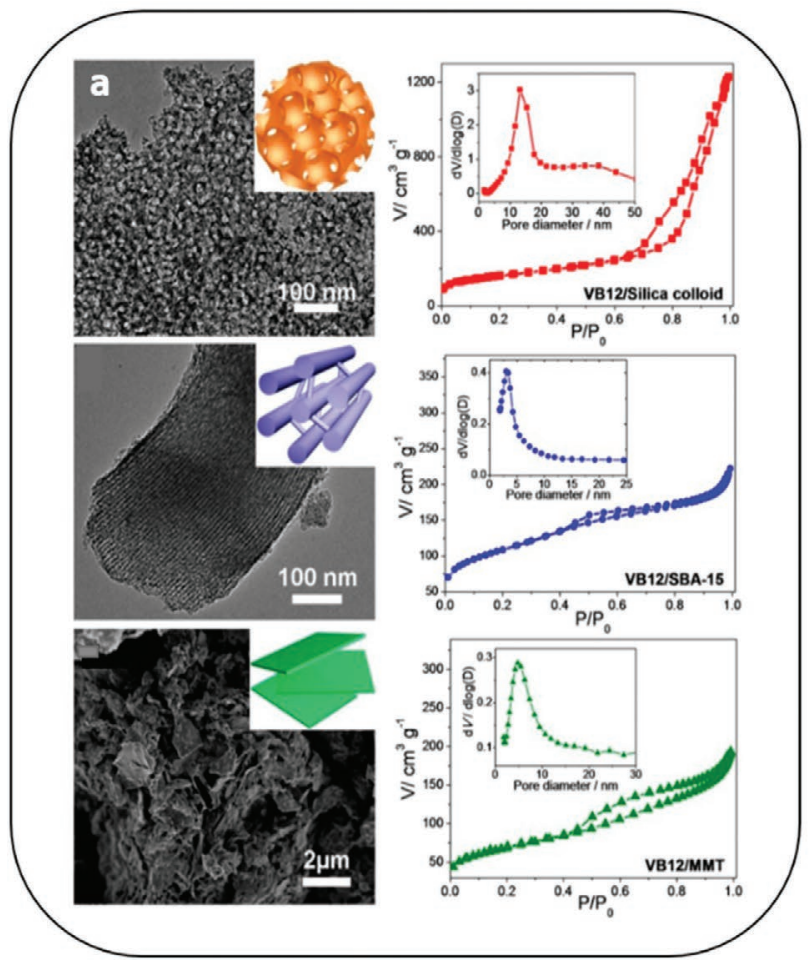
carbons. Reproduced with permission. ${ }^{[123]}$ Copyright 2018, Elsevier.
$\mathrm{SiO}_{2},{ }^{[106-108]} \mathrm{MgO},{ }^{[109-111]} \mathrm{ZnO}^{[112-114]} \mathrm{Al}_{2} \mathrm{O}_{3},{ }^{[115,116]} \mathrm{TiO}_{2},{ }^{[117]}$ as 1 well as zeolite ${ }^{[118,119]}$ are usually used as templates which can be 2 easily synthesized into uniform and regular porous structure. 3 The key steps in the hard template methodology include:[120] 4 1) fabrication of the desirable hard template, 2) impregnation 5 of hard template with carbon sources, 3) pyrolysis under high temperature, and 4) etching templates by acid or alkali solution etching. Among these oxide templates, silica is one of the most mature templates used for mesoporous carbon synthesis, and some silica templates have been commercially produced. ${ }^{[107,108]}$ Liang et al. fabricated three kinds of mesoporous carbon catalysts using $12 \mathrm{~nm} \mathrm{SiO}_{2}$ nanoparticles (silica colloid), ordered mesoporous silica (SBA-15), and montmorillonite (MMT) as templates. ${ }^{[106]}$ By employing vitamin B12 (VB12) as a carbon precursor, the carbon catalyst fabricated with silica nanoparticles exhibited a higher SSA $\left(572 \mathrm{~m}^{2} \mathrm{~g}^{-1}\right)$ than that of the other samples (Figure 7a). ${ }^{[106]}$ The carbon catalysts fabricated with SBA-15 and MMT as templates presented SSAs about 387 and $134 \mathrm{~m}^{2} \mathrm{~g}^{-1}$ with the pore-size distribution centered at 3.5 and $4.5 \mathrm{~nm}$. Porous anodic aluminum oxide (AAO) is a porous hard template that has been widely used for preparing porous carbons for nano-functional devices. ${ }^{[121]}$ The porous carbons prepared using AAO templates have evenly distributed pores sizes in the range of $50-200 \mathrm{~nm}$, which is too large for SC electrode application. Zhao et al. prepared ordered mesoporous carbon nanosheets using AAO membrane as template. ${ }^{[116]}$ The resultant mesoporous carbon nanosheets had pore sizes of

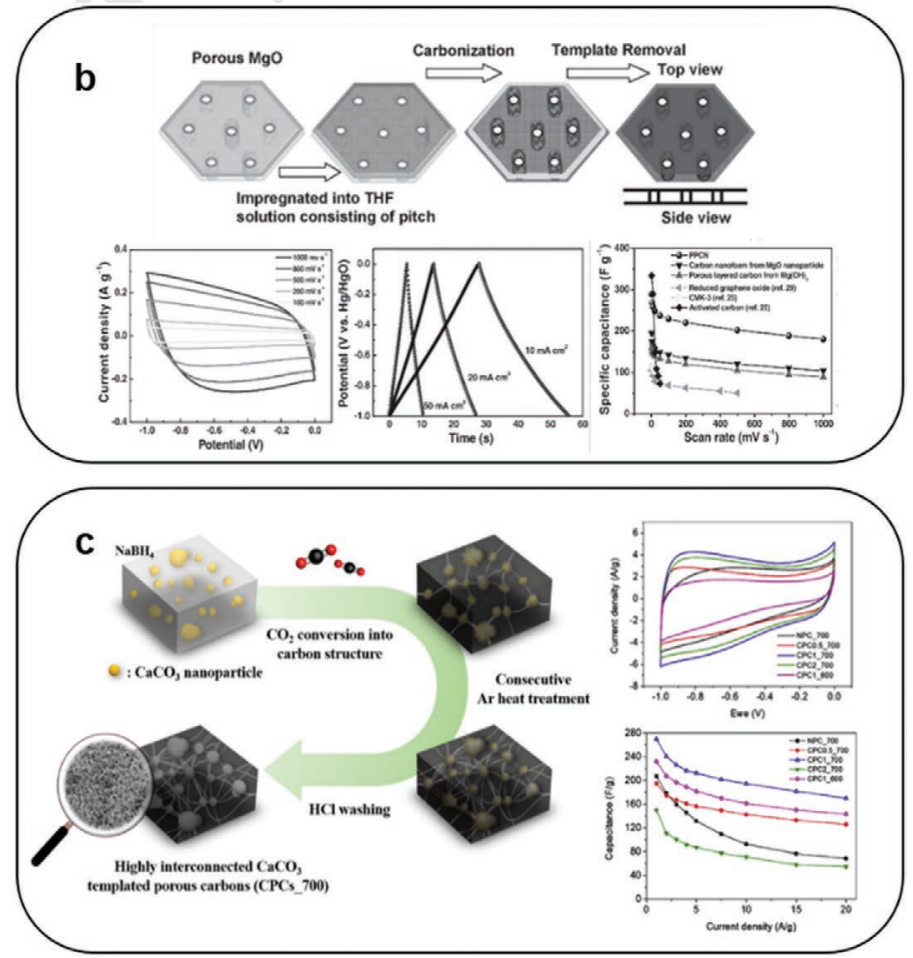

Figure 7. a) TEM, SEM images, and $\mathrm{N}_{2}$ adsorption isotherms of as-prepared porous carbon electrocatalysts: VB12/silica colloid, VB12/SBA-15, and VB12/MMT. Reproduced with permission. ${ }^{[106]}$ Copyright 2013, American Chemical Society. b) The preparation schematic diagram of 3D pillared-PCNSs and the corresponding electrochemical performances: CV curves, GCD curves at various current densities, and specific capacitances versus scan rates of the as-prepared carbon materials. Reproduced with permission. ${ }^{110]}$ Copyright 2012, Wiley- $\mathrm{VCH}$. c) The schematic diagram for one-step nanotemplated $\mathrm{CO}_{2}$ conversion into porous carbons, and the corresponding $\mathrm{CV}$ curves, specific capacitances at various current densities of the porous 
hundreds of nanometers, tens of micrometers in length, and sheet thickness values of about $1 \mathrm{~nm}$. Thus, the structural features of porous carbons prepared using the hard templates greatly depend on the properties of the templates used.

Magnesium oxide $(\mathrm{MgO})$ can be easily synthesized with morphologies of 2D sheets and 3D clusters, and consequently, many porous carbons have been synthesized using $\mathrm{MgO}$ templates. Fan et al. proposed a strategy to fabricate a large number of new porous carbons using $\mathrm{MgO}$ templates with different morphologies, such as $\mathrm{MgO}$ nanoparticles and $\mathrm{Mg}(\mathrm{OH})_{2}$ nanosheets (Figure 7b). ${ }^{[110]}$ Self-supporting layered 3D pillared-PCNSs with an average mesopore size of $7 \mathrm{~nm}$ were formed during the carbonization of coal tar pitch. In this strategy, carbon layers were deposited on the $\mathrm{MgO}$ nanosheets, so the porous carbon inherited the morphology of $\mathrm{MgO}$ templates. The structure of 3D pillared-PCNSs can be controlled by changing boiling times, which makes the fabrication strategy easy to control. When used as an electrode material for SC, the 3D pillared-PCNSs with SSA up to $883 \mathrm{~m}^{2} \mathrm{~g}^{-1}$, exhibited a high gravimetric specific capacitance of $289 \mathrm{~F} \mathrm{~g}^{-1}$ at $2 \mathrm{mV} \mathrm{s}^{-1}$ and a high capacitance retention ratio of $76 \%$ at a scan rate of $1000 \mathrm{mV} \mathrm{s}^{-1}$ compared with the specific capacitance obtained at $5 \mathrm{mV} \mathrm{s}^{-1}$. In some cases, carbon sources can also be combined with chemicals that generate gases during the pyrolysis process. In this way, the porogens are bifunctional, and pore sizes less than the templates can thus be generated. $\mathrm{Hu}$ et al. used a 3D flower-shaped $\mathrm{MgO}$ as a template and synthesized nitrogen-doped porous carbon using cellulose acetate as a decomposable carbon source and urea as a nitrogen source. ${ }^{[122]}$ The as-synthesized hierarchical porous graphene-like carbon displayed ultrathin graphene-like sheets and an SSA of $937 \mathrm{~m}^{2} \mathrm{~g}^{-1}$. A high specific capacitance of $333 \mathrm{~F} \mathrm{~g}^{-1}$ at $1 \mathrm{~A} \mathrm{~g}^{-1}$ was achieved with the hierarchical porous graphene-like carbon as SC electrode material. The specific capacitance of hierarchical porous graphene-like carbon at $10 \mathrm{~A} \mathrm{~g}^{-1}$ retained $84 \%$ compared with the capacitance measured at $1 \mathrm{~A} \mathrm{~g}^{-1}$. Besides the high gravimetric specific capacitances achieved with hard template methods, the enhancement of volumetric capacitance can be achieved by reducing the macropores and mesopores derived from hard template methods. Bu et al. obtained a high-density porous carbon named CCNC (collapsed carbon nanocage) by depositing a thin shell on the MgO template and then collecting the collapsed sample after removing the MgO template. ${ }^{[21]}$ The CCNC with a high compaction density of $1.32 \mathrm{~g} \mathrm{~cm}^{-3}$ exhibited an SSA of $1788 \mathrm{~m}^{2} \mathrm{~g}^{-1}$ and a pore volume of $0.79 \mathrm{~cm}^{3} \mathrm{~g}^{-1}$. Using ionic liquid electrolyte, the CCNC achieved a high volumetric energy density of $73 \mathrm{Wh} \mathrm{L}^{-1}$ with a maximal volumetric power density of $67 \mathrm{~kW} \mathrm{~L}{ }^{-1}$.

Because of the well-shaped tunnel or hollow oxides, the hard template method can be easily combined with other novel synthesis strategies. Kim et al. proposed a single-step process to convert $\mathrm{CO}_{2}$ into hierarchical porous carbon by-using $\mathrm{NaBH}_{4}$ as a reducing agent and $\mathrm{CaCO}_{3}$ as a nano-template (Figure 7c). ${ }^{[123]}$ The $\mathrm{NaBH}_{4}$ and $\mathrm{CaCO}_{3}$ were mechanically mixed and heated up to high temperatures under a $\mathrm{CO}_{2}$ gas flow. The as-prepared porous carbon showed an SSA up to $1262 \mathrm{~m}^{2} \mathrm{~g}^{-1}$ with a broad pore-size distribution ranging from 10 to $50 \mathrm{~nm}$. The gravimetric specific capacitance of porous carbon was $170 \mathrm{~F} \mathrm{~g}^{-1}$ at
$20 \mathrm{~A} \mathrm{~g} \mathrm{~g}^{-1}$ with a high capacitance retention of $63 \%$ with respect 1 to the capacitance obtained at $1 \mathrm{~A} \mathrm{~g}^{-1}$.

One unique template mentioned here is zinc metal. $\mathrm{Zn} 3$ metal has a special feature that can be removed through evapo- 4 ration under high temperatures. ${ }^{[0,91]}$ In the case of $\mathrm{Zn}$ species 5 used as templates, the removals of templates are not necessary 6 if the preparation goes through high-temperature treatment 7 due to the relatively low boiling point of zinc $\left(907^{\circ} \mathrm{C}\right) \cdot{ }^{[114]} \mathrm{Zinc} 8$ metal can be directly used as a template for the synthesis of gra- 9 phitic porous carbons, in which various organics can be used as 10 carbon sources. At an annealing temperature of $550{ }^{\circ} \mathrm{C}$, zinc 11 metal and sucrose mixture were directly carbonized into porous 12 graphitic carbons through a one-step pyrolysis process. ${ }^{[124]} 13$ In this case, the zinc metal may act as a soft template, as the 14 melting temperature of zinc is as low as $420{ }^{\circ} \mathrm{C}$. Zinc metal 15 template strategy can also be used to synthesize mesoporous 16 zinc-guided graphene (ZNG) monolith using glucose as carbon 17 source, ${ }^{[125]}$ in which metal zinc introduces a metal-carbon 18 interaction tiering process beyond the templating role of zinc. 19 The ZNG possessed an SSA as high as $2020 \mathrm{~m}^{2} \mathrm{~g}^{-1}$ and small 20 pores of 2.0-3.0 nm, which enabled a high specific capaci- 21 tance of $336 \mathrm{~F} \mathrm{~g}^{-1}$ in $1 \mathrm{~mol} \mathrm{~L}^{-1} \mathrm{H}_{2} \mathrm{SO}_{4}$ electrolyte. Zinc metal 22 can be used as a template and graphitic carbon nitride $\left(g-\mathrm{C}_{3} \mathrm{~N}_{4}\right) \quad 23$ as a carbon source to synthesize porous graphenes. ${ }^{[126]}$ As the 24 g- $\mathrm{C}_{3} \mathrm{~N}_{4}$ cannot be converted to carbon at high annealing tem- 25 peratures, the interaction between zinc and g- $\mathrm{C}_{3} \mathrm{~N}_{4}$ is important 26 for the growth of graphene over the zinc catalyst, which needs 27 further investigation. By introducing $\mathrm{CO}_{2}$ as a carbon source, 28 Xing et al. used $\mathrm{Mg}$ powder as a reduction agent to convert $\mathrm{CO}_{2} 29$ into carbon, and $\mathrm{Zn}$ as the metal reductant to induce micropo- 30 rous structure. The resultant nanoporous graphene exhibited a 31 high SSA of $1900 \mathrm{~m}^{2} \mathrm{~g}^{-1}$ and a specific capacitance of $190 \mathrm{~F} \mathrm{~g}^{-1} 32$ at $10 \mathrm{~A} \mathrm{~g}^{-1} \cdot[127]$

Carbide is another hard template for porous carbon syn- 34 thesis. CDCs are produced by chlorine gas etching of metal 35 carbides, in which metals and metalloids are removed as vola- 36 tile chlorides. CDC turns out to be a nanoporous carbon with 37 a narrow pore-size distribution, usually around $0.5-3 \mathrm{~nm}$, and 38 high SSA, beyond $2000 \mathrm{~m}^{2} \mathrm{~g}^{-1} \cdot{ }^{[128,129]}$ Particularly, the SSA and 39 pore-size distribution of CDCs depend on the carbide precur- 40 sors and synthesis parameters. By controlling the synthesis 41 parameters, such as chlorination temperature, the CDCs usu- 42 ally show a narrow pore-size distribution $(0.6-1.1 \mathrm{~nm}) \cdot{ }^{[128]} 43$ To achieve hierarchical porous CDCs, the composite precur- 44 sors of carbide and $\mathrm{Si}^{\left[{ }^{[130]}\right.}{ }^{\text {polymer, }}{ }^{[131]}$ as well as any other 45 materials $^{[132-134]}$ have been investigated. Gogotsi et al. fabricated 46 a CDC with hierarchical pores by high-temperature chlorina- 47 tion of macroporous polymer-derived silicon carbide. ${ }^{[135]}$ The 48 as-prepared CDC exhibited a high SSA exceeding $2300 \mathrm{~m}^{2} \mathrm{~g}^{-1}, 49$ high micropore and mesopore volume of $1.1 \mathrm{~cm}^{3} \mathrm{~g}^{-1}$, and high 50 macropore volume of $7.45 \mathrm{~cm}^{3} \mathrm{~g}^{-1}$. 51

Through the hard-template method, porous carbons with 52 uniform and controllable pores can be synthesized easily. 53 However, the preparation of the template itself is costly, time- 54 consuming, and tedious. Another challenge is the ability to 55 tailor the wall thickness of pores, which is the key factor for 56 controlling the pore sizes of as-prepared carbon materials. ${ }^{[136]} 57$ Besides, inorganic templates have to be removed by acid or 58 alkali etching, which hinders their practical applications. ${ }^{[18]} 59$ 

2
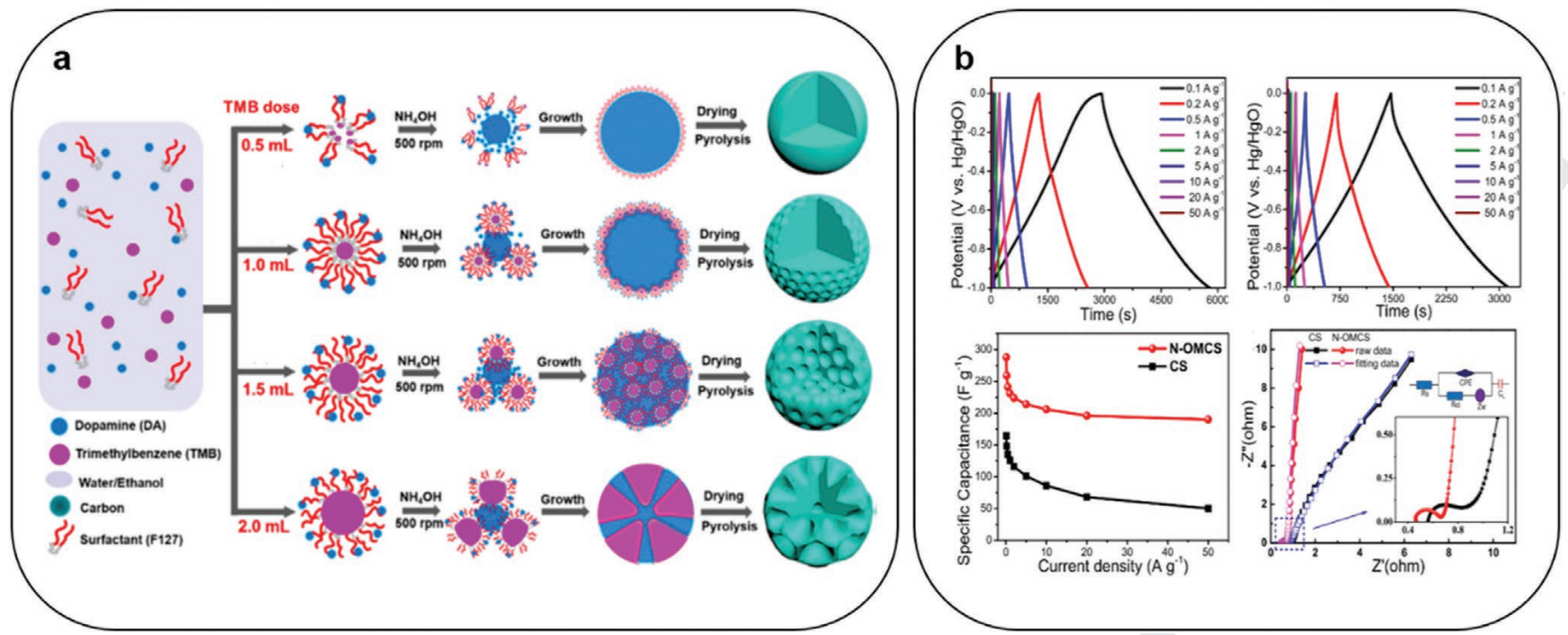

Figure 8. a) Versatile nanoemulsion assembly approach to synthesize functional mesoporous carbons. Reproduced with permission. ${ }^{[147]}$ Copyright 2019, American Chemical Society. b) GCD curves (above), specific capacitances as a function of current density, and Nyquist plots (below) of mesoporous carbon spheres. Reproduced with permission. ${ }^{[149]}$ Copyright 2017, Elsevier.

The unique templates (like zinc) give us more opportunities to carbonize those carbon sources that cannot be carbonized using traditional methods. By using these novel templates, the interaction between carbon sources and templates need to be studied thoroughly.

\subsection{Soft Templates}

In a soft template synthesis strategy, the templates are usually organic molecules or supermolecules with functional groups. ${ }^{[84,121]}$ In the particular solvent, the functional groups of soft templates can provide strong interaction force, such as hydrogen bonding, ${ }^{[137,138]}$ hydrophilic and hydrophobic interactions,$^{[139,140]}$ or electrostatic interactions. ${ }^{[141,142]}$ Once the proper solvent is added, the soft templates turn into micelles. The micelles combined with carbon sources result in heterogenous composites that turn into carbon materials with special porous architectures during the carbonization process. ${ }^{[143-145]}$ In particular, the pore size of carbon can be enlarged or decreased by controlling the ratio of solvent and micelle.

Although the mesoporous carbon can be prepared by carbonizing the mixture of carbon source and soft template, the requirements to develop soft templates are stringent and complex. The first attempt to synthesize mesoporous carbon with cetyltrimethylammonium bromide is based on the Coulombic interaction between the surfactant with positive charge and the phenolic resin with negative charge. ${ }^{[143]}$ However, no mesoporous carbon was obtained because the micelles collapse before the formation of a carbon skeleton at temperatures of about $200{ }^{\circ} \mathrm{C}$. A successful soft template must satisfy several important requirements: ${ }^{[120]} 1$ ) the ability to assemble into nanostructures, 2) inclusion of at least one component can turn into micro- or mesopores, and 3) sustaining the softtemplate porogens before the formation of the carbon skeleton. According to these basic principles, the soft templates like polystyrene- $b$-poly(4-vinylpyridine) (PS-P4VP), ${ }^{[146]}$ the poly(ethylene oxide)-b-poly(propylene oxide)- $b$-poly(-ethylene oxide) (PEO-PPO-PEO) (F127, ${ }^{[147-149]}$ F108, ${ }^{[150]}$ and P123 ${ }^{[149,151]}$ ) and some surfactants have been developed rapidly.

Liang et al. developed a method to form strong covalent interactions between carbon precursors and soft templates during the self-assembly process. ${ }^{[152]}$ The commercial triblock copolymer EO106-PO70-EO106 (F127) and the phenolformaldehyde resol were combined with a stable covalent bond which was formed by the replacement of the chain end of F127 from aldehyde group into hydroxyl-methyl group. With the enhanced interaction between resol and soft template, the as-prepared ordered cubic mesoporous carbon exhibited an SSA of $637 \mathrm{~m}^{2} \mathrm{~g}^{-1}$ and a pore volume of $0.32 \mathrm{~cm}^{3} \mathrm{~g}^{-1}$ which endows it a specific capacitance of $159 \mathrm{~F} \mathrm{~g}^{-1}$ at $10 \mathrm{mV} \mathrm{s}^{-1}$. Peng et al. explored a synthesis route to fabricate a series of highly uniform polymer nanospheres, with various surface morphologies (smooth, golf ball type, multichambered, and dendritic nanospheres) (Figure 8a). ${ }^{[147]}$ In this synthesis route, F127 was employed as a soft template and the organic molecule, 1,3,5-trimethylbenzene, was used to affect the interfacial interaction between the soft templates and carbon precursors. Through this method, carbon nanospheres achieved an ultralarge pore size of $37 \mathrm{~nm}$, a small particle size of $128 \mathrm{~nm}$, an SSA of $635 \mathrm{~m}^{2} \mathrm{~g}^{-1}$, and a high $\mathrm{N}$ doping ratio of $6.8 \%$. In some cases, ordered mesoporous carbon spheres can be synthesized by the simple one-step route. Wang et al. used F127 as the soft template for the preparation of mesoporous carbon spheres in a one-step pyrolysis strategy. ${ }^{[149]}$ The as-obtained mesoporous carbon spheres possessed an SSA of $439 \mathrm{~m}^{2} \mathrm{~g}^{-1}$ and a uniform mesopore size of $5 \mathrm{~nm}$. When used as SC electrodes, the mesoporous carbon spheres delivered a gravimetric specific capacitance of $288 \mathrm{~F} \mathrm{~g} \mathrm{~g}^{-1}$ at $1 \mathrm{~A} \mathrm{~g}^{-1}$ with capacitance retention of $66 \%$ at $50 \mathrm{~A} \mathrm{~g}^{-1}$ (Figure $8 \mathrm{~b}$ ). Besides block polymers, surfactants like Triton X-100 can also be used as soft templates to prepare hollow carbon nanospheres (HCNs). ${ }^{[153]}$
1 
The hollow carbon spheres derived from the Triton X-100 template method exhibited an SSA around $893.3 \mathrm{~m}^{2} \mathrm{~g}^{-1}$ with a corresponding total pore volume of $0.76 \mathrm{~cm}^{3} \mathrm{~g}^{-1}$. The soft template methods are in principle more attractive than hard templates for the synthesis of mesoporous carbons since we do not need to remove the soft templates after carbonization. The main bottleneck is that the as-prepared porous carbon is mesopore-dominated, and it is hard to obtain high SSA and high specific capacitance. To pursue high SSAs, researchers also tried to combine chemical activation and soft template methods. ${ }^{[154]}$

\subsection{New Emerging Templates}

Recently, novel templates such as ice (water), ${ }^{[155-157]}$ Mxene $\left(\mathrm{Ti}_{3} \mathrm{C}_{2} \mathrm{~T}_{x}\right),{ }^{[158,159]}$ as well as melamine ${ }^{[160-162]}$ have been adapted to fabricate functional porous carbons. For example, ice templates can be applied to various carbon sources to fabricate the $3 \mathrm{D}$ macrostructures according to the following procedures: ${ }^{[163]}$ 1) the precursors are dissolved in water or in hydroalcoholic mixture with a suitable catalyst; 2) the precursors undergo gelation at mild temperatures; 3) the gel is frozen and the frozen solvent is removed by freeze-drying or solvent exchange; 4) the dry gel is carbonized in an inert atmosphere to produce carbon cryogels. Both of the initial composition of suspension and the parameters during the freezing process are critical for the 3D macroporous carbon fabrication. Park et al. achieved an ordered 3D lamellar microstructure CNTs by employing ice as a template. ${ }^{[155]}$ By changing the concentration of chitosan in the CNT suspension, disordered, lamellar, and cellular macroporous carbonaceous structures can be synthesized successfully. Zhang et al. prepared a hierarchically porous sulfur-containing activated carbon by ice-templating an aqueous sodium poly (4-styrenesulfonate) with thermal treatment (Figure 9a). ${ }^{[157]}$ In the thermal treatment, the carbon precursor generates $\mathrm{Na}_{2} \mathrm{SO}_{4}$ which contributes to the porous structure and SSA of porous carbon. The derived porous carbon exhibited a macropore volume of $3.19 \mathrm{~cm}^{3} \mathrm{~g}^{-1}$ with the macropores predominantly locating in the ranges of $1-3,5-7$, and around $100 \mu \mathrm{m}$. The macropore SSA created by ice templating was measured to be $73.66 \mathrm{~m}^{2} \mathrm{~g}^{-1}$, with an average pore diameter of $2.80 \mu \mathrm{m}$. Because ice template is good at introducing macroporous structures into carbon materials, the resultant porous carbon is usually of low SSA. Chemical activation is needed to enhance the SSA and specific capacitance of these carbons. Umar et al. prepared a hierarchical porous carbon with macro and mesoporous architectures using ice templates, and the micropores on mesoporous carbon walls were achieved by chemical activation. ${ }^{[164]}$ When this hierarchical porous carbon was used as an electrode in solid-state SC, a specific capacitance of $142.1 \mathrm{~F} \mathrm{~g}^{-1}$ was obtained at $0.5 \mathrm{~A} \mathrm{~g}^{-1}$.

MXene is a series of 2D transition metal carbides, carbonitrides, and nitrides whose formula is $\mathrm{M}_{n+1} \mathrm{X}_{n} \mathrm{~T}_{x} \cdot{ }^{[165]}$ Here $\mathrm{M}$ represents a transition metal, $\mathrm{X}$ represents carbon or nitrogen, and $\mathrm{T}_{x}$ represents the surface termination. MXene itself is a pseudocapacitive electrode material. Furthermore, MXenes can be used as hard templates for the preparation of porous carbons due to its 2D morphology and abundant surface terminations. Moreover, when MXene is used as a template, 1 polar organic molecules can spontaneously intercalate into 2 the interlayer spaces and occupy the active sites on the sur- 3 face of MXene. Wang et al. used $\mathrm{Ti}_{3} \mathrm{C}_{2}$, the most well-studied 4 MXene, as a 2D host and injected the low-molecular-weight 5 phenolic resol and the amphiphilic triblock copolymer F127 6 into MXene. ${ }^{[158]}$ After carbonization and chlorination, they 7 obtained MXene-derived carbon (MDC-OMC) with 2D-2D het- 8 erostructure (Figure 9b). The MDC-OMC possessed an SSA of 9 $1021 \mathrm{~m}^{2} \mathrm{~g}^{-1}$ and exhibited a specific capacitance of $249 \mathrm{~F} \mathrm{~g}^{-1} 10$ at $1 \mathrm{~A} \mathrm{~g}^{-1}$ in a $6 \mathrm{~mol} \mathrm{~L}^{-1} \mathrm{KOH}$ electrolyte. MDC-OMC still 11 displayed a high specific capacitance of $188 \mathrm{~F} \mathrm{~g}^{-1}$ at $40 \mathrm{~A} \mathrm{~g}^{-1} .12$ Melamine is a template that can be incorporated into the 13 carbon framework. Melamine decomposes to g- $\mathrm{C}_{3} \mathrm{~N}_{4}$ and finally 14 decomposes completely resulting in macropores. He et al. syn- 15 thesized a honeycomb-like porous carbon (HPC) using coal tar 16 pitch as a carbon precursor with melamine as a template cou- 17 pled with the $\mathrm{KOH}$ activation technique. ${ }^{[161]}$ Melamine decom- 18 posed at high temperatures $\left(>650^{\circ} \mathrm{C}\right)$ and formed macro- and 19 mesopores in the HPC framework. The HPCs exhibited an 20 SSA of $2038 \mathrm{~m}^{2} \mathrm{~g}^{-1}$ and pore volume of $1.07 \mathrm{~cm}^{3} \mathrm{~g}^{-1}$ which 21 endowed its specific capacitances of $221 \mathrm{~F} \mathrm{~g}^{-1}$ at $0.05 \mathrm{~A} \mathrm{~g}^{-1} 22$ and $179 \mathrm{~F} \mathrm{~g} \mathrm{~g}^{-1}$ at $20 \mathrm{~A} \mathrm{~g}^{-1}$. In addition to the above templates, 23 some particular metal nanoparticles can be used as templates 24 for porous carbon synthesis. Hou et al. synthesized a carbon 25 nano-cage by $\mathrm{CO}_{2}$ reduction with the $\mathrm{Mg}$ metal ribbon as a 26 reducing agent and template. ${ }^{[166]}$ The obtained carbon material 27 displayed an SSA of $806 \mathrm{~m}^{2} \mathrm{~g}^{-1}$, a narrow pore size centered 28 at $6-7 \mathrm{~nm}$, and a pore volume of $1.51 \mathrm{~cm}^{3} \mathrm{~g}^{-1}$. This carbon 29 nano-cage showed a high specific capacitance up to $304 \mathrm{~F} \mathrm{~g}^{-1} 30$ at $2 \mathrm{mV} \mathrm{s}^{-1}$ and a high specific capacitance of $96 \mathrm{~F} \mathrm{~g} \mathrm{~g}^{-1}$ at 31 $1000 \mathrm{mV} \mathrm{s}^{-1}$.

Basically, compared with activated carbons, the features of 33 porous carbons derived from template methods usually pos- 34 sess macro- and mesopores and relatively low SSA (several 35 hundreds of square meters per gram). ${ }^{[92,96]}$ The new emerging 36 template methods are capable of fabricating 3D functional 37 macroporous carbons or graphene-like materials. For the fab- 38 rication of carbon materials with high SSA, high pore volume, 39 and high ratio of micropores, chemical activation methods need 40 to be applied, which limits the commercial potential of tem- 41 plate-based methods for the synthesis of porous carbons as SC 42 electrodes. ${ }^{[80,167,168]}$ On the other hand, the template methods 43 can be used to fabricate high-frequency response SCs based on 44 their macroporous structures.

\section{Self-Template Methods}

Both activation agents and templates used in the above methods 50 are porogens that are needed to be added. There are also some 51 porous carbon fabrication strategies that use self-generated 52 porogens, ${ }^{[169]}$ which we henceforth designate as self-template 53 methods. In this section, we discuss the strategies used to fab- 54 ricate porous carbon materials by directly carbonizing the self- 55 templated materials, ${ }^{[170]}$ such as ethylenediamine tetraacetates 56 (EDTA)-based salts, ${ }^{[171,172]}$ glycolates, ${ }^{[173]} \mathrm{MOFS}^{[174]}$ and their 57 derivatives ${ }^{[175]}$ biomass-based organic salts, ${ }^{[176]}$ as well as other 58 special self-templated organic materials.

(n) 


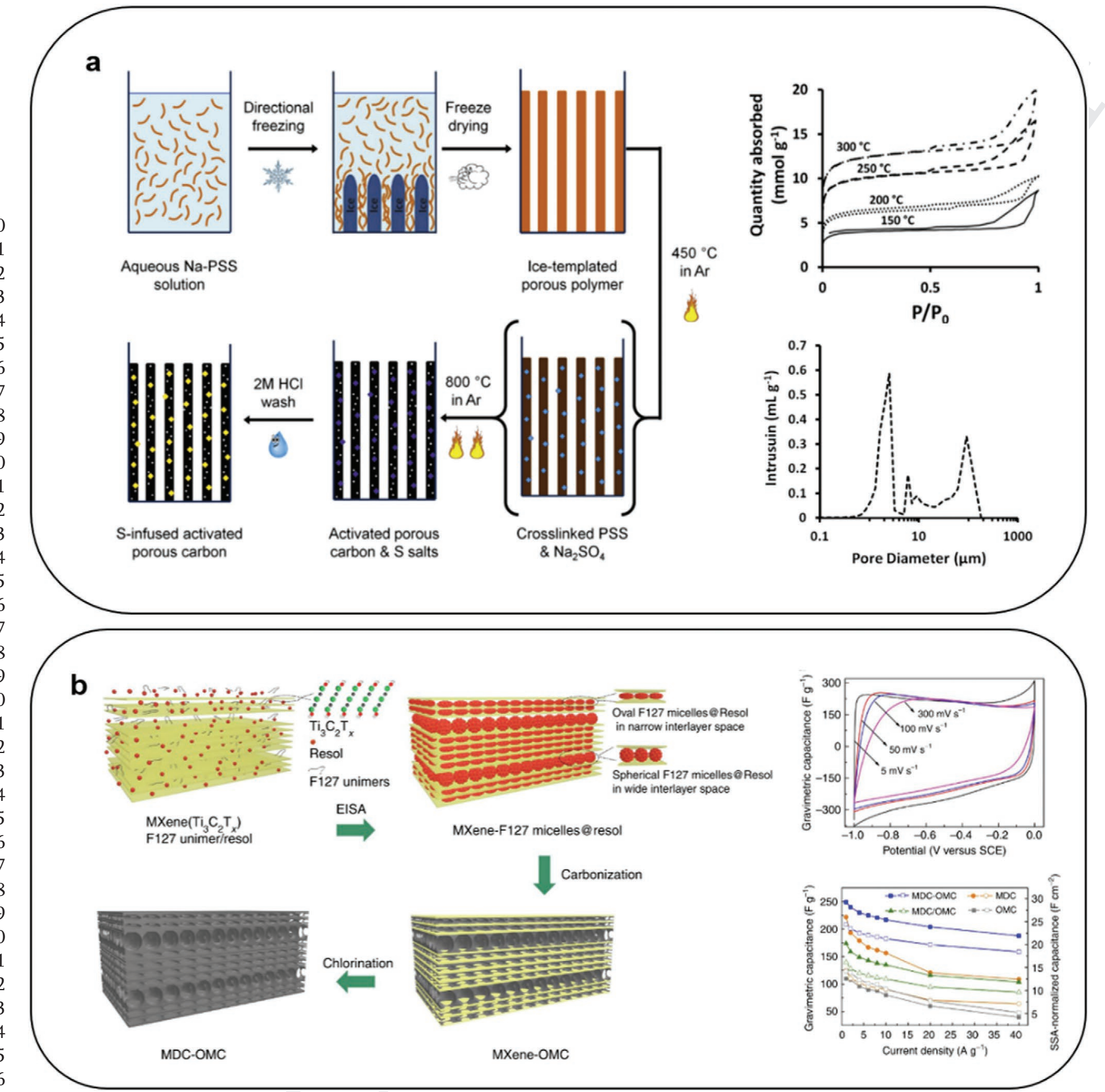

Figure 9. a) The preparation schematic diagram of ice-templated hierarchical activated carbon (left); $\mathrm{N}_{2}$ adsorption and desorption isothermals at different degas temperatures and pore-size distribution of ice-templated hierarchical activated carbon (right). Reproduced with permission. [157] Copyright 2015, Elsevier. b) The preparation schematic diagram of the MDC-OMC composite using MXene as template (left), the corresponding CV curves at various scan rates and the capacitances at different current densities for the MDC-OMC (right). Reproduced with permission. ${ }^{[158]}$ Copyright 2017, Nature Publishing Group.

\subsection{Organic Salts as Carbon Sources}

As an example of organic salt methods, interconnected porous carbon nanosheets (IPCNs) with SSA up to $1736 \mathrm{~m}^{2} \mathrm{~g}^{-1}$ were synthesized by the carbonization of potassium and sodium citrate salts. ${ }^{[177]}$ The IPCN was determined to have a thickness of $20-50 \mathrm{~nm}$ and a length of $0.5-2 \mu \mathrm{m}$. By optimizing the ratio of potassium citrate and sodium citrate at 2:8, IPCN with a high specific capacitance of $200 \mathrm{~F} \mathrm{~g}^{-1}$ at $5 \mathrm{mV} \mathrm{s}^{-1}$ was achieved (Figure 10a). In another study, zinc and calcium citrates with combination melamine were used to prepare the $\mathrm{N}$-doped mesoporous carbon with SSAs of $1190-1350 \mathrm{~m}^{2} \mathrm{~g}^{-1}$ and mesopore size around $11 \mathrm{~nm} .{ }^{[178]}$ By carbonizing the pure sodium citrate, the ultrathin porous carbon shells with SSAs of 
1

2

4

5
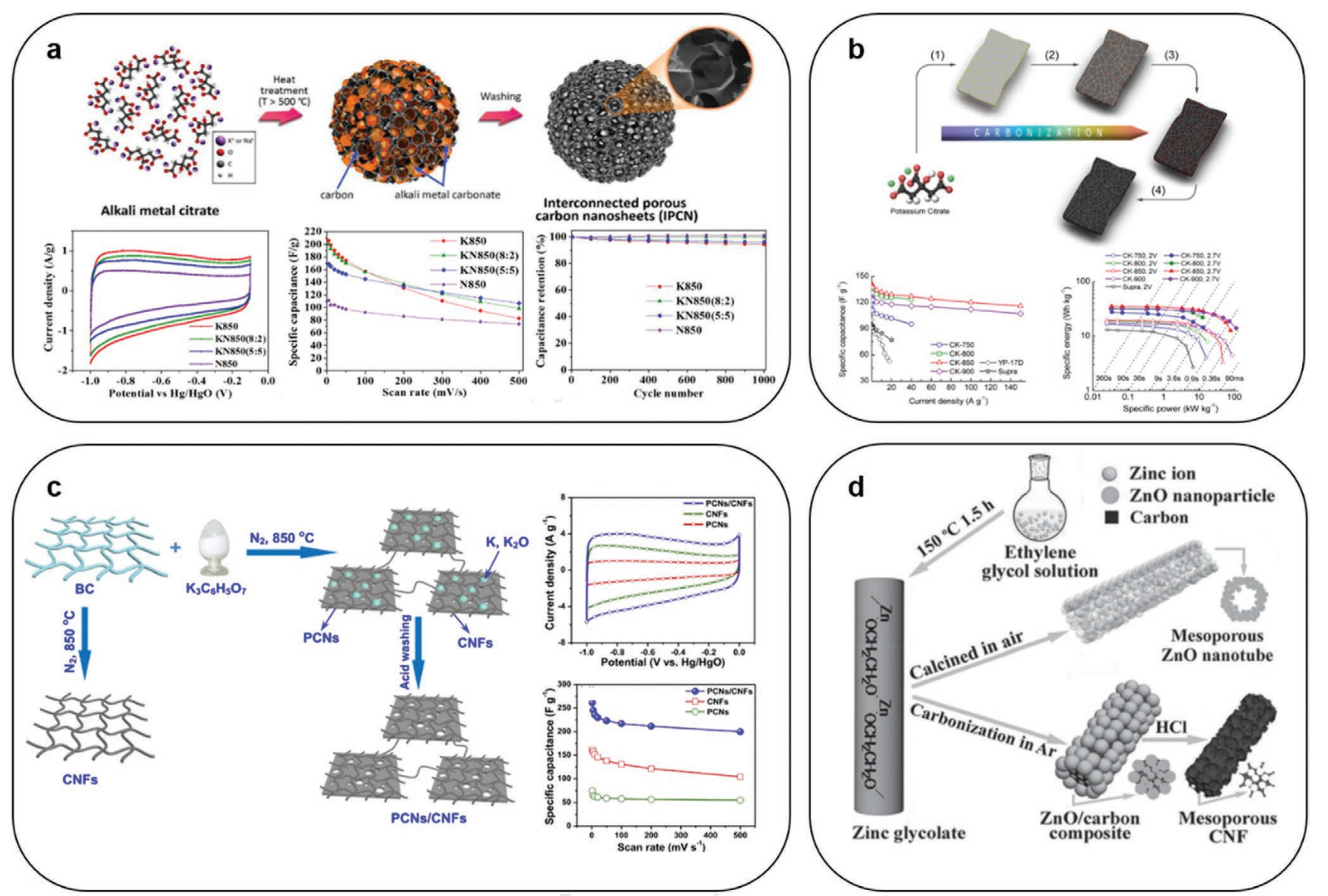

Figure 10. a) The preparation schematic diagram of IPCN (above), the corresponding $\mathrm{CV}$ curves at $5 \mathrm{mV} \mathrm{s}^{-1}$, the specific capacitances at different scan rates and cycling stability tested in $6 \mathrm{~mol} \mathrm{~L}^{-1} \mathrm{KOH}$ (below). Reproduced with permission ${ }^{[177]}$ Copyright 2017, Elsevier. b) The synthesis scheme for PCNSs from potassium citrate (above); the corresponding CCD curves and Ragone plot of the PCNS samples tested in $1 \mathrm{~m}$ tetraethylammonium tetrafluoroborate in acetonitrile (TEABF $/$ /AN) electrolyte (below). Reproduced with permission. ${ }^{[182]}$ Copyright 2014, American Chemical Society. c) Scheme illustration of the synthesis of the PCN/CNF composite (left), the corresponding CV curves at $20 \mathrm{mV} \mathrm{s}^{-1}$, specific capacitances at different scan rates of PCN/CNF composite tested in $6 \mathrm{~m} \mathrm{KOH}$ electrolyte (right). Reproduced with permission. [183] Copyright 2016, Elsevier. d) The schematic illustration of the formation process of CNFs. Reproduced with permission. ${ }^{[173]}$ Copyright 2011, Wiley-VCH.

400-600 $\mathrm{m}^{2} \mathrm{~g}^{-1}$ and pore size of $1 \mathrm{~nm}$ were achieved. ${ }^{[179]}$ The ultrathin porous carbon shells exhibited a gravimetric specific capacitance up to $251 \mathrm{~F} \mathrm{~g}^{-1}$ at $1 \mathrm{~A} \mathrm{~g}^{-1}$ and $228 \mathrm{~F} \mathrm{~g}^{-1}$ at $20 \mathrm{~A} \mathrm{~g}^{-1}$. A hierarchical microporous/mesoporous carbon nanosheet with a high SSA of $1890 \mathrm{~m}^{2} \mathrm{~g}^{-1}$ was fabricated by direct pyrolysis of sodium gluconate. ${ }^{[180]}$ Due to their hierarchical microporous/mesoporous structure, this carbon nanosheet exhibited a high specific capacitance of $140 \mathrm{~F} \mathrm{~g}^{-1}$ at $150 \mathrm{~A} \mathrm{~g}^{-1}$. Xu et al. prepared a nitrogen-doped porous carbon by the pyrolysis of EDTA disodium magnesium salt. ${ }^{[172]}$ The obtained nitrogendoped porous carbon exhibited an SSA of $1811 \mathrm{~m}^{2} \mathrm{~g}^{-1}$ and a pore volume of $1.16 \mathrm{~cm}^{3} \mathrm{~g}^{-1}$, while the specific capacitances of the nitrogen-doped porous carbon were $281 \mathrm{~F} \mathrm{~g}^{-1}$ at $0.05 \mathrm{~A} \mathrm{~g}^{-1}$ and $196 \mathrm{~F} \mathrm{~g}^{-1}$ at $20 \mathrm{~A} \mathrm{~g}^{-1}$. Similarly, EDTA disodium zinc salt was used as a self-templated carbon precursor. ${ }^{[181]}$ Porous carbon derived from EDTA disodium zinc salt possessed a high SSA of $1368 \mathrm{~m}^{2} \mathrm{~g}^{-1}$ and exhibited a high specific capacitance of $275 \mathrm{~F} \mathrm{~g}^{-1}$ and an excellent rate capability $\left(207 \mathrm{~F} \mathrm{~g}^{-1}\right.$ at $\left.100 \mathrm{~A} \mathrm{~g}^{-1}\right)$. Through the direct pyrolysis of potassium citrate, highly porous interconnected carbon nanosheets (PCNS) with SSA of $2220 \mathrm{~m}^{2} \mathrm{~g}^{-1}$ were fabricated at $850{ }^{\circ} \mathrm{C} \cdot{ }^{[182]}$ The synthesis scheme 40 from potassium citrate to PCNS is described in Figure 10b. The 41 potassium citrate-derived 2D PCNS exhibited a microporous 42 architecture with pore sizes centered around $0.7-0.85$ and $0.95-43$ $1.6 \mathrm{~nm}$ and thickness less than $80 \mathrm{~nm}$. The PCNS showed a 44 good rate performance, where specific capacitances of $134 \mathrm{~F} \mathrm{~g}^{-1} \quad 45$ at $5 \mathrm{~A} \mathrm{~g}^{-1}$ and $120 \mathrm{~F} \mathrm{~g}^{-1}$ at $150 \mathrm{~A} \mathrm{~g}^{-1}$ were obtained using com- 46 mercial $1 \mathrm{M} \mathrm{TEABF}_{4} / \mathrm{AN}$ electrolyte. In another study, bacterial 47 cellulose (BC) and potassium citrate were mixed to fabricate 48 CNFs-bridged PCNS. ${ }^{[183]}$ As shown in Figure 10c, the potas- 49 sium citrate serves as the self-templated carbon precursor while 50 the $\mathrm{BC}$ bridge turns into CNFs which provides the $3 \mathrm{D}$ structure 51 to integrate porous carbon. The as-prepared PCN/CNF com- 52 posite exhibited an SSA of $1037 \mathrm{~m}^{2} \mathrm{~g}^{-1}$ and a specific capaci- 53 tance up to $261 \mathrm{~F} \mathrm{~g}^{-1}$ in aqueous electrolyte. Similarly, porous 54 carbon with a high surface area of $1094 \mathrm{~m}^{2} \mathrm{~g}^{-1}$ and pore sizes 55 distributed in a wide range from 1 to $100 \mathrm{~nm}$ were fabricated 56 by direct calcination of sodium citrate. ${ }^{[184]} \mathrm{Li}$ et al. synthe- 57 sized mesoporous CNFs with the thermal treatment of zinc 58 glycolate at $600{ }^{\circ} \mathrm{C}$ (Figure 10d). ${ }^{[173]}$ Zinc glycolate decomposed 59 

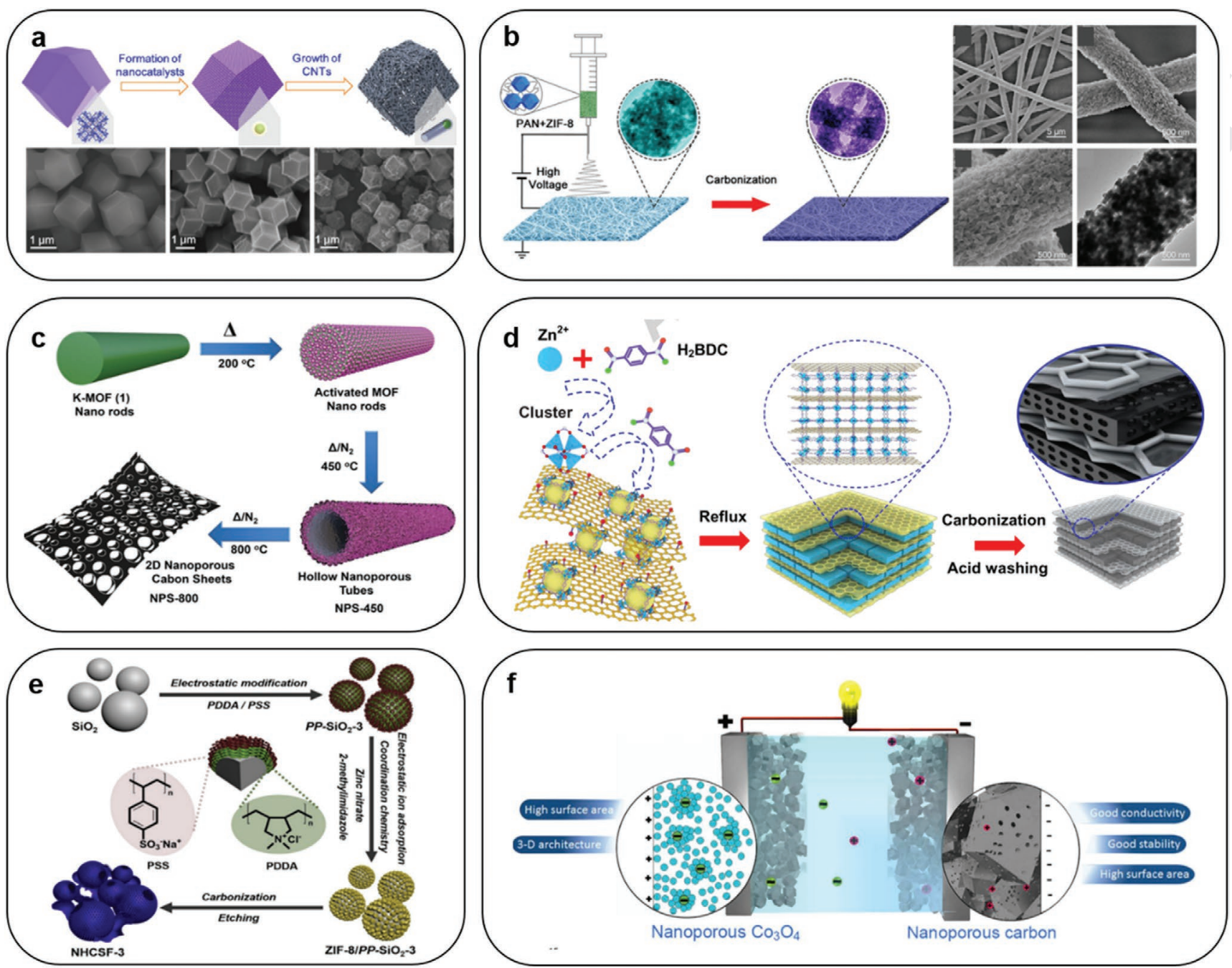

Figure 11. a) Synthesis and characterization of N-doped CNT-assembled hollow dodecahedra from zeolitic imidazolate frameworks (ZIF-67). Reproduced with permission. ${ }^{[185]}$ Copyright 2017, American Chemical Society. b) Schematic illustration of the synthesis of HPCNFs-N, SEM, and TEM images of the PAN/ZIF-8 composite nanofibers. Reproduced with permission. ${ }^{186]}$ Copyright 2017, The Royal Society of Chemistry. c) Schematic illustration of the synthesis of K-MOF rods under solvothermal conditions and morphologically controlled synthesis of $2 \mathrm{D}$ hierarchical nanoporous carbon sheets derived from K-MOF under various carbonization conditions. Reproduced with permission. ${ }^{[187]}$ Copyright 2018, Wiley-VCH. d) Schematic illustration showing the fabrication process for porous carbon using MOFs and graphene oxide as precursors. Reproduced with permission. ${ }^{[88]}$ Copyright 2016 , Elsevier. e) Scheme depicting the fabrication of NHCSF from ZIF-8/PP-SiO 2 precursor. Reproduced with permission. ${ }^{[189]}$ Copyright 2018, Elsevier. f) Schematic illustration of asymmetrical SC containing nanoporous $\mathrm{Co}_{3} \mathrm{O}_{4}$ and nanoporous carbon as the positive and negative electrodes, respectively. Reproduced with permission. ${ }^{[190]}$ Copyright 2015, American Chemical Society.

into $\mathrm{ZnO}$ /carbon composite in which $\mathrm{ZnO}$ was homogenously dispersed in the carbon matrix with average particle sizes of $\approx 4 \mathrm{~nm}$. After acid etching, the $\mathrm{ZnO} /$ carbon composite was transformed into mesoporous CNFs. The mesoporous CNFs exhibited a high SSA of $1725 \mathrm{~m}^{2} \mathrm{~g}^{-1}$ with a large pore size of $3.4 \mathrm{~nm}$, and a high specific capacitance of $280 \mathrm{~F} \mathrm{~g}^{-1}$.

\subsection{MOF Derivatives as Carbon Sources}

Due to the versatile, tunable porous structure and composition of MOFs, MOF is a promising material platform for the synthesis of various porous and functional carbon materials. The metal components inside MOFs can be directly used as self-templates during the pyrolysis processes of MOFs. An assembled CNTs array was obtained by the carbonization of $\mathrm{MOF}$ at a low pyrolysis temperature of $430{ }^{\circ} \mathrm{C} .{ }^{[185]}$ Various morphologies of the assembled carbon can be achieved by modulating Co, Fe, and Zn MOFs. As shown in Figure 11a, the as-prepared CNTs exhibited a uniform assembled morphology with a high SSA of $1389 \mathrm{~m}^{2} \mathrm{~g}^{-1}$. Chen et al. prepared hollow particle-based N-doped CNFs (HPCNFs-N) by the electrospinning of PAN/ZIF-8 composite (Figure 11b). ${ }^{[186]}$ The HPCNFs-N exhibited a high SSA of $417.9 \mathrm{~m}^{2} \mathrm{~g}^{-1}$ and specific capacitances of 307.2 and $193.4 \mathrm{~F} \mathrm{~g}^{-1}$ at 1 and $50 \mathrm{~A} \mathrm{~g}^{-1}$, respectively. PCNSs can be fabricated by pyrolysis of K-MOF nanorods at temperatures of 200,450 , and $800{ }^{\circ} \mathrm{C}$ (Figure 11c). ${ }^{[187]}$ The carbon nanosheets possessed the highest SSA of $1678 \mathrm{~m}^{2} \mathrm{~g}^{-1}$ among
1 
various MOF-derived porous carbons, which may be ascribed to the small-sized potassium compounds after pyrolysis and the possible activation effect of potassium oxide and carbonates. Carbon nanosheets presented a specific capacitance up to $233 \mathrm{~F} \mathrm{~g}^{-1}$ at a low scan rate of $5 \mathrm{mV} \mathrm{s}^{-1}$ in the $\mathrm{H}_{2} \mathrm{SO}_{4}$ electrolyte. Wang et al. synthesized a "brick-and-mortar" type sandwiched porous carbon (C-GMOF) by using MOF-5-derived porous carbon film as "mortar" and the graphene nanosheets as "brick" (Figure 11d). ${ }^{[188]}$ The C-GMOF showed a relatively low SSA $\left(979 \mathrm{~m}^{2} \mathrm{~g}^{-1}\right)$ and a relatively wide pore distribution (1-8 nm) compared with porous carbon derived from MOF-5 (C-MOF) (1117 $\mathrm{m}^{2} \mathrm{~g}^{-1}$ and 1-4 nm). The assembled "brickand-mortar" C-GMOF exhibited high specific capacitances of $345 \mathrm{~F} \mathrm{~g}^{-1}$ at $2 \mathrm{mV} \mathrm{s}^{-1}$ and $201 \mathrm{~F} \mathrm{~g}^{-1}$ at $2 \mathrm{~V} \mathrm{~s}^{-1}$. Since MOFs are synthesized in a solvent environment, the design of MOF composites with advanced structures can be realized by combining MOFs with other functional materials. A hollow carbon shell framework (NHCSF) was fabricated by the carbonization of core-shell hybrid precursors (ZIF-8-PP-SiO $)_{2}$. $^{[189]}$ The coreshell hybrid precursors were obtained by depositing a zeolitic imidazolate framework (ZIF 8) on the polyelectrolyte-decorated silica (Figure 11e). The as-prepared NHCSFs with SSAs of 585-847 $\mathrm{m}^{2} \mathrm{~g}^{-1}$ displayed high capacitances up to $253.6 \mathrm{~F} \mathrm{~g} \mathrm{~g}^{-1}$ at $1 \mathrm{~A} \mathrm{~g}^{-1}$ and $200.4 \mathrm{~F} \mathrm{~g}^{-1}$ at $50 \mathrm{~A} \mathrm{~g}^{-1}$. With the molecular scale special tunable structure of MOF, Salunkhe et al. assembled an SC by using the nanoporous carbon and nanoporous cobalt oxide materials derived from a single ZIF-67 (Figure 11f). $\left.{ }^{190}\right]$ The ZIF-derived carbon possessed an SSA of $350 \mathrm{~m}^{2} \mathrm{~g}^{-1}$, and the SC exhibited a capacitance of $101 \mathrm{~F} \mathrm{~g}^{-1}$ at $2 \mathrm{~A} \mathrm{~g}^{-1}$.

\subsection{Other Self-Template-Derived Methods}

Biomass is abundant, cheap, readily available, and most importantly, is renewable. High value-added utilization of biomass is regarded as a green solution for waste disposal problems in the agricultural industries. ${ }^{[176]}$ Moreover, by taking advantage of the unique bio-organized natural structures of biomass, carbon materials with hierarchical porous architectures, and excellent electrochemical performances of SCs can be achieved. ${ }^{[191]}$ BC is a common biomass precursor with $3 \mathrm{D}$ networks consisting of superfine nanofibers ( $\approx 50 \mathrm{~nm}$ in diameter). ${ }^{[192]}$ A 3D network structure consisting of numerous intertwined CNFs with a diameter of 30-60 $\mathrm{nm}$ was obtained by freeze-drying and carbonization of the $\mathrm{BC}$ aerogel. After coating, the polyanilinecoated $\mathrm{BC}$ nanofibers exhibited a high specific capacitance of $238.4 \mathrm{~F} \mathrm{~g}^{-1}$ at $0.5 \mathrm{~A} \mathrm{~g}^{-1}$. Zhang et al. prepared a rice huskderived carbon (RHC) through direct pyrolysis of rice husk in a sealed tube furnace without the injection of $\mathrm{N}_{2} \cdot{ }^{[193]} \mathrm{RHC}$ showed an SSA of $337 \mathrm{~m}^{2} \mathrm{~g}^{-1}$, a pore size centered at 0.7 and $3.6 \mathrm{~nm}$, and a pore volume of $0.207 \mathrm{~cm}^{3} \mathrm{~g}^{-1}$. Nano- $\mathrm{SiO}_{2}$ particles inside RHC were etched by $\mathrm{NaOH}$ to prepare RHPC that exhibited an SSA of $527 \mathrm{~m}^{2} \mathrm{~g}^{-1}$, a pore size centered at 0.8 and $3.4 \mathrm{~nm}$, a pore volume of $0.327 \mathrm{~cm}^{3} \mathrm{~g}^{-1}$, and a specific capacitance of $110 \mathrm{~F} \mathrm{~g}^{-1}$ at $0.1 \mathrm{~A} \mathrm{~g}^{-1}$. Zhang et al. also proposed a general strategy for the preparation of porous carbon from general lignocellulose-based biomasses. ${ }^{[194]}$ In this strategy, lignin was extracted from onion by $\mathrm{KOH}$ etching and transformed into a lignin potassium salt. The lignin potassium salt from onion was pyrolyzed into porous carbon materials (OPC). OPC exhib- 1 ited a high SSA of $1910 \mathrm{~m}^{2} \mathrm{~g}^{-1}$ dominated by micropores and 2 a high gravimetric specific capacitance of $200 \mathrm{~F} \mathrm{~g}^{-1}$. Using this 3 etching strategy, generally, any lignin-containing biomass can 4 be treated and transformed into porous carbons under pyrol- 5 ysis. More generally, efficient methods need to be developed 6 to prepare porous carbons derived from celluloses using self- 7 template strategies.

\section{Direct Pyrolysis Methods}

\subsection{Direct Pyrolysis of Conjugated Copolymers}

The pursuit of facile and green preparation techniques for 15 porous carbon materials for SC electrodes remains an active 16 research area. Although traditional carbonization-activation 17 methods can prepare porous carbons with controllable SSAs, 18 and pore-size distributions, the templates or the residues of 19 activation agents after carbonization and activation need to 20 be removed completely. Hence, activation-free methods are 21 becoming more attractive. In typical pyrolysis processes of 22 organics, organic sources decompose and release gases (e.g., 23 $\mathrm{H}_{2} \mathrm{O}, \mathrm{CO}_{2}, \mathrm{NH}_{2}$, and $\mathrm{CO}$ ), where the pyrolysis gases function 24 as porogens. However, most pyrolysis gases are released at 25 relatively low temperatures when the evolving carbon skeleton 26 is not robust enough to sustain pores. As a result, when poly- 27 aniline (PANi) or PPy were used as precursors for nitrogen- 28 doped carbons, PANi or PPy-derived carbons showed low SSAs 29 around $100-300 \mathrm{~m}^{2} \mathrm{~g}^{-1}$, which are too low to be used in SC 30 applications. ${ }^{[195,196]}$ Nevertheless, when aniline and pyrrole are 31 co-polymerized into a PANi-co-PPy (PACP) conjugated copol- 32 ymer, PACP acts as a unique precursor for porous carbons. 33 Wu et al. synthesized PACP hollow spheres with the assis- 34 tance of Triton X-100 soft template and used it as a precursor 35 for porous HCNs (Figure 12a). ${ }^{[197]}$ By controlling the pyrolysis 36 parameters, such as carbonization temperature, heat ramping 37 rate, and carbonization time, the SSA and pore-size distribu- 38 tion of HCNs can be finely engineered. Compared with tradi- 39 tional template-assisted carbonization and activation methods 40 for the synthesis of HCNs, the direct pyrolysis of PACP showed 41 unique simplicity and low-cost advantages. HCN-900-20H2R 42 sample (carbonization temperature is $900{ }^{\circ} \mathrm{C}$, carbonization 43 time is $20 \mathrm{~h}$, and the heat ramping rate is $2{ }^{\circ} \mathrm{C} \mathrm{min}-1$ ) showed 44 unexpectedly high SSA of $3022 \mathrm{~m}^{2} \mathrm{~g}^{-1}$ which guarantees a 45 moderate gravimetric specific capacitance of $200 \mathrm{~F} \mathrm{~g}^{-1}$ and good 46 rate capability (Figure 12b). The ultrahigh SSA did evolve from 47 the unique structure of PACP, since PACP itself only showed 48 a low SSA of $33 \mathrm{~m}^{2} \mathrm{~g}^{-1}$. Although there was still lack of fun- 49 damental understanding of the mechanism behind the forma- 50 tion of such a high SSA, this method opened a new pathway for 51 designing porous carbons with high pore volume and SSA by 52 direct copolymer pyrolysis. Kang et al. used PACP as precursor 53 and $\mathrm{MnO}_{2}$ (initiator) nanowire sacrificial template to synthe- 54 size hierarchically porous carbon nanotubes (HPCNTs). The 55 HPCNT showed a high SSA of $1419 \mathrm{~m}^{2} \mathrm{~g}^{-1}$, a high gravimetric 56 specific capacitance of $280 \mathrm{~F} \mathrm{~g}^{-1}$, and high rate capability. ${ }^{[198]} 57$ In contrast, CNTs derived from PANi and PPy showed much 58 lower SSA. The ultrahigh SSAs of HPCNT was derived from 59 

3

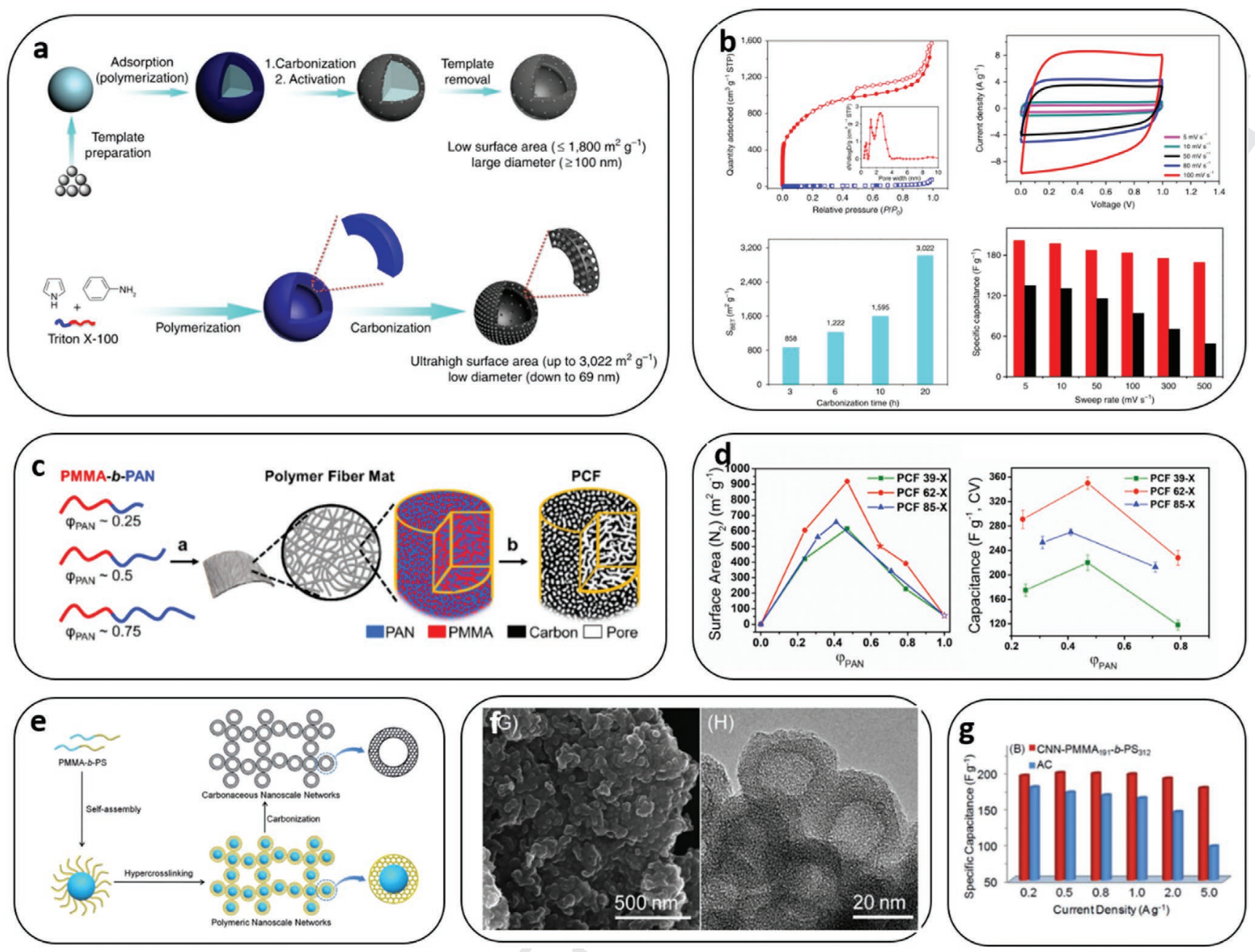

Figure 12. a) The schematic for the synthesis of high-specific-surface-area HCNs using traditional template-assisted carbonization and activation methods (above), and the direct pyrolysis carbonization of PACP (below). b) Physicochemical and electrochemical properties of HCNs, $\mathrm{N}_{2}$ adsorption/ desorption isotherms, and pore-size distribution of HCN-900-20H2R, CV curves of HCN-900-10H5R, the dependence of SSA on the carbonization temperature, dependence of specific capacitance of HCN-900-10H5R on the scan rate. Reproduced with permission. ${ }^{[197]}$ Copyright 2015 , Nature Publishing Group. c) The schematic for the synthesis of PCFs using PMMA-b-PAN block copolymer with the volume fraction of PAN. d) The dependence of SSA obtained from $\mathrm{N}_{2}$ adsorption/desorption, and the gravimetric capacitances of PCFs on the volume fraction of PAN. Reproduced with permission. ${ }^{[205]}$ Copyright 2019, American Chemical Society. e) The schematic illustration of the preparation of PNNs and CNNs from PMMA- $b$-PS

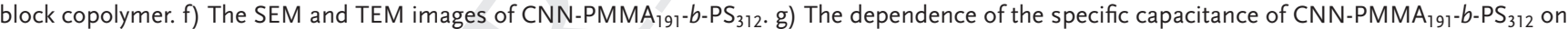
charge-discharge current densities. Reproduced with permission. ${ }^{[207]}$ Copyright 2014, The Royal Society of Chemistry.

the robust conjugated structure of PACP. Various covalent organic frameworks and conjugated copolymers can be used as precursors for the synthesis of porous carbons. During the past few years, many conjugated copolymers have been adopted as precursors for porous carbons in direct pyrolysis methods, such as triazine-based copolymers, ${ }^{[167,199,200]}$ polyimides, ${ }^{[201,202]}$ Schiff-base porous organic polymers, ${ }^{[203]}$ and other aromatic polymers. ${ }^{[204]}$ The general common feature of these polymers is that they have two or more different monomers. We speculate that the thermal stabilities of the monomers are very different. The monomer with higher thermal stability can function as a carbon skeleton, while the second monomer with lower thermal stability can act as a porogen. Based on this hypothesis, block copolymers possessing two polymer chains with different thermal stabilities can also be used as precursors for the preparation of porous carbons with high SSA and high specific capacitance.

\subsection{Direct Pyrolysis of Block Copolymers}

Poly(methyl methacrylate) (PMMA) is usually used as a template to prepare hollow carbon spheres since it can be completely decomposed at $\approx 345^{\circ} \mathrm{C}$. Using PMMA as an inner molecular sacrificial template, PMMA-based block copolymers can be used as precursors for highly porous carbons. Liu et al. prepared PMMA- $b$-PAN copolymer and carbonized it into highly porous carbons (Figure $12 \mathrm{c}$ ). ${ }^{[205]}$ By controlling the molecular weight of PMMA, tunable mesopore sizes ranging from 10.9 to $18.6 \mathrm{~nm}$ of the obtained porous carbons can be achieved. 
With a PAN volume fraction of 0.5 , the obtained porous carbon fibers (PCFs) exhibited a high SSA of $918 \mathrm{~m}^{2} \mathrm{~g}^{-1}$ and high specific capacitance of $345 \mathrm{~F} \mathrm{~g}^{-1}$ in $3 \mathrm{~mol} \mathrm{~L}^{-1} \mathrm{KOH}$ aqueous electrolyte (Figure 12d). The PMMA-b-PAN can be fabricated into a nanofiber mat by electrospinning technique. The fiber mat thus can be tuned into highly porous PCFs by direct pyrolysis. The PCFs possess abundant macropores, which enables them to be used as substrates of $\mathrm{MnO}_{2}$ electrodes. ${ }^{[206]}$

Based on the atom transfer radical polymerization techniques, the PMMA-b-PAN copolymer can be transformed into microemulsion hollow spheres and highly nanoporous carbon materials after pyrolysis (Figure 12e). ${ }^{[207]}$ Poly(methyl methacrylate)-b-polystyrene (PMMA-b-PS) block copolymers were also used to self-assemble into uniform spherical micelles (Figure 12f). What is more, the inter-sphere hypercrosslinking of PS chains on the colliding micelles connects the nanosphere network units in various directions forming the 3D polymeric nanoscale networks (PNNs). Thus, 3D PNNs could be further transformed into carbonaceous nanoscale networks (CNNs) after pyrolysis. CNNs derived from $\mathrm{PMMA}_{191}-b-\mathrm{PS}_{312}$ showed a BET SSA and microporous surface area of 839 and $561 \mathrm{~m}^{2} \mathrm{~g}^{-1}$, respectively. Given the high BET SSA and microporous surface area of PNN$\mathrm{PMMA}_{191}-b-\mathrm{PS}_{312}$ (288 and $116 \mathrm{~m}^{2} \mathrm{~g}^{-1}$ ), the formation of higher SSA and micropore surface area of CNNs could be attributed to the pore formation during the pyrolysis of PNN$\mathrm{PMMA}_{191}-b-\mathrm{PS}_{312}$. CNNs showed a high gravimetric specific capacitance of $195 \mathrm{~F} \mathrm{~g}^{-1}$ at a current density of $0.2 \mathrm{~A} \mathrm{~g} \mathrm{~g}^{-1}$, as shown in Figure 12g. There are renewed efforts in designing numerous block copolymers with different combinations for the preparation of porous carbons. In recent years, nanoporous carbon materials have been prepared from PS- $b$-PEO, [144] PAN-b-PBA, ${ }^{[208]} \mathrm{PS}_{235}-b-\mathrm{PEO}_{45},{ }^{[209]}$ PS- $b-\mathrm{PAN},{ }^{[210]}$ and PDA/ PS- $b$-PEO. ${ }^{[145]}$ As we can see, the SSAs of most porous carbons derived from these block copolymers are still limited to be $<1500 \mathrm{~m}^{2} \mathrm{~g}^{-1}$. The limited SSA of the decomposition of copolymers should be further enhanced by controlling the molecular design.

\subsection{Direct Pyrolysis of Ionic Liquids and Ionized Organics}

Another popular way to synthesize porous carbon from polymer-based materials is the direct pyrolysis of poly(ionic liquid)s (PILs). PILs have both the advantages of IL and polymers. PIL renders the choices of anion and cations, and the nano-objective engineering of the resultant carbon materials can be achieved by polymerization methods. The heteroatomrich PILs can be tuned into heteroatom-rich carbon structures. What is more, for SC applications, tuning porous structures of carbon materials can be achieved by tuning the chemical composition (porogens) and the parameters during direct pyrolysis of PILs. Gan et al. prepared p-phenylenediamine (pPD) sulfuric acid ( $\left.\mathrm{p}[\mathrm{pPD}]\left[2 \mathrm{HSO}_{4}\right]\right)$ PIL by a solution polymerization reaction. ${ }^{[211]}[\mathrm{pPD}]\left[2 \mathrm{HSO}_{4}\right]$ was also prepared without oxidative polymerization for comparison. Highly microporous carbon nanoparticles with nitrogen and sulfur doping (N/S$\mathrm{UCNs}$ ) were obtained by direct pyrolysis of $\mathrm{p}[\mathrm{pPD}]\left[2 \mathrm{HSO}_{4}\right]$. Furthermore, the N/S-UCN prepared at $800{ }^{\circ} \mathrm{C}$ exhibited a high SSA of $1018 \mathrm{~m}^{2} \mathrm{~g}^{-1}$ which endowed it with a high capaci- 1 tance of $225 \mathrm{~F} \mathrm{~g}^{-1}$ at $2 \mathrm{~A} \mathrm{~g}^{-1}$. One drawback of this research 2 is that the intrinsic mechanism for obtaining high surface 3 area porous carbon is not fully understood. Porous carbons 4 derived from $\mathrm{p}[\mathrm{pPD}]\left[2 \mathrm{HSO}_{4}\right]\left(1018 \mathrm{~m}^{2} \mathrm{~g}^{-1}\right)$ showed higher 5 SSA than porous carbons derived from nonpolymerized [pPD] 6 $\left[2 \mathrm{HSO}_{4}\right]\left(834 \mathrm{~m}^{2} \mathrm{~g}^{-1}\right)$. Since $\mathrm{p}[\mathrm{pPD}]\left[2 \mathrm{HSO}_{4}\right]$ is more stable 7 than $[\mathrm{pPD}]\left[2 \mathrm{HSO}_{4}\right]$ due to the polymerization, the pPD can 8 act as a carbon skeleton while the $\mathrm{HSO}_{4}{ }^{-}$species act as pore- 9 forming agent. Similarly, Gan et al. mixed 5-carboxybenzene- 10 1,3-diamine (DABA) and $\mathrm{H}_{2} \mathrm{SO}_{4}$ in a dimethylformamide 11 solvent and obtained protic salt $[\mathrm{DABA}]\left[2 \mathrm{HSO}_{4}\right]$ without 12 polymerization. ${ }^{[212]} \mathrm{N} / \mathrm{S}$-co-doped porous carbon (NSC) was 13 obtained from the direct pyrolysis of [DABA][2HSO $\mathrm{DS}_{4}$. NSC-900 14 displayed a high SSA of $1543 \mathrm{~m}^{2} \mathrm{~g}^{-1}$, and a high gravimetric 15 specific capacitance of $285 \mathrm{~F} \mathrm{~g} \mathrm{~g}^{-1}$ at $1 \mathrm{~A} \mathrm{~g}^{-1}$. Gan et al. also 16 developed a similar protic salt using p-phenylenediamine and 17 toluenesulfonic acid for porous carbon preparation. ${ }^{[213]}$ The 18 synthesis of protic salt is a more facile way for the preparation 19 of porous carbons since it avoids polymerization and tedious 20 reaction processes. Because inorganic acid and amine-based 21 precursors are abundant and cost-effective, this approach can 22 be developed to fabricate porous carbon with much higher 23 SSA and higher specific capacitances. Chitosan is an abun- 24 dant natural biopolymer with abundant amine functional 25 groups. Methanesulfonic acid and chitosan were used to pre- 26 pare an ionic organic compound. ${ }^{[214]}$ After carbonizing this 27 ionic organic compound at $750{ }^{\circ} \mathrm{C}$, a N/S doped carbon with 28 an SSA of $1094 \mathrm{~m}^{2} \mathrm{~g}^{-1}$ was obtained.

A nitrogen-doped, graphitic nanoporous carbon membrane 30 (HNDCM) was prepared from PILs composed of cationic 31 poly[1-cyanomethyl-3-vinylimidazolium bis (trifluorometh- 32 anesulfonyl)imide] (PCMVImTf ${ }_{2} \mathrm{~N}$ ) and anionic neutralized 33 poly(acrylic acid) (PAA), as shown in Figure 13a. ${ }^{[215]}$ In the 34 structure of $\left(\mathrm{PCMVImTf} \mathrm{I}_{2} \mathrm{~N}\right)(\mathrm{PAA})$, PAA acts as a crosslinker to 35 chemically lock PCMVImTf ${ }_{2} \mathrm{~N}$ in a porous network via electro- 36 static complexation. $\mathrm{Tf}_{2} \mathrm{~N}^{-}$ions are believed to be the porogens. 37 Due to the considerable mass loss in the form of volatile spe- 38 cies during carbonization, the HNDCM prepared at $1000{ }^{\circ} \mathrm{C} 39$ showed an SSA of $907 \mathrm{~m}^{2} \mathrm{~g}^{-1}$ with a high pore volume of 40 $0.79 \mathrm{~cm}^{3} \mathrm{~g}^{-1}$.

Recently, Zhao et al. developed a B/N co-doped nanoporous 42 carbon membrane (B/N-GCM) from the pyrolysis of membrane 43 composing of PAA matrix and poly[1-cyanomethyl-3-vinylimi- 44 dazolium bis(trifluoromethane sulfonyl)imide] (PCMVImTFSI) 45 PIL (Figure 13b). ${ }^{[216]}$ Zhao et al. demonstrated the pore-forming 46 mechanism was directly related to the contents of TFSI ions. In 47 other words, TFSI acts as the porogen during pyrolysis. B, N-co- 48 doped nanoporous carbon membranes (B/N-GCM) derived 49 from (PCMVImTFSI)(PAA) showed a high SSA of $1500 \mathrm{~m}^{2} \mathrm{~g}^{-1} 50$ with an ultrahigh areal capacitance of $3 \mathrm{~F} \mathrm{~cm}^{-2}$.

The advantages of the carbonization of PILs for the prepa- 52 ration of porous carbon are obvious. The porogens are evenly 53 distributed in the polymer matrix due to the electrostatic 54 forces between anion and cations so that the morphology and 55 porous microstructure of porous carbons can be tuned by 56 porogens easily. The polymer matrix can be easily tuned into 57 flexible matrix or fiber morphology for flexible and integrated 58 SC devices. ${ }^{[217,218]}$

\author{
(n)
}




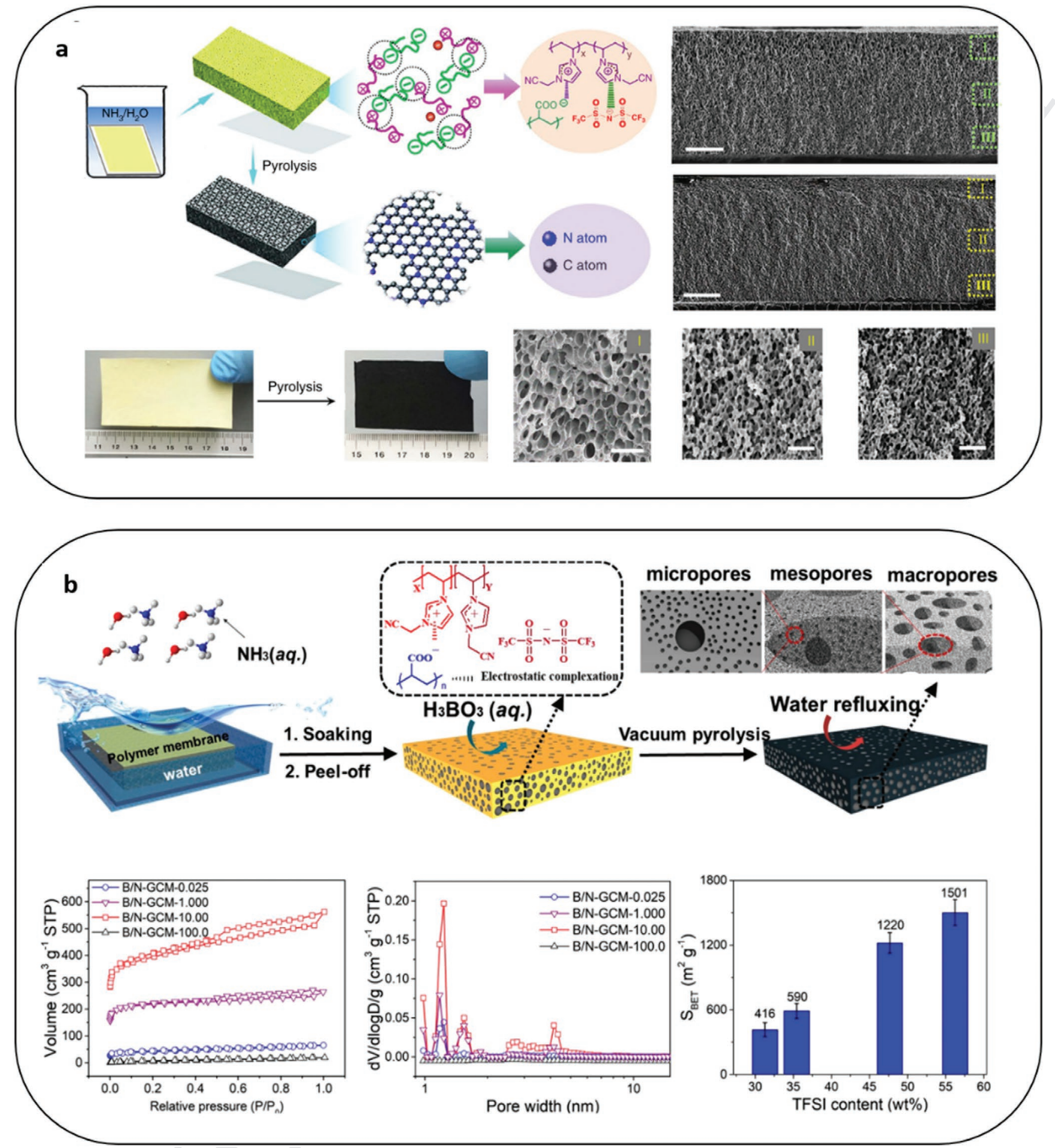

Figure 13. a) The schematic illustration of the preparation of nanoporous carbon membrane from cationic poly[1-cyanomethyl-3-vinylimidazolium bis(trifluoromethanesulfonyl)imide] $\left(\mathrm{PCMVImTf}_{2} \mathrm{~N}\right.$ ) and anionic neutralized poly(acrylic acid) (PAA), the SEM images of the cross-section of the obtained membrane (above), the digital photograph of the polymer and obtained B/N-GCM membrane, and the SEM images of its top view (below). Reproduced with permission. ${ }^{[215]}$ Copyright 2017, Nature Publishing Group. b) The schematic fabrication process of hierarchically structured $\mathrm{B}, \mathrm{N}$-co-doped nanoporous carbon membranes (B/N-GCM) and the typical pore-parameters as a function of doping ratio of TFSI in the membrane (above), the $\mathrm{N}_{2}$ adsorption/desorption isotherms, pore-size distribution, and SSA as a function of TFSI content. Reproduced with permission.[216] Copyright 2019, American Chemical Society. 


\section{New Porogen Engineering Methods}

\subsection{Self-Activation of Carbohydrate}

Although the direct pyrolysis of co-polymer can be used to synthesize porous carbon with high SSAs, the copolymer precursors are expensive and nonrenewable. Besides, it takes a long time and tedious procedures are needed to prepare these copolymer precursors. Given the abundance of carbohydrates, preparing porous carbons directly by carbohydrate pyrolysis can reduce the usage of activating agents and avoid using nonrenewable petrochemicals. Biomass-based char shows low SSA because the carbon skeleton forms at temperatures higher than the temperatures at which decomposition gases are released. The low interatomic distance between carbon atoms and heteroatom functional groups enables significant shrinkage during pyrolysis, which results in the nonporous nature of biomass chars. In consideration of this, one effective way is to exfoliate the carbon skeleton into sheets and enlarge the interatomic spacing between oxygen functional groups by oxidation. Li et al. synthesized sheet-like porous carbons by a facile hydrothermalassisted carbonization process. ${ }^{[219]}$ In the hydrothermal process, $\mathrm{H}_{2} \mathrm{O}_{2}$ and acetic acid (HAc) were added into the reactor which contains biomass precursor. Subsequently, the resultant porous carbon was obtained by carbonization. The resultant carbon $\left(\mathrm{C}-\mathrm{H}_{2} \mathrm{O}_{2} / \mathrm{HAc}\right.$, Figure 14a) showed a sheet-like structure, a high SSA of $1015 \mathrm{~m}^{2} \mathrm{~g}^{-1}$, and a high specific capacitance of $340 \mathrm{~F} \mathrm{~g}^{-1}$ at a current density of $0.5 \mathrm{~A} \mathrm{~g}^{-1}$ (Figure 14b). During the hydrothermal process, $\mathrm{H}_{2} \mathrm{O}_{2}$ acts as a driller which assists in forming mesopores, while HAc exfoliates bulk carbon particles into lamellar carbon sheets. Functional groups such as $\mathrm{C}(\mathrm{O}) \mathrm{OH}$ and $\mathrm{C}=\mathrm{O}$ decompose to generate gas, which prevents the formation of dense structure and introduces the unique porous structure into carbon skeleton during carbonization. This study offered a general method for the pyrolysis of carbohydrates to prepare porous carbon for SC applications. In principle, any carbon precursors with oxygen functional groups that can enlarge the interatomic spaces of carbon atoms can be carbonized directly to synthesize porous carbon.

Direct pyrolysis strategy is an advance for the preparation of porous carbons since it eliminated the post-synthesis activation process. Ji et al. also discovered a general strategy to prepare porous carbon from the direct pyrolysis of cellulose (the most abundant biomass on the earth). ${ }^{[220]}$ In this strategy, the argon gas flow rate was controlled during pyrolysis. They found that the BET SSA and the pore volume of the obtained porous carbon showed a negative correlation with the argon flow rate (Figure 14c). Through high-resolution transmission electron microscope (HRTEM; Figure 14d), it can be observed that a more mesoporous structure was obtained under a $20 \mathrm{sccm}$ argon flow compared with a $100 \mathrm{sccm}$ argon flow. Apparent textural differences of carbons were observed due to the different self-activation reactions under different argon gas flow rates. Namely, the decomposition gases $\left(\mathrm{CO}_{2}, \mathrm{H}_{2} \mathrm{O}\right)$ of cellulose can react with the carbon skeleton which is formed during pyrolysis (confirmed by the increase of $\mathrm{H}_{2}$ concentration by mass spectroscopy (Figure 14e)) in the temperature range from 750 to $800{ }^{\circ} \mathrm{C}$ (Equations (3) and (4)). Argon gas with lower flow rate enables longer residence time, which results in a better activation effect. Surprisingly, C-10 sample (Ar flow is $10 \mathrm{sccm}$ ) 1 showed a high SSA of $2602 \mathrm{~m}^{2} \mathrm{~g}^{-1}$. With a high SSA and a pore- 2 size distribution of 2-20 nm, C-10 had a specific capacitance of 3 $132 \mathrm{~F} \mathrm{~g}^{-1}$, good rate capability, and superior cycling stability. 4

These studies indicated that all carbohydrates can essen- 5 tially be used as precursors to synthesize porous carbon by this 6 self-activation strategy. Self-activation even can be applied in 7 the activation of other carbon-rich biomasses. ${ }^{[193,221,222]}$ Defect 8 mesopore-dominant porous carbon (termed as HDMPC) with 9 SSA of $2192 \mathrm{~m}^{2} \mathrm{~g}^{-1}$ was prepared through direct pyrolysis of 10 low-cost sheep bone in an argon atmosphere through self- 11 activation strategy. When used as the cathode in a lithium-ion 12 capacitor, HDMPC displayed a high capacity of $110 \mathrm{mAh} \mathrm{g}^{-1} 13$ in the potential range of $2.0-4.5 \mathrm{~V}$ versus $\mathrm{Li} / \mathrm{Li}^{+}$. Given the 14 unique feature of the self-activation mechanism, more oxygen- 15 abundant organic precursors can be pyrolyzed to synthesize 16 porous carbons for SC applications.

\section{2. $\mathrm{CO}_{2}$ Laser Scribing}

Laser scribing is a new technique based on the photochem- 22 ical and photothermal reaction between laser spot and carbon 23 precursors. In 2011, Ajayan et al. synthesized laser-reduced 24 graphene oxide (rGO) on the GO membrane and directly used 25 the rGOs as electrodes for sandwiched and in-plane microsu- 26 percapacitors. ${ }^{[223]}$ Laser-reduced rGO showed 3D morphology, 27 high capacitance, and high conductivity. Later, in 2012, Kaner 28 et al. demonstrated that GO can be reduced as laser-scribed gra- 29 phene (henceforth termed as LSG) by a commercial LightScribe 30 DVD laser. ${ }^{[224]}$ LSG with high conductivity $\left(1738 \mathrm{~S} \mathrm{~m}^{-1}\right)$ and 31 high SSAs $\left(1520 \mathrm{~m}^{2} \mathrm{~g}^{-1}\right)$ endows LSG with high areal capaci- 32 tance and an ultralow time constant of $33 \mathrm{~ms}$. Microspercapaci- 33 tors based on LSG electrodes showed a high energy density of 34 $1 \mathrm{mWh} \mathrm{cm}^{-3}$ and superior rate capability. Tour et al. showed 35 another example that commercial polyimide can be laser scribed 36 into LSG by using a commercial $\mathrm{CO}_{2}$ laser cutting machine 37 (Figure 15a).[225] Furthermore, they developed inert-gas- 38 protected laser scribing and multiple laser scribing processes 39 which enable the successful transformation from wood,[226] 40 cloth, ${ }^{[227]}$ bread into LSG (Figure 15b). Alshareef et al. devel- 41 oped the LSG from natural lignin and used LSG as electrodes 42 for high-energy microsupercapacitors through a direct-write 43 lignin laser lithography technique. ${ }^{[228]}$ Besides, Alshareef et al. 44 developed high-power SC based on the LSG from laser scribing 45 amorphous carbon spheres. ${ }^{[229]}$ What is more, due to the hydro- 46 phobic nature of LSG, a wettability-driven assembly process was 47 developed to fabricate microsupercapacitor using particulate 48 active materials. ${ }^{[230]}$ Despite the above achievements, the SSAs 49 of LSG derived from polyimide, lignin, and wood are limited to 50 $<500 \mathrm{~m}^{2} \mathrm{~g}^{-1}$, which limits its application as electrodes for SCs. 51 The interesting phenomena of transforming organic sources 52 into LSG needs to be elaborated for the further development 53 of LSG-based materials. Kaner et al. proposed a mechanism 54 for the graphene formation during $\mathrm{CO}_{2}$ laser scribing. Carbon 55 dots absorb $\mathrm{CO}_{2}$ laser energy which is very close to the absorb- 56 ance of $\mathrm{sp}^{3} \mathrm{C}-\mathrm{C}$, thus breaking the chemical bonds between 57 $\mathrm{C}-\mathrm{C}$ and forming $\mathrm{sp}^{2}$-dominated carbon dots (Figure 15c). ${ }^{[231]} 58$ The carbon dots then self-assembled into porous long-range 59 


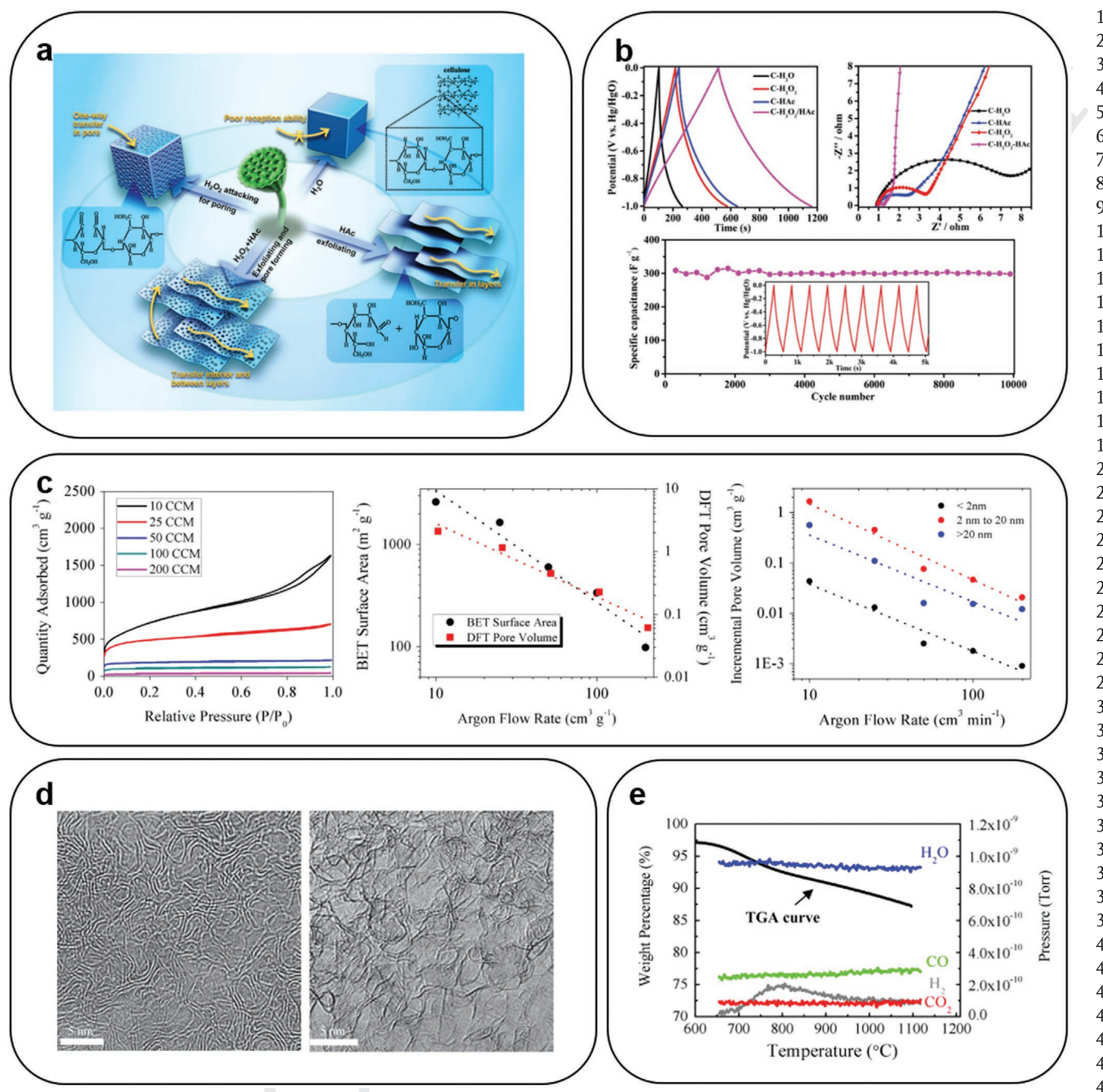

1

Figure 14. a) Mechanisms of the synthesis and the enhancements of the electrochemical performances of the porous graphene-like carbon using different hydrothermal protocols. b) The CV curves, GCD curves of different carbon materials using different recipe combinations in hydrothermal reactions, and the cycling performances of $\mathrm{C}-\mathrm{H}_{2} \mathrm{O}_{2} / \mathrm{HAc}$ carbon under of current density of $1 \mathrm{~A} \mathrm{~g} \mathrm{~g}^{-1}$ using a three-electrode set-up. Reproduced with permission. ${ }^{219]}$ Copyright 2018, Wiley-VCH. c) The influence of flow rate of argon gas during the pyrolysis of cellulose, the dependence of SSA on the flow rate of argon during pyrolysis, the pore volume as a function of the argon gas flow rate. d) HRTEM images showing the different microstructures of C-100 and C-20. e) The MS spectra during the pyrolysis of a $650{ }^{\circ} \mathrm{C}$ pre-heat-treated cellulose sample. Reproduced with permission. ${ }^{[220]}$ Copyright 2015, Elsevier.

turbostratic graphene nanodomains. The pursuit of high SSA from direct laser scribing organics, has significant potential because direct laser scribing is a fast technique that can also be used to fabricate LSG electrodes on metal current collectors without binders. Kaner et al. investigated a laser scribed mixture 9 of carbon quantum dots and graphene oxide (Figure 15d). ${ }^{[232]}$ At a carbon quantum dot concentration of $35 \%$, the LSG exhibited the highest SSA around $1000 \mathrm{~m}^{2} \mathrm{~g}^{-1}$ and a specific capacitance of $190 \mathrm{~F} \mathrm{~g}^{-1}$. Kaner et al. also discovered that the performances of commercially activated carbon electrode could be greatly enhanced by laser scribing (Figure 15e). ${ }^{[233]}$ After laser scribing, both the areal and gravimetric capacitances of activated carbon 


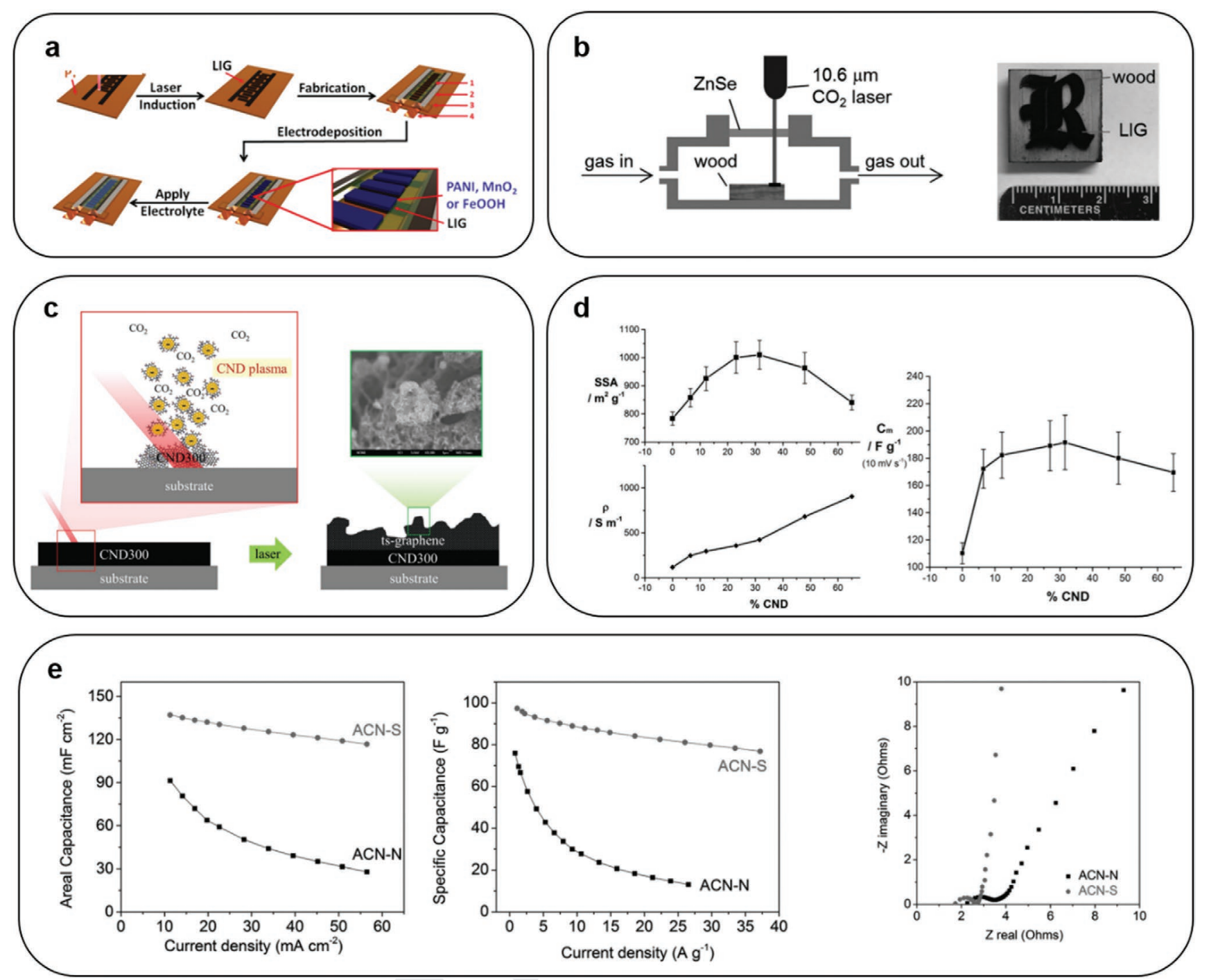

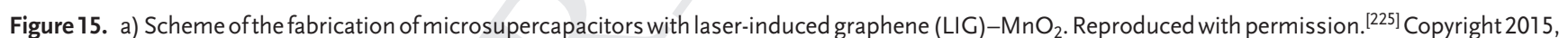
Wiley-VCH. b) The formation of graphene can be done by laser scribing natural wood under inert-atmosphere protection. Reproduced with permission. ${ }^{[226]}$ Copyright 2017, Wiley-VCH. c) Proposed LSG formation mechanism by laser scribing of carbon quantum dots. Reproduced with permission. ${ }^{[231]}$ Copyright 2018, Wiley-VCH. d) The dependence of SSA, conductivity, the specific capacitance of the obtained LSG on the weight ratio of carbon quantum dots using a $\mathrm{CO}_{2}$ laser scribing process. Reproduced with permission. ${ }^{[232]}$ Copyright 2019, The Royal Society of Chemistry. e) The electrochemical behaviors (dependence of areal capacitance and the gravimetric specific capacitance on current density, the electrochemical impedance spectroscopy) of laserscribed activated carbon and activated carbon in acetonitrile electrolytes. Reproduced with permission. ${ }^{[233]}$ Copyright 2017, Wiley- $\mathrm{VCH}$.

are enhanced apparently. What is more, the impedance of activated carbon electrode was reduced by laser scribing, as demonstrated by the Nyquist plot. Still, the mechanism and what happed to the commercial activated carbon need to be elaborated. Given the advantages of laser scribing, it is suitable to develop the LSG electrodes with both high areal capacitance and high rate capability for commercial SC applications. The SSAs of LSGs can be further enhanced by incorporating some porogens in the laser scribing process.

\subsection{Dehalogenation Carbonization}

Carbonization can be achieved by not only pyrolysis but also deoxygenation and dehydrogenation with concentrated sulfuric acid treatment. However, the SSAs of carbons derived from 46 dehydrogenation using $\mathrm{H}_{2} \mathrm{SO}_{4}$ was as low as $2.4 \mathrm{~m}^{2} \mathrm{~g}^{-1}$. [28] 47 Recently, dehalogenation became a general method that can 48 transform halogen-containing polymers into porous carbons. 49 Dai et al. discovered that polyvinylidene chloride (PVDC) could 50 be directly transformed into a carbonaceous material using 51 dehalogenation reaction by $\mathrm{KOH}$ in ethyl alcohol solution 52 (Figure 16a). ${ }^{[37]}$ The dehalogenation of PVDC is composed of 53 multiple processes. $\mathrm{HCl}$ molecules are eliminated by $\mathrm{KOH} 54$ etching. Then the partially cyclized structure was transformed 55 into carbonaceous structure through either intramolecular 56 cyclization or intermolecular dehalogenation (Figure 16b). 57 The obtained ball-milled carbon (BMC) showed particulate 58 morphology and $\mathrm{sp}^{2}$ hybridized crystalline structure with 59 
4

5

6

7

12

13

14

16

17

18

19

20

21

22

23

24

25

26

27

28

29

30

31

32

33

34
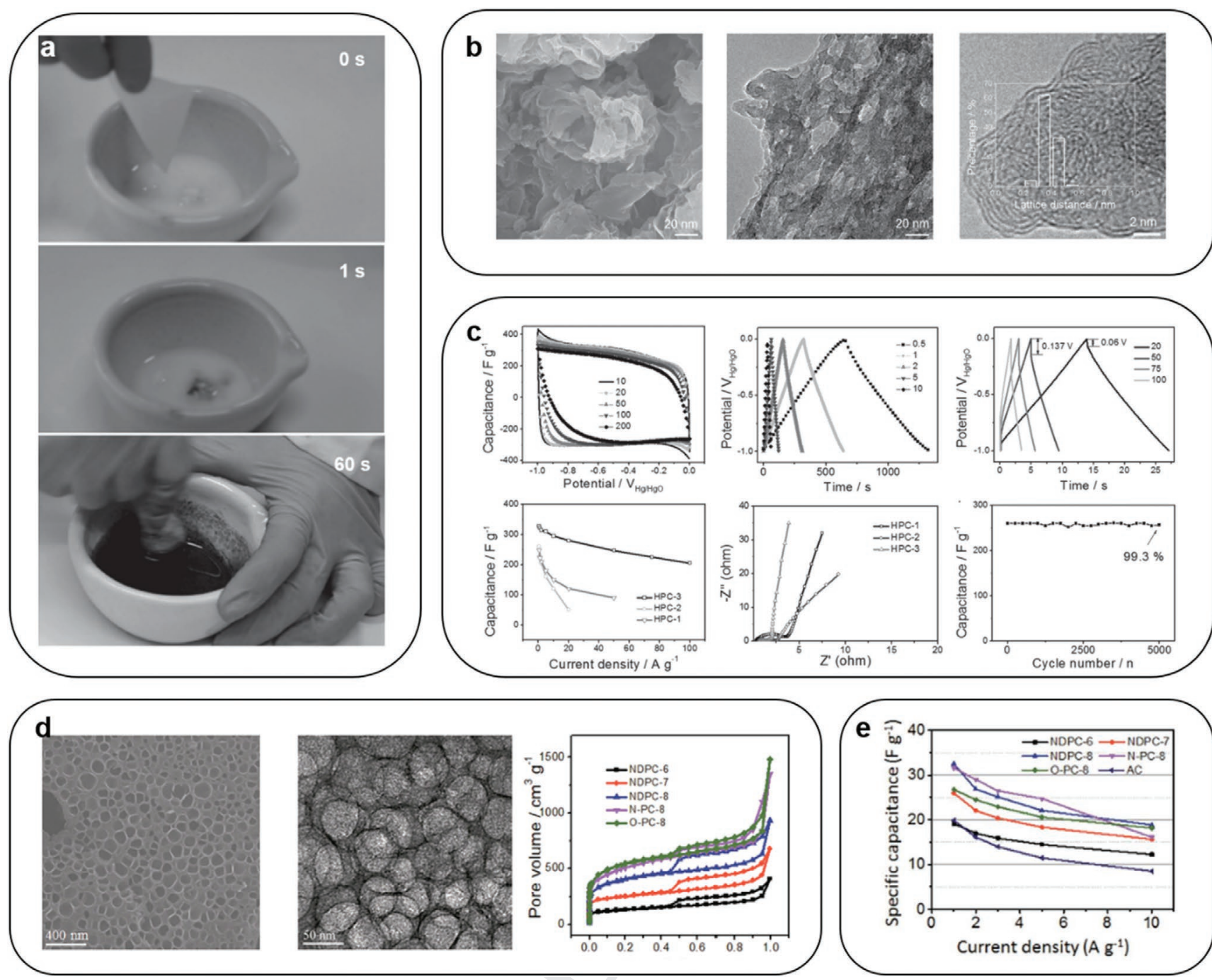

Figure 16. a) Hand-grinding processing mixture of PVDC/KOH powders in ethyl alcohol solution at different time. b) The SEM, TEM, and HRTEM images of BMC. c) The electrochemical performance of BMC (CV, GCD, and EIS). Reproduced with permission. ${ }^{[37]}$ Copyright 2016, Wiley-VCH. d) The SEM, TEM images, and the $\mathrm{N}_{2}$ adsorption/desorption isotherms of nondoped porous carbon (NDPC). e) The rate capability of symmetric capacitor using NDPC as electrodes. Reproduced with permission. ${ }^{[234]}$ Copyright 2017, The Royal Society of Chemistry.

an interlayer spacing of $0.35 \mathrm{~nm}$. BMC shows a high SSA of $1735 \mathrm{~m}^{2} \mathrm{~g}^{-1}$ and a pore sizes below $5 \mathrm{~nm}$. BMC exhibits a high specific capacitance of $328 \mathrm{~F} \mathrm{~g}^{-1}$ at $0.5 \mathrm{~A} \mathrm{~g}^{-1}$ (Figure 16c). Besides, BMC also shows high rate capability and good cycling stability. These studies show that dehalogenation-based carbonization can be used to prepare porous carbons with high surface areas. As a general process, various halogen-containing polymers can be used as carbon sources. Polyvinyl fluoride (PVDF) can be dehalogenated by $\mathrm{NaNH}_{2}{ }^{[29]}$ and sodium ethoxide $^{[234]}$ to prepare porous carbon. The dehalogenated PVDF using sodium ethoxide showed a high SSA of $1920 \mathrm{~m}^{2} \mathrm{~g}^{-1}$ (Figure 16d). This porous carbon enables a $2 \mathrm{~V}$ symmetric SC with a capacitance $32.5 \mathrm{~F} \mathrm{~g}^{-1}$ in $\mathrm{Li}_{2} \mathrm{SO}_{4}$ electrolyte (Figure 16e).

\section{Summary and Outlook}

SCs are important energy storage devices that are playing increasingly important roles in nowadays energy storage applications. SC modules are being evaluated for electrical transportation, uninterruptible power supplies, power tools, and high power electronics. At present, the capital cost of SC (price per watt-hour) is too high compared with mature rechargeable battery technologies such as LIBs and lead-acid batteries, partially due to the high cost of porous carbon active materials (around $30-50 \$ \mathrm{~kg}^{-1}$ ). Searching new porous carbons that offer both low cost, moderate SSA (1500 to $2000 \mathrm{~m}^{2} \mathrm{~g}^{-1}$ ), and decent performance is crucial for the further market penetration of SC. Thus, this review presents several strategies that are being developed to achieve porous carbons with higher performance and addresses the synthesis and development difficulties for each approach.

Porous carbon electrodes used in commercial SCs are currently mostly produced by physical activation. Physical activation $\left(\mathrm{H}_{2}, \mathrm{CO}_{2}\right.$ activation) produces porous carbons with micropore-dominated porous structures and limited SSAs. Air, as a free activation agent, has seldom been used in the
1 
preparation of high-SSA porous carbon in physical activation method because carbon faces combustion in the oxygen-rich atmosphere. Diluted air in an inert atmosphere can exert as a high-oxidative physical activation agent that enhances the SSA of the resultant porous carbons obtained from physical activation.

In chemical activation methods, a $\mathrm{KOH}$ or $\mathrm{NaOH}$ is used, which causes the emission of highly corrosive byproducts and pollutants during activation. Thus, chemically activated porous carbons require post-treatments in industrial production. The chemical activation method needs to be redesigned to develop porous carbons at a reasonable cost and minimal environmental impact. Green chemical engineering processes are essential for the sustainable preparation of chemically activated porous carbons for SCs. During the past few years, various new chemical activation agents have been developed, but unfortunately, some of them are highly corrosive and even toxic. In addition, the porous carbons obtained from these new activation agents usually possess macropores that significantly reduce the tap density of the resultant porous carbons. In that case, porous carbons without macroporous structures prepared by new chemical activation agents $\left(\mathrm{CuCl}_{2}\right.$ as a typical activation agent) are of special interests for developing SCs. The porogen mechanisms of these new chemical agents are also needed to be studied thoroughly through in situ techniques. Besides, the environmental impacts of these new chemical activation agents still need to be re-evaluated.

Direct pyrolysis of self-template organic salts may be a solution for fabricating porous carbons used in SCs. Based on some low-cost precursors such as alkaline metal citrate salts, the self-template method can be cheap and easy to be applied in the preparation of porous carbons with high SSA. The biggest disadvantage of this method can be the low tap density of the obtained porous carbons due to its macroporous structures. On the one hand, the macroporous structure of these porous carbons can be crushed to increase the tap density. On the other hand, the self-templated carbons with opened 3D macroporous structures may be used as supports for pseudocapacitive materials (such as $\mathrm{RuO}_{2}, \mathrm{MnO}_{2}$ ) in aqueous SCs.

The pyrolysis of conjugated copolymers, block copolymers, and PILs are new strategies that have been recently developed to improve the quality of porous carbons for SC applications. Through direct pyrolysis of copolymers, high SSAs and impressive specific capacitance values have been obtained, but these processes are admittedly complex and the precursors are expensive. So cheaper polymer precursors, simplified and scalable processes are needed to make these processes practical. The intrinsic mechanism of these direct pyrolysis methods needs to be studied so that better copolymers can be designed and used to prepare porous carbons. The decomposition gases of these heteroatom-rich polymers are toxic and need to be treated to minimize their environmental impact, which adds cost to the pyrolysis process. From the perspective of material synthesis, the SSA of porous carbons can be further improved by tuning the intermolecular design (such as decrease the molecular chain of PMMA and PAN) and optimization of preparation parameters (pyrolysis time, pyrolysis temperature, and inert gas flow rate). Because pyrolysis of polyaniline-co-polypyrrole generates amine species, these amine species may be used as activation agents simultaneously in the pyrolysis process. On the appli- 1 cation aspect, the copolymer (block polymer, PILs) pyrolysis 2 strategy is versatile for preparing free-standing PCF mats or 3 flexible porous carbon electrodes. These integrated electrodes 4 have great potentials for advanced flexible and wearable SCs. 5

Self-activation of carbohydrate biomasses has been playing 6 increasingly important roles in producing porous carbons. 7 The self-activation method is a successful example that 8 porous carbons can be prepared by the direct pyrolysis of bio- 9 carbohydrates. Thus, inert gas lines in a traditional physical 10 activation production line can be eliminated. Still, based on 11 the self-activation mechanism, reactors that can fully utilize the 12 decomposition gases $\left(\mathrm{CO}_{2}\right)$ for porous carbon production are 13 needed to be designed.

As a huge power density gap between SCs and electrolytic 15 capacitors still exists, the development of high-power SCs is 16 still another major trend. SCs with high energy density and 17 high power density require that the porous carbon materials 18 have not only high SSA but also high conductivity enabled by 19 highly graphitic structure. High graphitization (conductivity) 20 and high SSA are contradictory factors since amorphous car- 21 bons with relatively low conductivities $\left(<1 \mathrm{~S} \mathrm{~cm}^{-1}\right)$ are obtained 22 from the traditional pyrolysis process. Laser scribing opens a 23 new pathway for graphene-based electrode materials with high 24 conductivity (as high as $60 \mathrm{~S} \mathrm{~cm}^{-1}$ ) for SCs. ${ }^{[228]}$ Given the lim- 25 ited SSA of state-of-art LSG electrodes, we still need other ways 26 to improve the SSA of LSG. In the next stage of development 27 of LSG electrodes for SCs, various porogens, such as alkaline 28 metal hydroxides, metal-organic salts, and organics that cannot 29 be laser-carbonized (such as PMMA), may be added into the 30 carbon precursors to synthesize porous, graphitic carbon mate- 31 rials in the laser scribing process.

In the development of porous carbons for commercial SC 33 applications, we also need to consider the tap density of porous 34 carbons. Tap density is a critical parameter that is seldom 35 investigated by researchers. The tap density of porous carbon 36 is directly related to the volumetric energy density of the SCs. 37 Using graphene materials with high pack density as electrode 38 materials, SC can achieve a high volumetric energy density of 39 13.1 Wh L $\mathrm{L}^{-1} \cdot[235,236]$ However, due to the existence of a huge 40 amount of micropores, the tap densities of activated carbon are 41 limited to $0.35 \mathrm{~cm}^{3} \mathrm{~g}^{-1}$. The tap density decreases as the SSA 42 increases, so the tap density should be optimized concurrently 43 with SSA for new production processes. For achieving higher 44 energy density SCs, we may design asymmetric hybrid lithium 45 (sodium, potassium) ion SCs that use porous carbon as the 46 cathode to increase the operating voltage and energy density. 47 The major role of porous carbon in hybrid SCs is to provide 48 a high surface area that provides high double-layer capacitance 49 with high power capability. The designing of asymmetric hybrid 50 lithium (sodium, potassium) SCs requires optimization of the 51 relationship between pore architecture and active electrolyte 52 ions. For practical applications, the stability of porous carbon in 53 mobile ion SCs need to be investigated.

SCs have become important energy storage devices with 55 potential in many types of applications. With the development 56 of novel, facile, and green methods for synthesis of high-quality 57 porous carbons, we can achieve SCs with higher storage energy 58 density and lower costs soon. . 


\section{Acknowledgements}

J.Y. and W.L.Z. contributed equally to this work. The this publication is supported by King Abdullah University of Science and Fechnology (KAUST).

\section{Conflict of Interest}

The authors declare no conflict of interest.

\section{Keywords}

activation, carbonization, porous carbon, pyrolysis, self-activation, self-template, supercapacitors

Received: December 10, 2019 Revised: January 10, 2020 Published online:

[1] J. R. Miller, P. Simon, Science 2008, 321, 651

[2] S. Zhang, N. Pan, Adv. Energy Mater. 2015, 5, 1401401.

[3] M. F. El-Kady, Y. Shao, R. B. Kaner, Nat. Rev. Mater. 2016, 1, 16033

[4] A. K. Talukder, Electrochem. Soc. Interface 2008, 17, 53.

[5] B. Dunn, B. Dunn, H. Kamath, J. Tarascon, Sci. Mag. 2011, 334, 928

[6] J. R. Miller, Science 2012, 335, 1312.

[7] K. Fic, A. Platek, J. Piwek, E. Frackowiak, Mater. Today 2018, 21, 437.

[8] K. S. W. Sing, D. H. Everett, R. A. W. Haul, L. Moscou, R. A. Pierotti, J. R. Rouquerol, T. Siemieniewska, Pure Appl. Chem. 1985, 57, 603.

[9] F. Rodríguez-Reinoso, M. Molina-Sabio, Carbon 1992, 30, 1111.

[10] J. Wang, S. Kaskel, J. Mater. Chem. 2012, 22, 23710.

[11] M. Rodenas, D. Amoros, A. Solano, Carbon 2003, 41, 267.

[12] Y. Zhu, S. Murali, M. D. Stoller, K. J. Ganesh, W. Cai, P. J. Ferreira A. Pirkle, R. M. Wallace, K. A. Cychosz, M. Thommes, D. Su, E. A. Stach, R. S. Ruoff, Science 2011, 332, 1537.

[13] D. Liu, W. Zhang, H. Lin, Y. Li, H. Lu, Y. Wang, J. Cleaner Prod. 2016, 112, 1190.

[14] J. A. Maciá-Agulló, B. C. Moore, D. Cazorla-Amorós, A. Linares-Solano, Carbon 2004, 42, 1367.

[15] A. Hamasaki, A. Furuse, Y. Sekinuma, K. Fujio, M. lide, S. Ozeki, Sci. Rep. 2019, 9, 7489.

[16] Z. Miao, Y. Huang, J. Xin, X. Su, Y. Sang, H. Liu, J. J. Wang, ACS Appl. Mater. Interfaces 2019, 11, 18044.

[17] S. Liu, Y. Liang, W. Zhou, W. Hu, H. Dong, M. Zheng, H. Hu, B. Lei, Y. Xiao, Y. Liu, J. Mater. Chem. A 2018, 6, 12046.

[18] J. Liu, N. P. Wickramaratne, S. Z. Qiao, M. Jaroniec, Nat. Mater. 2015, 14, 763.

[19] J. Chmiola, G. Yushin, Y. Gogotsi, C. Portet, P. Simon, P. L. Taberna, Science 2006, 313, 1760.

[20] Y. Zhai, Y. Dou, D. Zhao, P. F. Fulvio, R. T. Mayes, S. Dai, Adv. Mater. 2011, 23, 4828.

[21] Y. Bu, T. Sun, Y. Cai, L. Du, O. Zhuo, L. Yang, Q. Wu, X. Wang, Z. Hu, Adv. Mater. 2017, 29, 1700470.

[22] G. Xu, P. Nie, H. Dou, B. Ding, L. Li, X. Zhang, Mater. Today 2017, 20, 191.

[23] F. Xu, D. Wu, R. Fu, B. Wei, Mater. Today 2017, 20, 629

[24] R. Ye, D. K. James, J. M. Tour, Adv. Mater. 2019, 31, 1803621.

[25] J. Luo, H. Zhang, Z. Zhang, J. Yu, Z. Yang, Carbon 2019, 155, 1.

[26] S. S. Lam, R. K. Liew, Y. M. Wong, P. N. Y. Yek, N. L. Ma, C. L. Lee, H. A. Chase, J. Cleaner Prod. 2017, 162, 1376.
[27] Y. Liu, X. Yang, H. Liu, Y. Ye, Z. Wei, Appl. Catal., B 2017, 218, 679.1

[28] D. Damodar, A. Kunamalla, M. Varkolu, S. K. Maity, 2 A. S. Deshpande, ACS Sustainable Chem. Eng. 2019, 7, 12707.

[29] M. Guo, Y. Li, K. Du, C. Qiu, G. Dou, G. Zhang, Appl. Surf. Sci. 4 2018, 440, 606

[30] X. Zheng, J. Luo, W. Lv, D. W. Wang, Q. H. Yang, Adv. Mater. 2015, 27, 5388.

[31] Z. Liu, F. Mo, H. Li, M. Zhu, Z. Wang, G. Liang, C. Zhi, Small Methods 2018, 2, 1800124.

[32] R. J. White, V. Budarin, R. Luque, J. H. Clark, D. J. MacQuarrie, Chem. Soc. Rev. 2009, 38, 3401.

[33] L. Borchardt, M. Oschatz, S. Kaskel, Mater. Horiz. 2014, 1, 157.

[34] T. M. Alslaibi, I. Abustan, M. A. Ahmad, A. A. Foul, Chem. Technol. Biotechnol. 2013, 88, 1183

[35] Z. Rozlívková, M. Trchová, M. Exnerová, J. Stejskal, Synth. Met. 2011, 161, 1122.

[36] W. Chaiwat, I. Hasegawa, J. Kori, K. Mae, Ind. Eng. Chem. Res. 2008, 47, 5948 .

[37] G. Zhang, L. Wang, Y. Hao, X. Jin, Y. Xu, Y. Kuang, L. Dai, X. Sun, Adv. Funct. Mater. 2016, 26, 3340.

[38] A. Zheng, Z. Zhao, S. Chang, Z. Huang, X. Wang, F. He, H. Li, Bioresour. Technol. 2013, 128, 370 .

[39] M. Pala, I. C. Kantarli, H. B. Buyukisik, J. Yanik, Bioresour. Technol. 2014, 161, 255.

[40] W. H. Chen, S. C. Ye, H. K. Sheen, Bioresour. Technol. 2012, 118, 195.

[41] S. W. Han, D. W. Jung, J. H. Jeong, E. S. Oh, Chem. Eng. J. 2014, 254, 597.

[42] M. M. Tang, R. Bacon, Carbon 1964, 2, 211.

[43] A. K. Kercher, D. C. Nagle, Carbon 2003, 41, 15.

[44] K. Yang, J. Peng, H. Xia, L. Zhang, C. Srinivasakannan, S. Guo, J. Taiwan Inst. Chem. Eng. 2010, 41, 367.

[45] M. S. Contreras, C. A. Páez, L. Zubizarreta, A. Léonard, S. Blacher, C. G. Olivera-Fuentes, A. Arenillas, J. P. Pirard, N. Job, Carbon $2010,48,3157$.

[46] D. W. Kim, H. S. Kil, K. Nakabayashi, S. H. Yoon, J. Miyawaki, Carbon 2017, 114, 98.

[47] M. J. Prauchner, F. Rodríguez-Reinoso, Microporous Mesoporous Mater. 2012, 152, 163

[48] R. M. Navarro, M. A. Peña, J. L. G. Fierro, Chem. Rev. 2007, 107, 3952.

[49] K. Suresh Kumar Reddy, A. Al Shoaibi, C. Srinivasakannan, New Carbon Mater. 2012, 27, 344.

[50] Ö. Şahin, C. Saka, Bioresour. Technol. 2013, 136, 163.

[51] G. Lin, R. Ma, Y. Zhou, Q. Liu, X. Dong, J. Wang, Electrochim. Acta 2018, 261, 49.

[52] K. Zou, Y. Deng, J. Chen, Y. Qian, Y. Yang, Y. Li, G. Chen, J. Power Sources 2018, 378, 579

[53] M. A. Islam, M. J. Ahmed, W. A. Khanday, M. Asif, B. H. Hameed, J. Environ. Manage. 2017, 203, 237.

[54] M. A. Lillo-Ródenas, D. Lozano-Castelló, D. Cazorla-Amorós, A. Linares-Solano, Carbon 2001, 39, 751.

[55] H. Sayğili, F. Güzel, J. Cleaner Prod. 2016, 113, 995.

[56] D. Prahas, Y. Kartika, N. Indraswati, S. Ismadji, Chem. Eng. J. 2008, $140,32$.

[57] H. Yin, B. Lu, Y. Xu, D. Tang, X. Mao, W. Xiao, D. Wang, A. N. Alshawabkeh, Environ. Sci. Technol. 2014, 48, 8101.

[58] F. Zhang, T. Liu, M. Li, M. Yu, Y. Luo, Y. Tong, Y. Li, Nano Lett. 2017, 17, 3097.

[59] M. Gao, S. Y. Pan, W. C. Chen, P. C. Chiang, Mater. Today Energy 2018, 7, 58

[60] D. Kang, Q. Liu, J. Gu, Y. Su, W. Zhang, D. Zhang, ACS Nano 2015, 9, 11225.

[61] X. Fan, C. Yu, J. Yang, Z. Ling, C. Hu, M. Zhang, J. Qiu, Adv. Energy Mater. 2015, 5, 1401761.

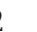
5

\section{6} 7 8 8 9 
[62] C. Wang, D. Wang, S. Zheng, X. Fang, W. Zhang, Y. Tian, H. Lin, H. Lu, L. Jiang, Chem. Res. Chin. Univ. 2018, 34, 983.

[63] F. Zhang, T. Liu, G. Hou, T. Kou, L. Yue, R. Guan, Y. Li, Nano Res. 2016, 9, 2875.

[64] M. Sevilla, R. Mokaya, A. B. Fuertes, Energy Environ. Sci. 2011, 4, 2930.

[65] M. Sevilla, P. Valle-Vigõn, A. B. Fuertes, Adv. Funct. Mater. 2011, 21, 2781.

[66] W. Zhang, H. Lin, Z. Lin, J. Yin, H. Lu, D. Liu, M. Zhao, ChemSusChem 2015, 8, 2114.

[67] W. Zhang, M. Zhao, R. Liu, X. Wang, H. Lin, Colloids Surf., A 2015, 484, 518.

[68] W. Zhang, D. Liu, H. Lin, H. Lu, J. Xu, D. Liu, Colloids Surf., A 2016, 511, 294

[69] Y. X. Tian, C. Xiao, J. Yin, W. Zhang, J. P. Bao, H. Lin, H. Lu, ChemistrySelect 2019, 4, 2314.

[70] M. Yu, D. Lin, H. Feng, Y. Zeng, Y. Tong, X. Lu, Angew. Chem., Int. Ed. 2017, 56, 5454.

[71] Y. Han, Y. Lu, S. Shen, Y. Zhong, S. Liu, X. Xia, Y. Tong, X. Lu, Adv. Funct. Mater. 2019, 29, 1806329.

[72] C. Wang, D. Wu, H. Wang, Z. Gao, F. Xu, K. Jiang, J. Mater. Chem. A 2018, 6, 1244.

[73] Y. Chen, Z. Zhang, Y. Lai, X. Shi, J. Li, X. Chen, K. Zhang, J. Li, J. Power Sources 2017, 359, 529.

[74] Y. Chen, S. Ji, H. Wang, V. Linkov, R. Wang, Int. J. Hydrogen Energy 2018, 43, 5124.

[75] Z. Xu, Y. Zhou, Z. Sun, D. Zhang, Y. Huang, S. Gu, W. Chen, Chemosphere 2020, 241, 125120.

[76] J. Li, L. Tian, F. Liang, J. Wang, L. Han, J. Zhang, S. Ge, L. Dong, H. Zhang, S. Zhang, Carbon 2019, 141, 739

[77] H. Zhu, X. Wang, X. Liu, X. Yang, Adv. Mater. 2012, 24, 6524.

[78] S. I. Yun, S. H. Kim, D. W. Kim, Y. A. Kim, B. H. Kim, Carbon 2019, 149, 637.

[79] Y. Lv, L. Gan, M. Liu, W. Xiong, Z. Xu, D. Zhu, D. S. Wright, J. Power Sources 2012, 209, 152.

[80] J. Li, N. Wang, J. Tian, W. Qian, W. Chu, Adv. Funct. Mater. 2018, 28, 1806153.

[81] G. Zhang, X. Ou, C. Cui, J. Ma, J. Yang, Y. Tang, Adv. Funct. Mater. 2019, 29, 1806722.

[82] W. Gao, X. Feng, T. Zhang, H. Huang, J. Li, W. Song, ACS Appl. Mater. Interfaces 2014, 6, 19109.

[83] L. Wan, P. Song, J. Liu, D. Chen, R. Xiao, Y. Zhang, J. Chen, M. Xie, C. Du, J. Power Sources 2019, 438, 227013.

[84] T. Liu, F. Zhang, Y. Song, Y. Li, J. Mater. Chem. A 2017, 5, 17705.

[85] J. Chen, H. Wei, H. Chen, W. Yao, H. Lin, S. Han, Electrochim. Acta 2018, 271, 49 .

[86] J. Yi, Y. Qing, C. T. Wu, Y. Zeng, Y. Wu, X. Lu, Y. Tong, J. Power Sources 2017, 351, 130 .

[87] X. Liu, N. Fechler, M. Antonietti, Chem. Soc. Rev. 2013, 42, 8237.

[88] M. Molina-Sabio, F. Rodríguez-Reinoso, Colloids Surf., A 2004, 241, 15.

[89] A. Ahmadpour, D. D. Do, Carbon 1996, 34, 471.

[90] X. Liu, M. Antonietti, C. Giordano, Chem. Mater. 2013, 25, 2021.

[91] P. Kuhn, A. Forget, D. Su, A. Thomas, M. Antonietti, J. Am. Chem. Soc. 2008, 130, 13333.

[92] X. Liu, C. Giordano, M. Antonietti, Small 2014, 10, 193.

[93] X. Liu, N. Fechler, M. Antonietti, M. G. Willinger, R. Schlögl, Mater. Horiz. 2016, 3, 214.

[94] X. Liu, M. Antonietti, Adv. Mater. 2013, 25, 6284.

[95] X. Liu, M. Antonietti, Carbon 2014, 69, 460.

[96] C. M. Yang, H. Noguchi, K. Murata, M. Yudasaka, A. Hashimoto, S. lijima, K. Kaneko, Adv. Mater. 2005, 17, 866.

[97] H. Hwang, C. H. Kim, J. H. Wee, J. H. Han, C. M. Yang, Appl. Surf. Sci. 2019, 489, 708 .
[98] T. Lin, W. Chen, F. Liu, C. Yang, H. Bi, F. Xu, F. Huang, Science 1 2015, 350, 1508

[99] G. Wang, H. Wang, X. Lu, Y. Ling, M. Yu, T. Zhai, Y. Tong, Y. Li, 3 Adv. Mater. 2014, 26, 2676.

[100] D. Qiu, N. Guo, A. Gao, L. Zheng, W. Xu, M. Li, F. Wang, R. Yang, 5 Electrochim. Acta 2019, 294, 398.

[101] Y. Li, Y. Liang, H. Hu, H. Dong, M. Zheng, Y. Xiao, Y. Liu, Carbon 2019, 152, 120.

[102] D. Wang, J. Nai, L. Xu, T. Sun, J. Energy Storage 2019, 24, 100764.

[103] W. Yang, W. Yang, L. Kong, A. Song, X. Qin, G. Shao, Carbon 2018, 127, 557.

[104] T. Wei, X. Wei, L. Yang, H. Xiao, Y. Gao, H. Li, J. Power Sources 2016, 331, 373.

[105] L. Tang, Y. Liu, J. Wang, G. Zeng, Y. Deng, H. Dong, H. Feng, 13 J. Wang, B. Peng, Appl. Catal., B 2018, 231, 1.

[106] H. W. Liang, W. Wei, Z. S. Wu, X. Feng, K. Müllen, J. Am. Chem. Soc. 2013, 135, 16002.

[107] P. Schmidt-Winkel, J. W. W. Lukens, D. Zhao, P. Yang, B. F. Chmelka, G. D. Stucky, J. Am. Chem. Soc. 1999, 121, 254.

[108] S. Schacht, Q. Huo, I. G. Voigt-Martin, G. D. Stucky, F. Schüth, Science 1996, 273, 768.

[109] K. Xie, X. Qin, X. Wang, Y. Wang, H. Tao, Q. Wu, L. Yang, Z. Hu, 20 Adv. Mater. 2012, 24, 347

[110] Z. Fan, Y. Liu, J. Yan, G. Ning, Q. Wang, T. Wei, L. Zhi, F. Wei, Adv. 22 Energy Mater. 2012, 2, 419.

[111] C. Zhu, M. Takata, Y. Aoki, H. Habazaki, Chem. Eng. J. 2018, 350, 278.

[112] M. Mecklenburg, A. Schuchardt, Y. K. Mishra, S. Kaps, R. Adelung 25 A. Lotnyk, L. Kienle, K. Schulte, Adv. Mater. 2012, 24, 3486.

[113] C. Wang, M. J. O'Connell, C. K. Chan, ACS Appl. Mater. Interfaces 27 2015, 7, 8952.

[114] S. He, C. Zhang, C. Du, C. Cheng, W. Chen, J. Power Sources 2019, 29 434, 226701.

[115] Y. Liang, M. G. Schwab, L. Zhi, E. Mugnaioli, U. Kolb, X. Feng, 31 K. Müllen, J. Am. Chem. Soc. 2010, 132, 15030.

[116] Y. Fang, Y. Lv, R. Che, H. Wu, X. Zhang, D. Gu, G. Zheng, D. Zhao, 33 J. Am. Chem. Soc. 2013, 135, 1524.

[117] C. deA. Filho, A. J. G. Zarbin, Carbon 2006, 44, 2869.

[118] T. Kyotani, T. Nagai, S. Inoue, A. Tomita, Chem. Mater. 1997, 9, 609.

[119] T. Kyotani, Z. Ma, A. Tomita, Carbon 2003, 41, 1451.

[120] C. Liang, Z. Li, S. Dai, Angew. Chem., Int. Ed. 2008, 47, 3696.

[121] Y. Xie, D. Kocaefe, C. Chen, Y. Kocaefe, J. Nanomater. 2016, 2016, 2302595.

[122] W. Chen, Z. Hu, Y. Yang, X. Wang, Y. He, Y. Xie, C. Zhu, Y. Zhang, L. Lv, Ionics 2019, 25, 5429.

[123] Y. K. Kim, J. H. Park, J. W. Lee, Carbon 2018, 126, 215 Adv. Energy Mater. 2011, 1, 798.

[125] X. F. Jiang, R. Li, M. Hu, Z. Hu, D. Golberg, Y. Bando, X. Bin Wang, Adv. Mater. 2019, 31, 1901186.

[126] J. Liu, Y. Zhang, L. Zhang, F. Xie, A. Vasileff, S. Z. Qiao, Adv. Mater. 2019, 31, 1901261.

[127] Z. Xing, B. Wang, W. Gao, C. Pan, J. K. Halsted, E. S. Chong, J. Lu, X. Wang, W. Luo, C. H. Chang, Y. Wen, S. Ma, K. Amine, X. Ji, 50 Nano Energy 2015, 11, 600.

[128] Y. Gogotsi, A. Nikitin, H. Ye, W. Zhou, J. E. Fischer, B. Yi, 52 H. C. Foley, M. W. Barsoum, Nat. Mater. 2003, 2, 591.

[129] P. Simon, Y. Gogotsi, Nat. Mater. 2008, 7, 845.

[130] M. Schmirler, T. Knorr, T. Fey, A. Lynen, P. Greil, B. J. M. Etzold, Carbon 2011, 49, 4359.

[131] H. J. Liu, J. Wang, C. X. Wang, Y. Y. Xia, Adv. Energy Mater. 2011, 1, 1101.

[132] M. Oschatz, S. Boukhalfa, W. Nickel, J. P. Hofmann, C. Fischer, G. Yushin, S. Kaskel, Carbon 2017, 113, 283. (6) 34 35 36 38 39 42 45 47 48

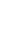
(1)

\section{0}

\section{.} 14 列 . is 19 20

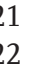

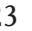

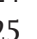

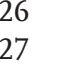
${ }_{28}$

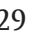
年

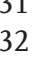

\section{年} 37 40 41 43 46 49

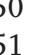


[133] M. Rose, Y. Korenblit, E. Kockrick, L. Borchardt, M. Oschatz, S. Kaskel, G. Yushin, Small 2011, 7, 1108.

[134] W. Y. Tsai, P. C. Gao, B. Daffos, P. L. Taberna, C. R. Perez, Y. Gogotsi, F. Favier, P. Simon, Electrochem. Commun. 2013, 34, 109.

[135] M. Oschatz, L. Borchardt, M. Thommes, K. A. Cychosz, I. Senkovska, N. Klein, R. Frind, M. Leistner, V. Presser, Y. Gogotsi, S. Kaskel, Angew. Chem., Int. Ed. 2012, 51, 7577.

[136] L. Chuenchom, R. Kraehnert, B. M. Smarsly, Soft Matter 2012, 8, 10801.

[137] W.-C. Chu, B. P. Bastakoti, Y. V. Kaneti, J.-G. Li, H. R. Alamri, Z. A. Alothman, Y. Yamauchi, S.-W. Kuo, Chem. - Eur. J. 2017, 23 13734.

[138] H. Wu, G. Yu, L. Pan, N. Liu, M. T. McDowell, Z. Bao, Y. Cui, Nat. Commun. 2013, 4, 1943.

139] Y. Zhao, L. Jiang, Adv. Mater. 2009, 21, 3621.

[140] F. Zhang, Y. Meng, D. Gu, Y. Yan, Z. Chen, B. Tu, D. Zhao, Chem. Mater. 2006, 18, 5279 .

[141] D. Zhao, Q. Huo, J. Feng, B. F. Chmelka, G. D. Stucky, J. Am Chem. Soc. 1998, 120, 6024 .

[142] J. Wei, D. Zhou, Z. Sun, Y. Deng, Y. Xia, D. Zhao, Adv. Funct. Mater. 2013, 23, 2322

[143] I. Moriguchi, A. Ozono, K. Mikuriya, Y. Teraoka, S. Kagawa, M. Kodama, Chem. Lett. 1999, 28, 1171.

[144] H. Tian, Z. Lin, F. Xu, J. Zheng, X. Zhuang, Y. Mai, X. Feng, Small 2016, 12, 3155

[145] J. Tang, J. Liu, C. Li, Y. Li, M. O. Tade, S. Dai, Y. Yamauchi, Angew. Chem., Int. Ed. 2015, 54, 588.

[146] C. Liang, K. Hong, G. A. Guiochon, J. W. Mays, S. Dai, Angew. Chem., Int. Ed. 2004, 43, 5785.

[147] L. Peng, C. Te Hung, S. Wang, X. Zhang, X. Zhu, Z. Zhao, C. Wang, Y. Tang, W. Li, D. Zhao, J. Am. Chem. Soc. 2019, 141, 7073.

[148] G. Hasegawa, K. Kanamori, T. Kiyomura, H. Kurata, T. Abe, K. Nakanishi, Chem. Mater. 2016, 28, 3944.

[149] J. G. Wang, H. Liu, H. Sun, W. Hua, H. Wang, X. Liu, B. Wei, Carbon 2018, 127, 85.

[150] Y. Meng, D. Gu, F. Zhang, Y. Shi, L. Cheng, D. Feng, Z. Wu Z. Chen, Y. Wan, A. Stein, D. Zhao, Chem. Mater. 2006, 18, 4447.

[151] X. Zhou, L. Yu, X. W. D. Lou, Nanoscale 2016, 8, 8384.

[152] Y. Liang, R. Fu, D. Wu, ACS Nano 2013, 7, 1748.

[153] L. Zhou, C. Yang, J. Wen, P. Fu, Y. Zhang, J. Sun, H. Wang, Y. Yuan, J. Mater. Chem. A 2017, 5, 19343.

[154] H. Peng, B. Yao, X. Wei, T. Liu, T. Kou, P. Xiao, Y. Zhang, Y. Li, Adv. Energy Mater. 2019, 9, 1803665.

[155] S. H. Park, K. H. Kim, K. C. Roh, K. B. Kim, J. Porous Mater. 2013 20, 1289.

[156] L. Estevez, V. Prabhakaran, A. L. Garcia, Y. Shin, J. Tao, A. M. Schwarz, J. Darsell, P. Bhattacharya, V. Shutthanandan, J. G. Zhang, ACS Nano 2017, 11, 11047.

[157] A. D. Roberts, X. Li, H. Zhang, Carbon 2015, 95, 268.

[158] J. Wang, J. Tang, B. Ding, V. Malgras, Z. Chang, X. Hao, Y. Wang, H. Dou, X. Zhang, Y. Yamauchi, Nat. Commun. 2017, 8, 15717.

[159] R. B. Rakhi, B. Ahmed, M. N. Hedhili, D. H. Anjum, H. N. Alshareef, Chem. Mater. 2015, 27, 5314.

[160] D. Hulicova, J. Yamashita, Y. Soneda, H. Hatori, M. Kodama, Chem. Mater. 2005, 17, 1241.

161] X. He, H. Yu, L. Fan, M. Yu, M. Zheng, Mater. Lett. 2017, 195, 31.

[162] M. Li, J. Xue, J. Phys. Chem. C 2014, 118, 2507.

[163] A. D. Roberts, X. Li, H. Zhang, Chem. Soc. Rev. 2014, 43, 4341.

[164] P. Hao, Z. Zhao, J. Tian, H. Li, Y. Sang, G. Yu, H. Cai, H. Liu, C. P. Wong, A. Umar, Nanoscale 2014, 6, 12120.

[165] B. Anasori, M. R. Lukatskaya, Y. Gogotsi, Nat. Rev. Mater. 2017, 2, 16098.

[166] L. Jiang, J. Wang, X. Mao, X. Xu, B. Zhang, J. Yang, Y. Wang, J. Zhu, S. Hou, Carbon 2017, 111, 207.
[167] D. Xue, D. Zhu, W. Xiong, T. Cao, Z. Wang, Y. Lv, L. Li, M. Liu, 1 L. Gan, ACS Sustainable Chem. Eng. 2019, 7, 7024.

[168] N. Zhang, H. Qiu, Y. Si, W. Wang, J. Gao, Carbon 2011, 49, 827.

[169] L. Yu, H. Bin Wu, X. W. (D) Lou, Acc. Chem. Res. 2017, 50, 293.

[170] Y. He, X. Zhuang, C. Lei, L. Lei, Y. Hou, Y. Mai, X. Feng, Nano Today 2019, 24, 103

[171] B. Yang, J. Chen, L. Liu, P. Ma, B. Liu, J. Lang, Y. Tang, X. Yan Energy Storage Mater. 2019, 23, 522.

[172] B. Xu, H. Duan, M. Chu, G. Cao, Y. Yang, J. Mater. Chem. A 2013 1, 4565 .

[173] W. Li, F. Zhang, Y. Dou, Z. Wu, H. Liu, X. Qian, D. Gu, Y. Xia, B. Tu, D. Zhao, Adv. Energy Mater. 2011, 1, 382.

[174] P. Pachfule, D. Shinde, M. Majumder, Q. Xu, Nat. Chem. 2016, 8 718.

[175] Z. Liang, C. Qu, W. Guo, R. Zou, Q. Xu, Adv. Mater. 2018, 30, 1702891.

[176] A. M. Abioye, F. N. Ani, Renewable Sustainable Energy Rev. 2015 $52,1282$.

[177] J. Lee, Y. A. Lee, C. Y. Yoo, J. J. Yoo, R. Gwak, W. K. Cho, B. Kim, H. Yoon, Microporous Mesoporous Mater. 2018, 261, 119.

[178] G. A. Ferrero, A. B. Fuertes, M. Sevilla, M. M. Titirici, Carbon 2016, $106,179$.

[179] W. Yang, W. Yang, F. Ding, L. Sang, Z. Ma, G. Shao, Carbon 2017, $111,419$.

[180] A. B. Fuertes, M. Sevilla, ACS Appl. Mater. Interfaces 2015, 7, 4344.

[181] S. Yu, N. Sun, L. Hu, L. Wang, Q. Zhu, Y. Guan, B. Xu, J. Power Sources 2018, 405, 132.

[182] M. Sevilla, A. B. Fuertes, ACS Nano 2014, 8, 5069.

[183] Y. Jiang, J. Yan, X. Wu, D. Shan, Q. Zhou, L. Jiang, D. Yang, Z. Fan J. Power Sources 2016, 307, 190

[184] B. Yang, J. Chen, S. Lei, R. Guo, H. Li, S. Shi, X. Yan, Adv. Energy Mater. 2018, 8, 1702409

[185] J. Meng, C. Niu, L. Xu, J. Li, X. Liu, X. Wang, Y. Wu, X. Xu, W. Chen, Q. Li, Z. Zhu, D. Zhao, L. Mai, J. Am. Chem. Soc. 2017, 139 8212.

[186] L. F. Chen, Y. Lu, L. Yu, X. W. Lou, Energy Environ. Sci. 2017, 10 1777.

[187] K. Jayaramulu, D. P. Dubal, B. Nagar, V. Ranc, O. Tomanec, M. Petr, K. K. R. Datta, R. Zboril, P. Gómez-Romero, R. A. Fischer, Adv. Mater. 2018, 30, 1705789

[188] L. Wang, T. Wei, L. Sheng, L. Jiang, X. Wu, Q. Zhou, B. Yuan, J. Yue, Z. Liu, Z. Fan, Nano Energy 2016, 30, 84

[189] Z. Li, H. Mi, L. Liu, Z. Bai, J. Zhang, Q. Zhang, J. Qiu, Carbon 2018, 136, 176

[190] R. R. Salunkhe, J. Tang, Y. Kamachi, T. Nakato, J. H. Kim, Y. Yamauchi, ACS Nano 2015, 9, 6288.

[191] H. Jin, J. Li, Y. Yuan, J. Wang, J. Lu, S. Wang, Adv. Energy Mater. 2018, 8, 1801007

[192] F. Lai, Y. E. Miao, L. Zuo, H. Lu, Y. Huang, T. Liu, Small 2016, 12, 3235.

[193] W. Zhang, N. Lin, D. Liu, J. Xu, J. Sha, J. Yin, X. Tan, H. Yang, H. Lu, H. Lin, Energy 2017, 128, 618.

[194] W. L. Zhang, J. H. Xu, D. X. Hou, J. Yin, D. B. Liu, Y. P. He H. B. Lin, J. Colloid Interface Sci. 2018, 530, 338.

[195] T. Zhu, J. Zhou, Z. Li, S. Li, W. Si, S. Zhuo, J. Mater. Chem. A 2014, 2, 12545 .

[196] F. Xu, Y. Lai, R. Fu, D. Wu, J. Mater. Chem. A 2013, 1, 5001.

[197] F. Xu, Z. Tang, S. Huang, L. Chen, Y. Liang, W. Mai, H. Zhong, R. Fu, D. Wu, Nat. Commun. 2015, 6, 7221.

[198] J. G. Wang, H. Liu, X. Zhang, X. Li, X. Liu, F. Kang, Small 2018, 14 1703950.

[199] M. Kim, P. Puthiaraj, Y. Qian, Y. Kim, S. Jang, S. Hwang, E. Na, W. S. Ahn, S. E. Shim, Electrochim. Acta 2018, 284, 98.

[200] L. Shao, Y. Li, J. Huang, Y. N. Liu, Ind. Eng. Chem. Res. 2018, 57 2856.

\section{2} 5 6 7 8 
[201] Z. Xu, X. Zhuang, C. Yang, J. Cao, Z. Yao, Y. Tang, J. Jiang, D. Wu, X. Feng, Adv. Mater. 2016, 28, 1981.

[202] J. Gu, Z. Du, C. Zhang, S. Yang, Adv. Energy Mater. 2016, G, 1600917.

[203] H. Li, J. Li, A. Thomas, Y. Liao, Adv. Funct. Mater. 2019, 29, 1904785.

[204] P. Puthiaraj, Y. R. Lee, W. S. Ahn, Chem. Eng. J. 2017, 319, 65.

[205] J. Serrano, T. Liu, A. U. Khan, B. Botset, B. J. Stovall, Z. Xu, D. Guo, K. Cao, G. Liu, Chem. Mater. 2019, 31, 8898

[206] T. Liu, Z. Zhou, Y. Guo, D. Guo, G. Liu, Nat. Commun. 2019, 10, 675.

[207] Z. Li, D. Wu, X. Huang, J. Ma, H. Liu, Y. Liang, R. Fu, K. Matyjaszewski, Energy Environ. Sci. 2014, 7, 3006.

[208] R. Yuan, H. Wang, M. Sun, K. Damodaran, E. Gottlieb, M. Kopeć, K. Eckhart, S. Li, J. Whitacre, K. Matyjaszewski, T. Kowalewski, ACS Appl. Nano Mater. 2019, 2, 2467.

[209] Z. Lin, H. Tian, F. Xu, X. Yang, Y. Mai, X. Feng, Polym. Chem. 2016, 7, 2092.

[210] Y. X. Tong, X. M. Li, L. J. Xie, F. Y. Su, J. P. Li, G. H. Sun, Y. D. Gao, N. Zhang, Q. Wei, C. M. Chen, Energy Storage Mater. 2016, 3, 140.

[211] L. Miao, H. Duan, M. Liu, W. Lu, D. Zhu, T. Chen, L. Li, L. Gan, Chem. Eng. J. 2017, 317, 651

[212] L. Miao, D. Zhu, M. Liu, H. Duan, Z. Wang, Y. Lv, W. Xiong, Q. Zhu, L. Li, X. Chai, L. Gan, Electrochim. Acta 2018, 274, 378.

[213] D. Zhu, K. Cheng, Y. Wang, D. Sun, L. Gan, T. Chen, J. Jiang, M. Liu, Electrochim. Acta 2017, 224, 17.

[214] S. Huo, M. Liu, L. Wu, M. Liu, M. Xu, W. Ni, Y. M. Yan, J. Power Sources 2018, 387, 81 .

[215] H. Wang, S. Min, C. Ma, Z. Liu, W. Zhang, Q. Wang, D. Li, Y. Li, S. Turner, Y. Han, H. Zhu, E. Abou-Hamad, M. N. Hedhili, J. Pan, W. Yu, K. W. Huang, L. J. Li, J. Yuan, M. Antonietti, T. Wu, Nat. Commun. 2017, 8, 13592.

[216] W. Zhang, S. Wei, Y. Wu, Y.-L. Wang, M. Zhang, D. Roy, H. Wang, J. Yuan, Q. Zhao, ACS Nano 2019, 13, 10261.

[217] Y. Wang, F. Chen, Z. Liu, Z. Tang, Q. Yang, Y. Zhao, S. Du, Q. Chen, C. Zhi, Angew. Chem., Int. Ed. 2019, 58, 15707.

[218] Z. Wang, M. Zhu, Z. Pei, Q. Xue, H. Li, Y. Huang, C. Zhi, Mater. Sci. Eng., $R$ 2019, 139, 100520
[219] S. Y. Lu, M. Jin, Y. Zhang, Y. B. Niu, J. C. Gao, C. M. Li, Adv. Energy 1 Mater. 2018, 8, 1602545.

[220] C. Bommier, R. Xu, W. Wang, X. Wang, D. Wen, J. Lu, X. Ji, Nano Energy 2015, 13, 709.

[221] J. Dai, L. Qin, R. Zhang, A. Xie, Z. Chang, S. Tian, C. Li, Y. Yan, 5 Powder Technol. 2018, 331, 162

[222] Y. Zhao, W. Ran, J. He, Y. Song, C. Zhang, D. B. Xiong, F. Gao, 6 J. Wu, Y. Xia, ACS Appl. Mater. Interfaces 2015, 7, 1132.

[223] W. Gao, N. Singh, L. Song, Z. Liu, A. L. M. Reddy, L. Ci, R. Vajtai, 8 Q. Zhang, B. Wei, P. M. Ajayan, Nat. Nanotechnol. 2011, 6, 496.9

[224] M. F. El-Kady, V. Strong, S. Dubin, R. B. Kaner, Science 2012, 335, 10 1326.

[225] L. Li, J. Zhang, Z. Peng, Y. Li, C. Gao, Y. Ji, R. Ye, N. D. Kim, 12 Q. Zhong, Y. Yang, H. Fei, G. Ruan, J. M. Tour, Adv. Mater. 2016, 13 28, 838.

[226] R. Ye, Y. Chyan, J. Zhang Y. Li, X. Han, C. Kittrell, J. M. Tour Adv. Mater. 2017, 29, 1702211.

[227] Y. Chyan, R. Ye, Y. Li, S. P. Singh, C. J. Arnusch, J. M. Tour, ACS 16 Nano 2018, 12, 2176.

[228] W. Zhang, Y. Lei, F. Ming, Q. Jiang, P. M. F. J. Costa, 18 H. N. Alshareef, Adv. Energy Mater. 2018, 8, 1801840.

[229] W. Zhang, Y. Lei, Q. Jiang, F. Ming, P. M. F. J. Costa, 20 H. N. Alshareef, Small Methods 2019, 3, 1900005.

[230] W. Zhang, Q. Jiang, Y. Lei, H. N. Alshareef, ACS Appl. Mater. 22 Interfaces 2019, 11, 20905.

[231] V. Strauss, K. Marsh, M. D. Kowal, M. El-Kady, R. B. Kaner, Adv. Mater. 2018, 30, 1704449.

[232] V. Strauss, M. Muni, A. Borenstein, B. Badamdorj, T. Heil, 25 M. D. Kowal, R. Kaner, Nanoscale 2019, 11, 12712.

[233] J. Y. Hwang, M. Li, M. F. El-Kady, R. B. Kaner, Adv. Funct. Mater. 27 2017, 27, 1605745.

[234] L. Wang, G. Zhang, B. Han, Y. Chang, H. Li, J. Wang, 29 C. Hu, Z. Chang, Z. Huo, X. Sun, J. Mater. Chem. A 2017, 5, 30 6734.

[235] X. Yang, C. Cheng, Y. Wang, L. Qiu, D. Li, Science 2013, 341, 534.

[236] Y. Tao, X. Xie, W. Lv, D. M. Tang, D. Kong, Z. Huang, H. Nishihara, 33 T. Ishii, B. Li, D. Golberg, F. Kang, T. Kyotani, Q. H. Yang, Sci. Rep. 34 2013, 3, 2975

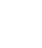
3 


\section{small methods}

\section{Reprint Order Form}

Wiley-VCH Verlag GmbH \& Co. KGaA

Small Methods

Boschstr. 12

69469 Weinheim

Germany

Charges for Reprints in Euro (excl. VAT), prices are subject to change. Minimum order 50 copies; single issues for authors at a reduced price.

\begin{tabular}{l|rrrrrr} 
No. of pages & $\mathbf{5 0}$ & $\mathbf{1 0 0}$ & $\mathbf{1 5 0}$ & $\mathbf{2 0 0}$ & $\mathbf{3 0 0}$ & $\mathbf{5 0 0}$ \\
& copies & copies & copies & copies & $\begin{array}{c}\text { copies } \\
\text { copies }\end{array}$ & \multicolumn{1}{c}{ copi,- } \\
\hline $\mathbf{1 - 4}$ & $345,-$ & $395,-$ & $425,-$ & $445,-$ & $548,-$ & $752,-$ \\
$\mathbf{5 - 8}$ & $490,-$ & $573,-$ & $608,-$ & $636,-$ & $784,-$ & $1077,-$ \\
$\mathbf{9 - 1 2}$ & $640,-$ & $739,-$ & $786,-$ & $824,-$ & $1016,-$ & $1396,-$ \\
$\mathbf{1 3 - 1 6}$ & $780,-$ & $900,-$ & $958,-$ & $1004,-$ & $1237,-$ & $1701,-$ \\
$\mathbf{1 7 - 2 0}$ & $930,-$ & $1070,-$ & $1138,-$ & $1196,-$ & $1489,-$ & $2022,-$ \\
\hline every additional & $147,-$ & $169,-$ & $175,-$ & $188,-$ & $231,-$ & $315,-$ \\
4 pages & & & & & &
\end{tabular}

\section{Please send me and bill me for}<smiles>C1CCC1</smiles>

no. of reprints

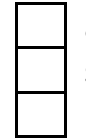

airmail (+ 25 Euro) surface mail Fedex No.:

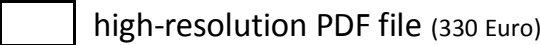
E-mail address:

Special Offer:

If you order 200 or more reprints you will get a PDF file for half price.

Please note: It is not permitted to present the PDF file on the internet or on company homepages.

Cover Posters (prices excl. VAT)

Posters of published covers are available in two sizes:

$\square$ DIN A2 $42 \times 60 \mathrm{~cm} / 17 \times 24$ in (one copy: 39 Euro)

DIN A1 $60 \times 84 \mathrm{~cm} / 24$ x 33in (one copy: 49 Euro)

Postage for shipping posters overseas by airmail:

+25 Euro

Postage for shipping posters within Europe by surface

mail: + 15 Euro

Date, Signature
Please complete this form and return it via E-Mail to the Editorial Office at

E-mail: small-methods@wiley-vch.de
Manuscript No.:

Customer No.: (if available)

Purchase Order No.:

Author:

Date:

Information regarding VAT: Please note that from German sales tax point of view, the charge for Reprints, Issues or Posters is considered as "supply of goods" and therefore, in general, such delivery is a subject to German sales tax. However, this regulation has no impact on customers located outside of the European Union. Deliveries to customers outside the Community are automatically tax-exempt. Deliveries within the Community to institutional customers outside of Germany are exempted from the German tax (VAT) only if the customer provides the supplier with his/her VAT number. The VAT number (value added tax identification number) is a tax registration number used in the countries of the European Union to identify corporate entities doing business there. Starting with a country code (e.g. FR for France), followed by numbers.

\section{VAT number:}

Mail reprints / copies of the issue to:

Send bill to:

I will pay by bank transfer

I will pay by credit card

VISA, Mastercard and AMERICAN EXPRESS

For your security please use this link (Credit Card Token Generator) to create a secure code Credit Card Token and include this number in the form

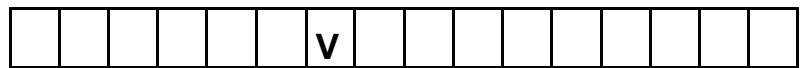

instead of the credit card data. Click here:

https://www.wiley-vch.de/editorial production/index.php

\section{CREDIT CARD TOKEN NUMBER}

